\title{
Discovery of 5,6-Bis(4-Methoxy-3-Methylphenyl)Pyridin-2-Amine as a WSB1 Degrader to Inhibit Cancer Cell Metastasis
}

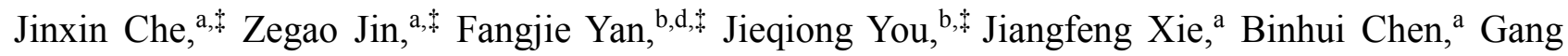

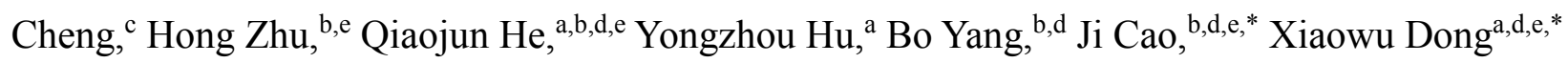

${ }^{\text {a }}$ Hangzhou Institute of Innovative Medicine, Institute of Drug Discovery and Design, College of Pharmaceutical Sciences, Zhejiang University, Hangzhou, 310058, P.R. China

${ }^{\mathrm{b}}$ Institute of Pharmacology \& Toxicology, Zhejiang Province Key Laboratory of Anti-Cancer Drug Research, College of Pharmaceutical Sciences, Zhejiang University, Hangzhou, 310058, P.R. China

${ }^{\mathrm{c}}$ College of Pharmaceutical Science, Zhejiang Chinese Medical University, Hangzhou, 311402, P.R. China

d Innovation Institute for Artificial Intelligence in Medicine of Zhejiang University, Hangzhou, 310018, P.R. China

${ }^{\mathrm{e}}$ Cancer Center, Zhejiang University, Hangzhou, 310058, P.R. China

* These authors contributed equally to this work.

\section{Corresponding Author}

*For J. Cao: E-mail: caoji88@zju.edu.cn

*For X. Dong: E-mail: dongxw@zju.edu.cn 
Table of contents

$\begin{array}{ll}\text { Figure S1 } & \text { S3 }\end{array}$

$\begin{array}{ll}\text { Figure S2 } & \text { S4 }\end{array}$

$\begin{array}{ll}\text { Figure S3 } & \text { S5 }\end{array}$

$\begin{array}{ll}\text { Table S1 } & \text { S6 }\end{array}$

$\begin{array}{ll}\text { Table S2 } & \text { S8 }\end{array}$

$\begin{array}{lr}\text { NMR Spectra } & \text { S10 }\end{array}$

$\begin{array}{ll}\text { HPLC Spectra } & \text { S57 }\end{array}$ 


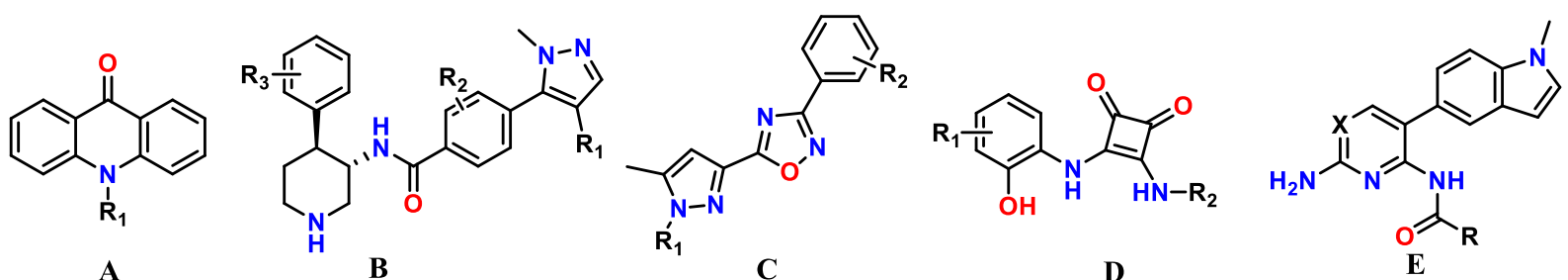

A

B

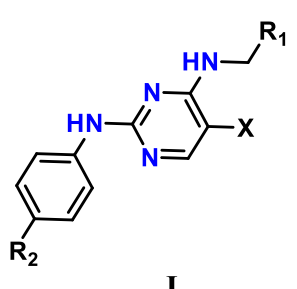<smiles>[X]c1ccc(NC(=O)c2cc(Br)nc(P)n2)cc1</smiles><smiles>O=C1OCC(c2ccccc2)=C1c1ccccc1</smiles>

G
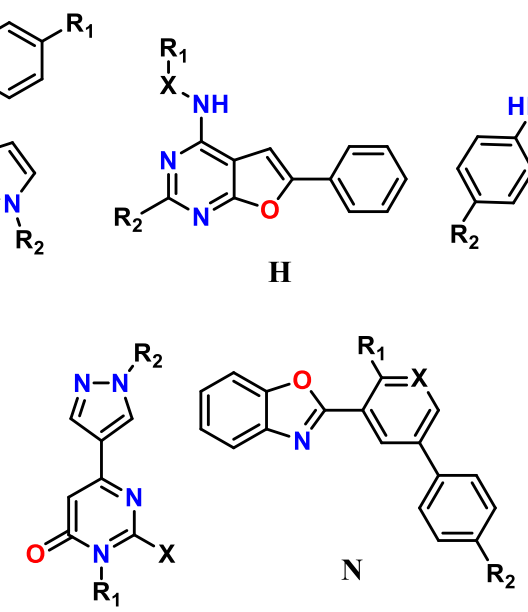

M

Figure S1. Structures of representative compounds from in-house structurally diverse library. 


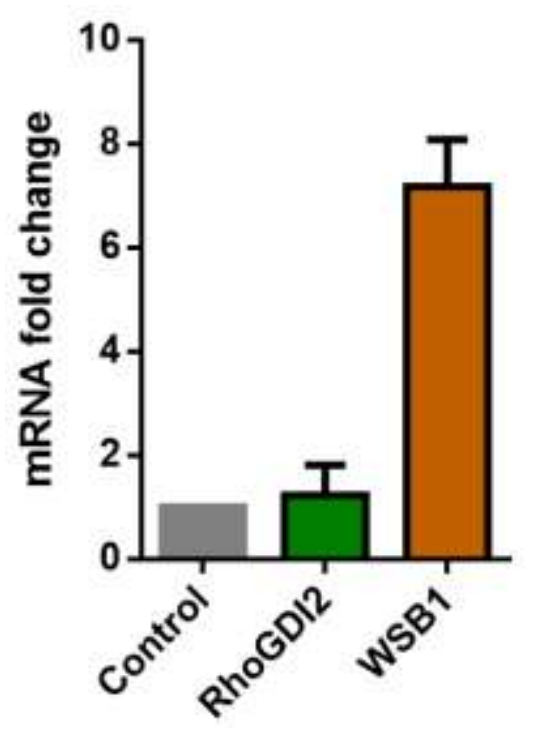

Figure S2. Relative mRNA levels of RhoGDI2 and WSB1 in H1299-WSB1 cells. mRNA expression was analyzed by RT-PCR and shown as a histogram after normalization, GAPDH was used as a control gene. 
At first, glutathione S-transferase (GST) was employed as tags at the WSB1 protein termini, which allow consequent bioconjugation and purification. GST-WSB1 protein was stably expressed in BL21 bacterial. The bacterial cell lysate was then flowed through a column by using glutathione (GSH) as eluent. Pure GST-WSB1 protein can be afforded and it showed good solubility, such as GSH elution 14-16 (Figure S3A, left gel). However, in subsequent experiments to improve the purity or concentration of the protein, protein degradation and precipitation were observed, as shown on the gel of the $2^{\text {nd }}$ and $7^{\text {th }}$ lanes in GST-WSB1 group (Figure S3A, right gel). A similar phenomenon was observed after GST cutting of the protein, other unknown bands appeared on the gel (Figure S3B), suggesting that the WSB1 protein may be highly unstable. Then GST tag was replaced with His tag. The His-WSB1 can also be stably expressed in BL21 bacterial (Figure S3C), but the solubility of the protein was very poor, a large amount of the protein precipitated out from the bacterial cell lysate (Figure S3D). The present resulted protein was not suitable for further binding experiments.

A

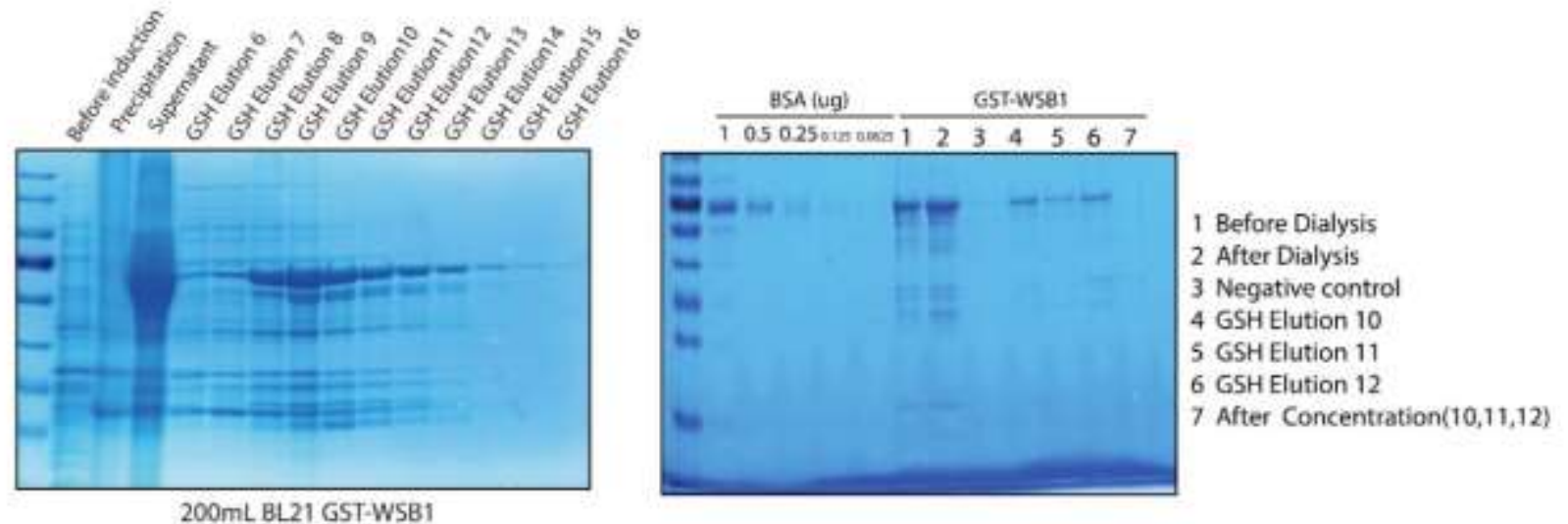

B

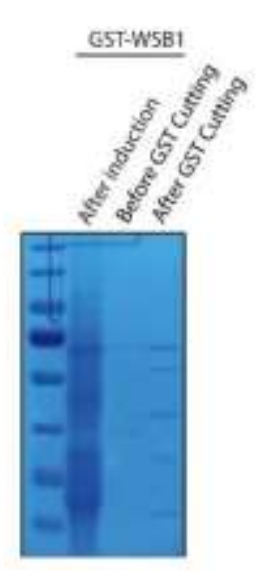

C

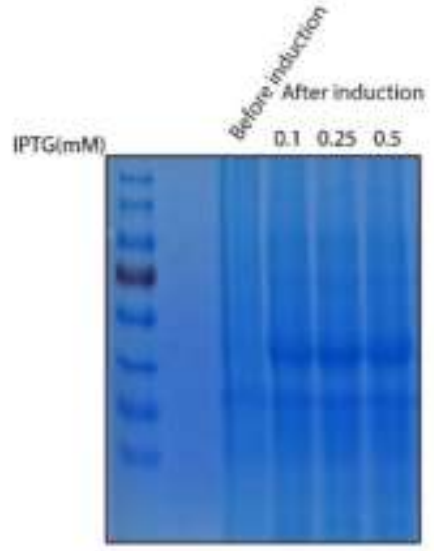

$200 \mathrm{~mL}$ BL 21 HIS-WSB1
D

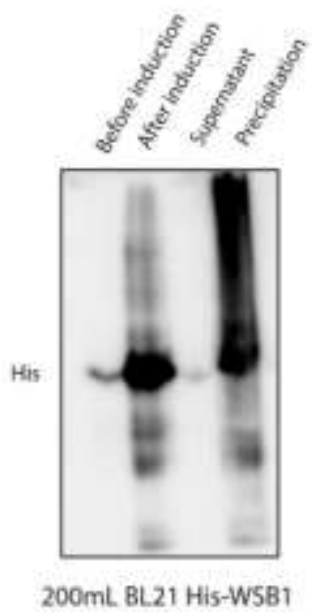

Figure S3. Purification of WSB1 protein using whole-cell lysate. (A) The bacterial cell lysate containing GST-WSB1 was subjected to purification and Coomassie-staining. (B) GST cutting result of GST-WSB1. (C) The bacterial cell lysate containing His-WSB1. (D) The detection of His-WSB1 via immunoblotting. 
Table S1. Representative figures of wound healing assay of compound 1a and $\mathbf{4}$ against KHOS cells.

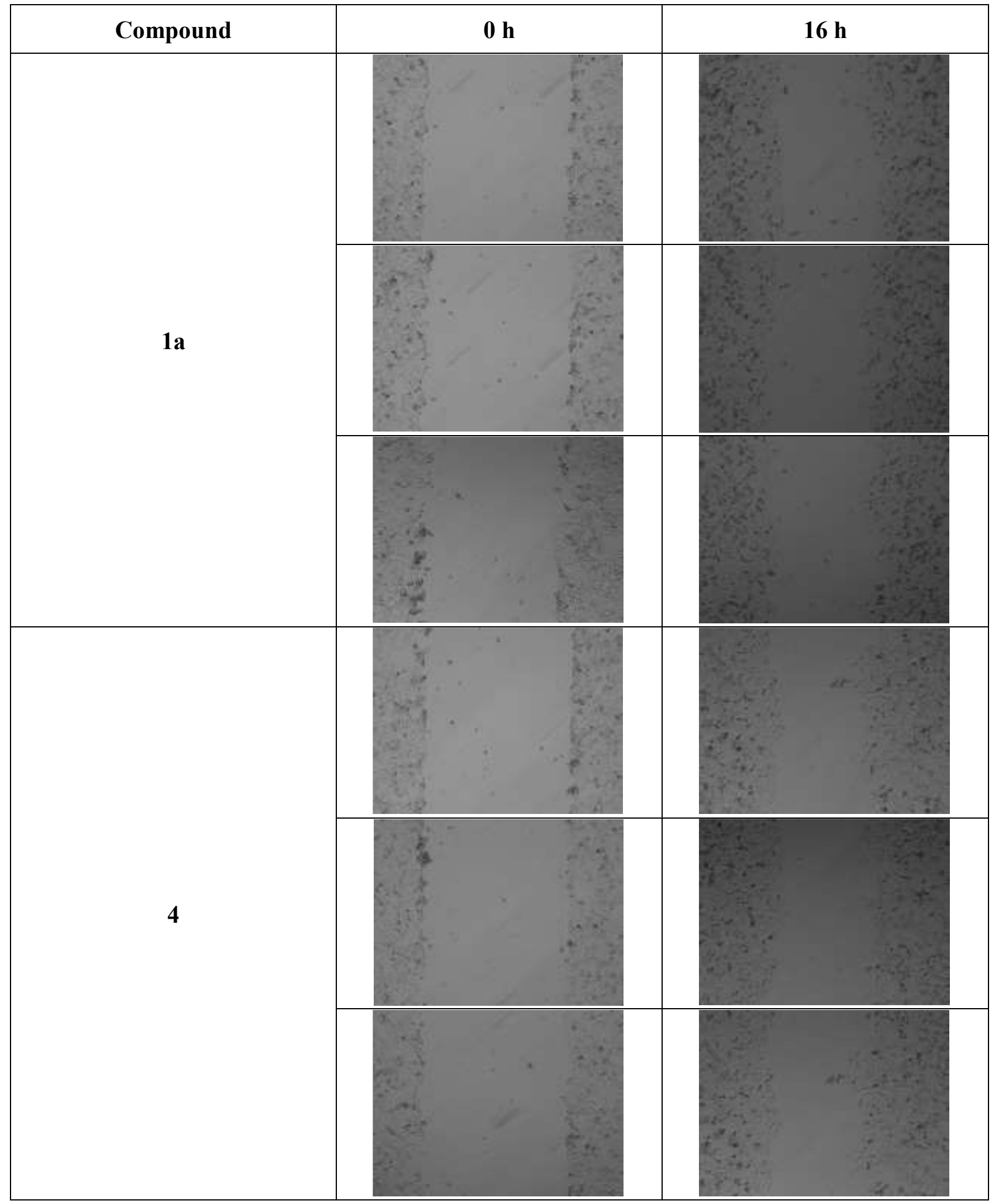




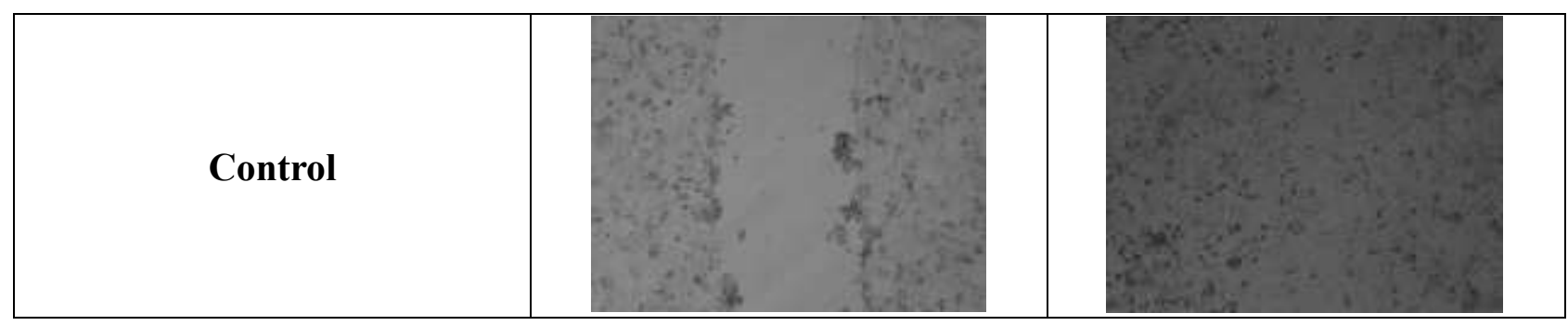


Table S2. Representative figures of wound healing assay of compound 1a and 4 against H460 cells.

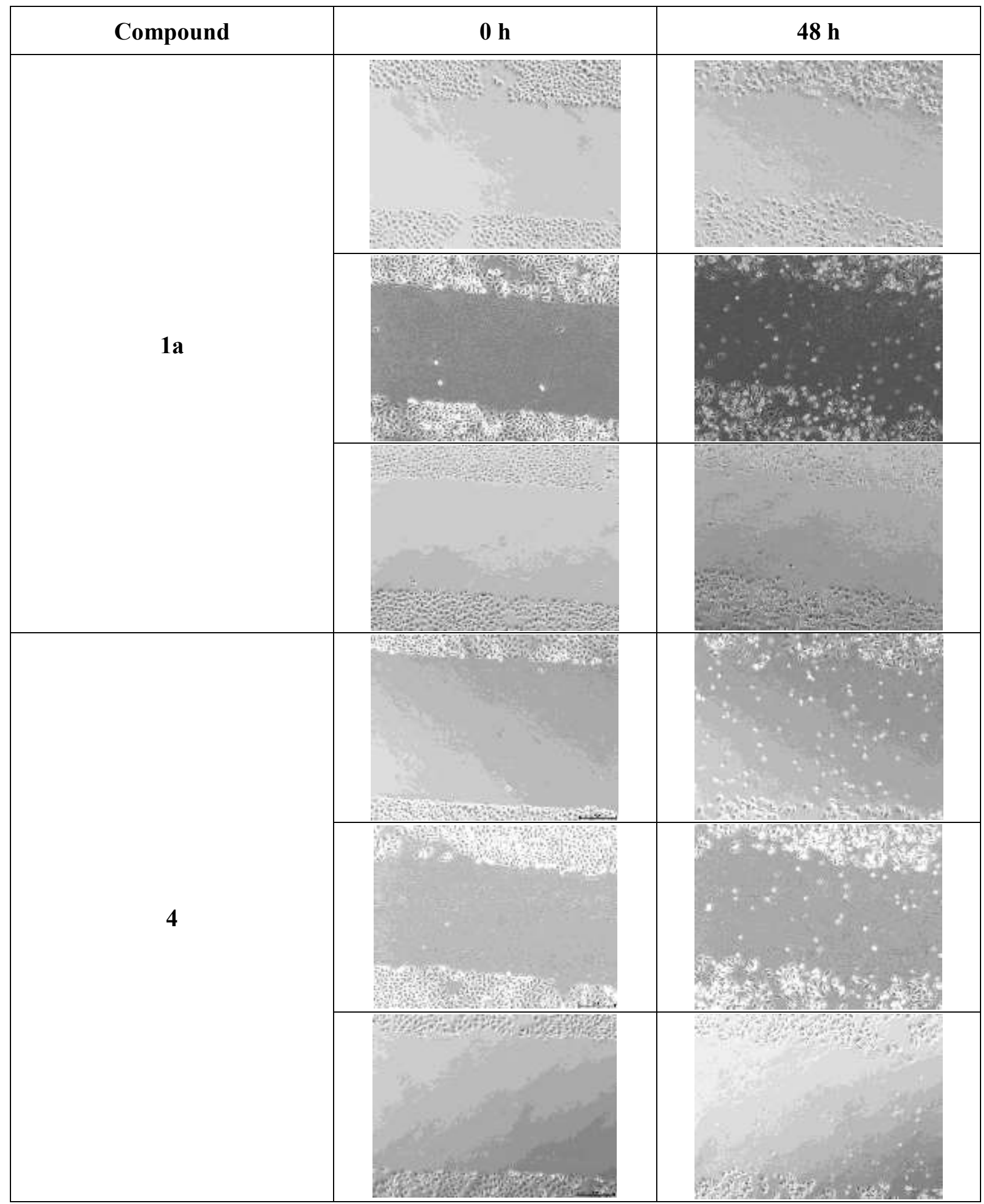




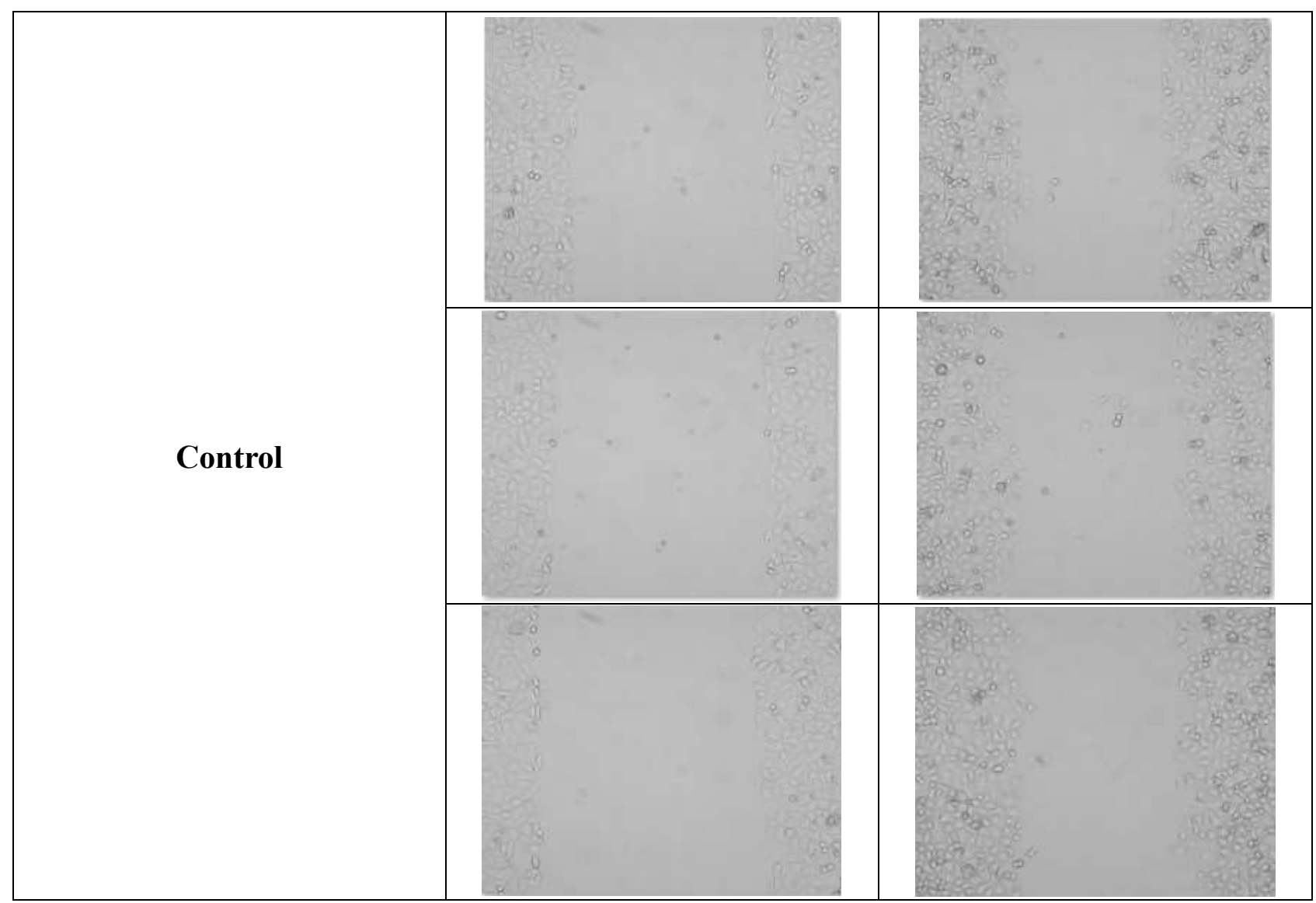




\section{NMR Spectra}

3-(2-Fluorophenyl)-4-(4-methoxy-3-methylphenyl)furan-2(5H)-one (1a)

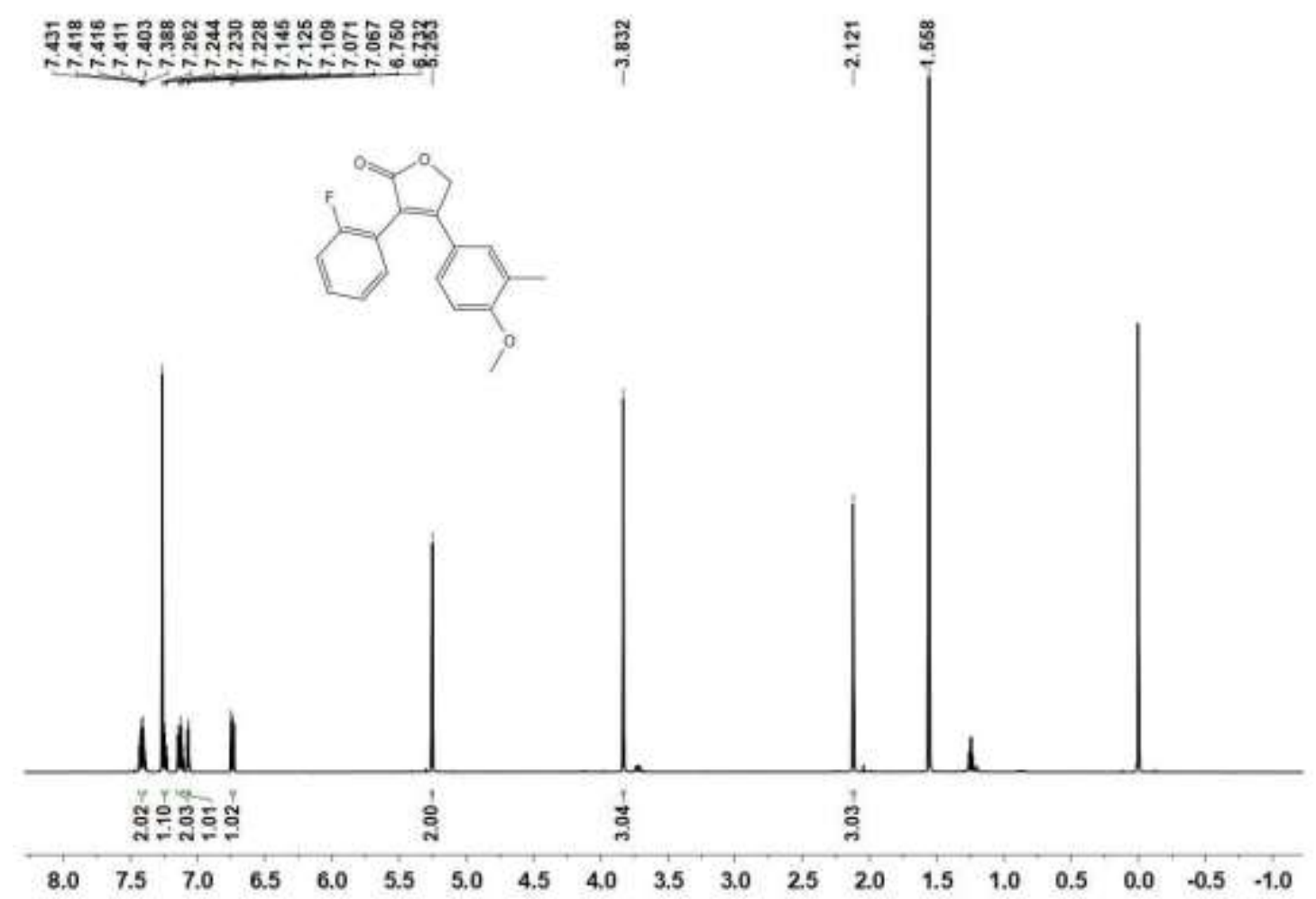

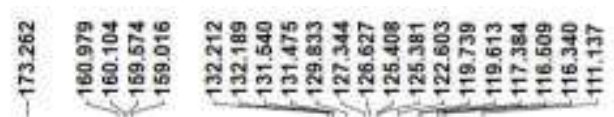

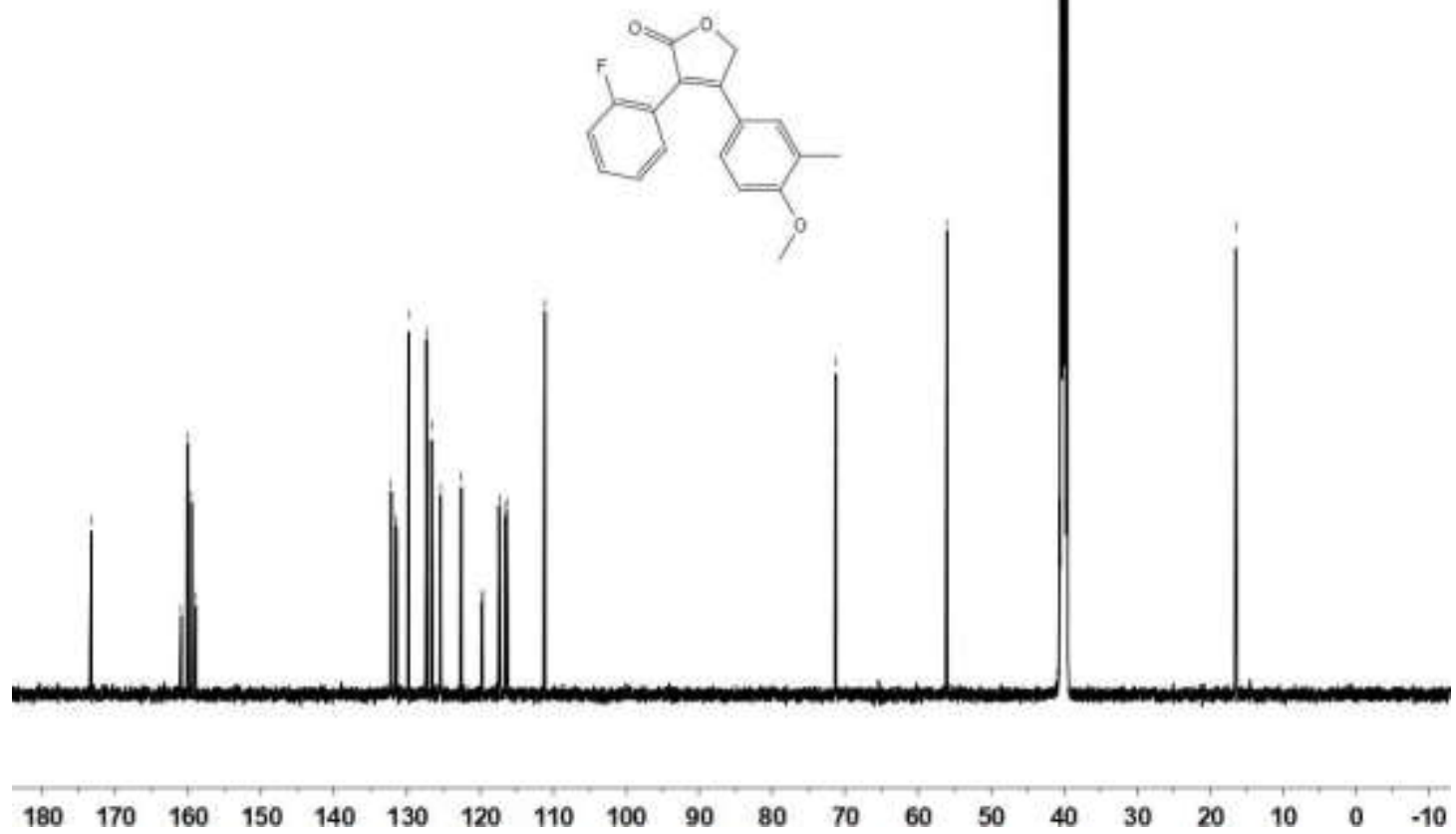


3-(2-Fluorophenyl)-4-(4-fluorophenyl)furan-2(5H)-one (1b)

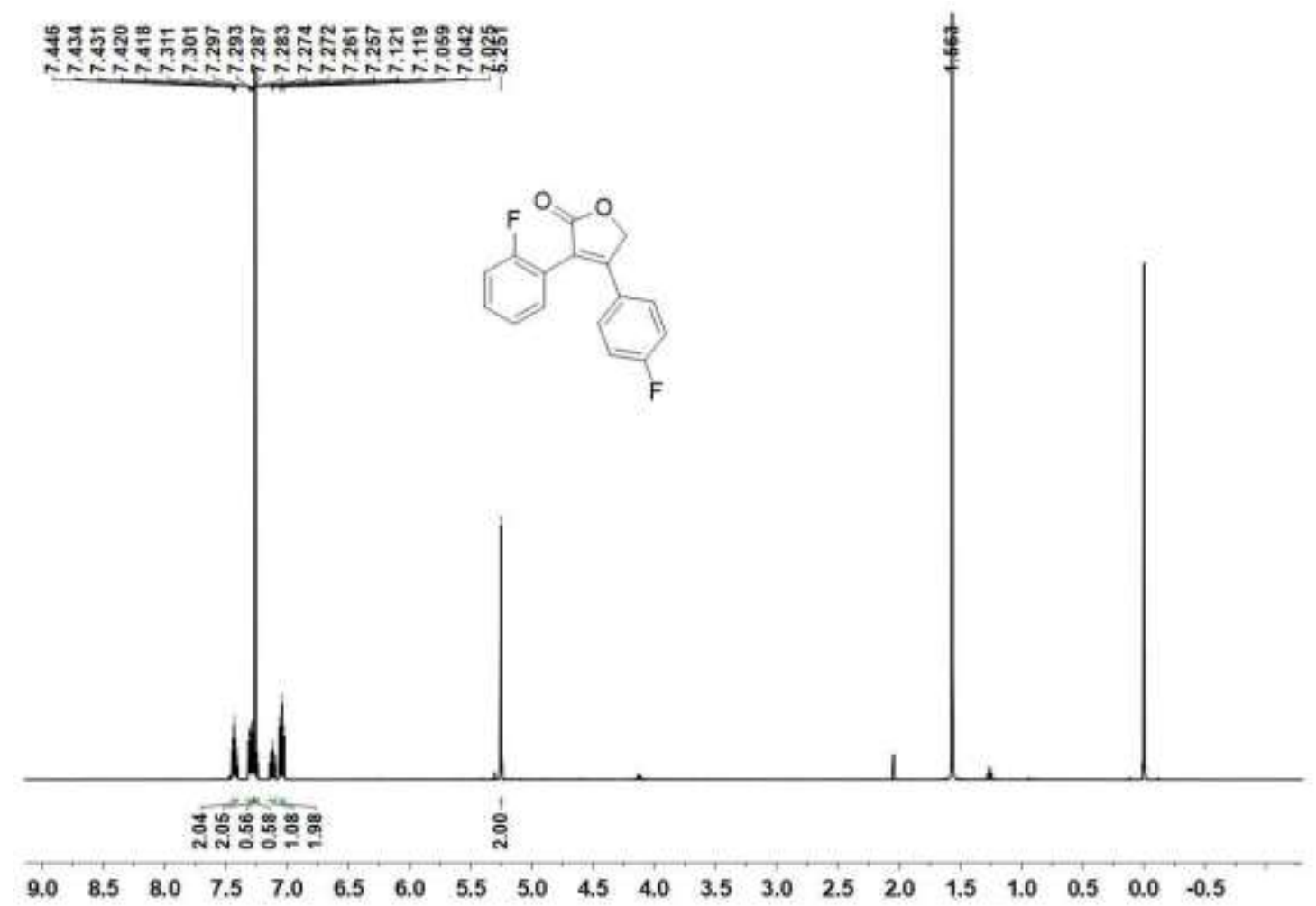

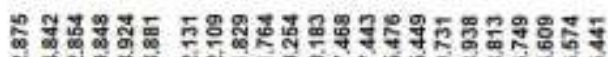

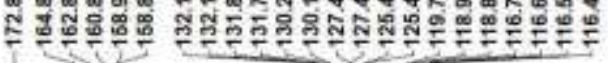

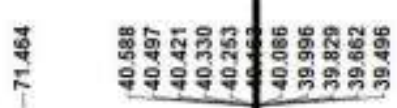
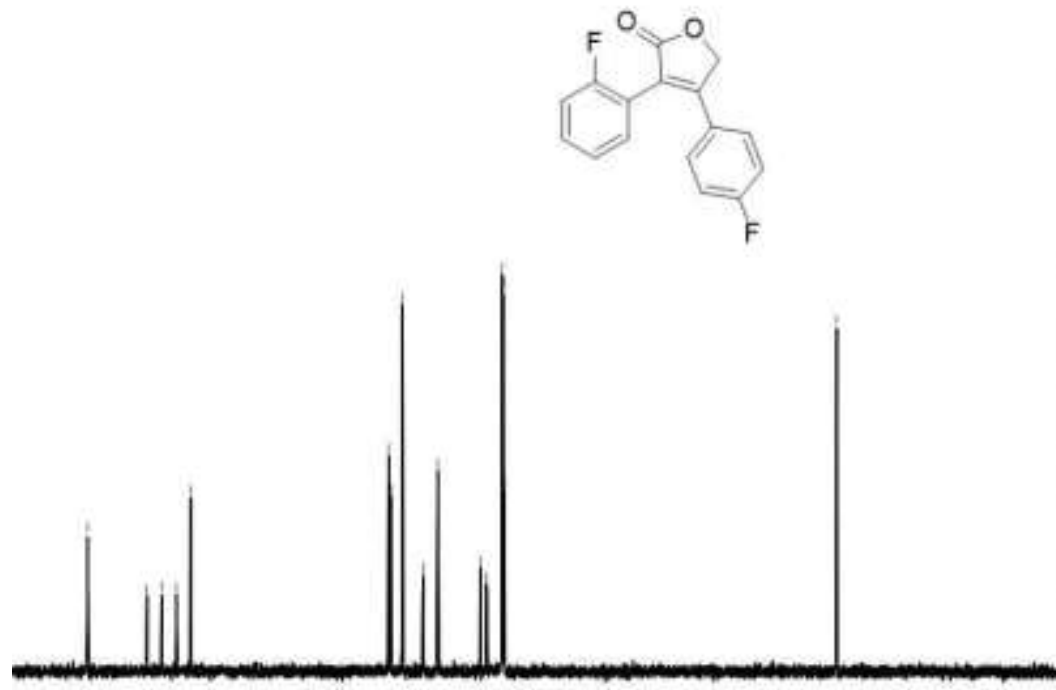

$\begin{array}{llllllllllllllllllll}180 & 170 & 160 & 150 & 140 & 130 & 120 & 110 & 100 & 90 & 80 & 70 & 60 & 50 & 40 & 30 & 20 & 10 & 0 & -10\end{array}$ 
4-(4-Chlorophenyl)-3-(2-fluorophenyl)furan-2(5H)-one (1c)

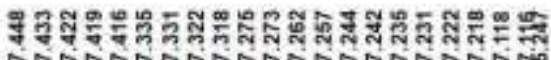

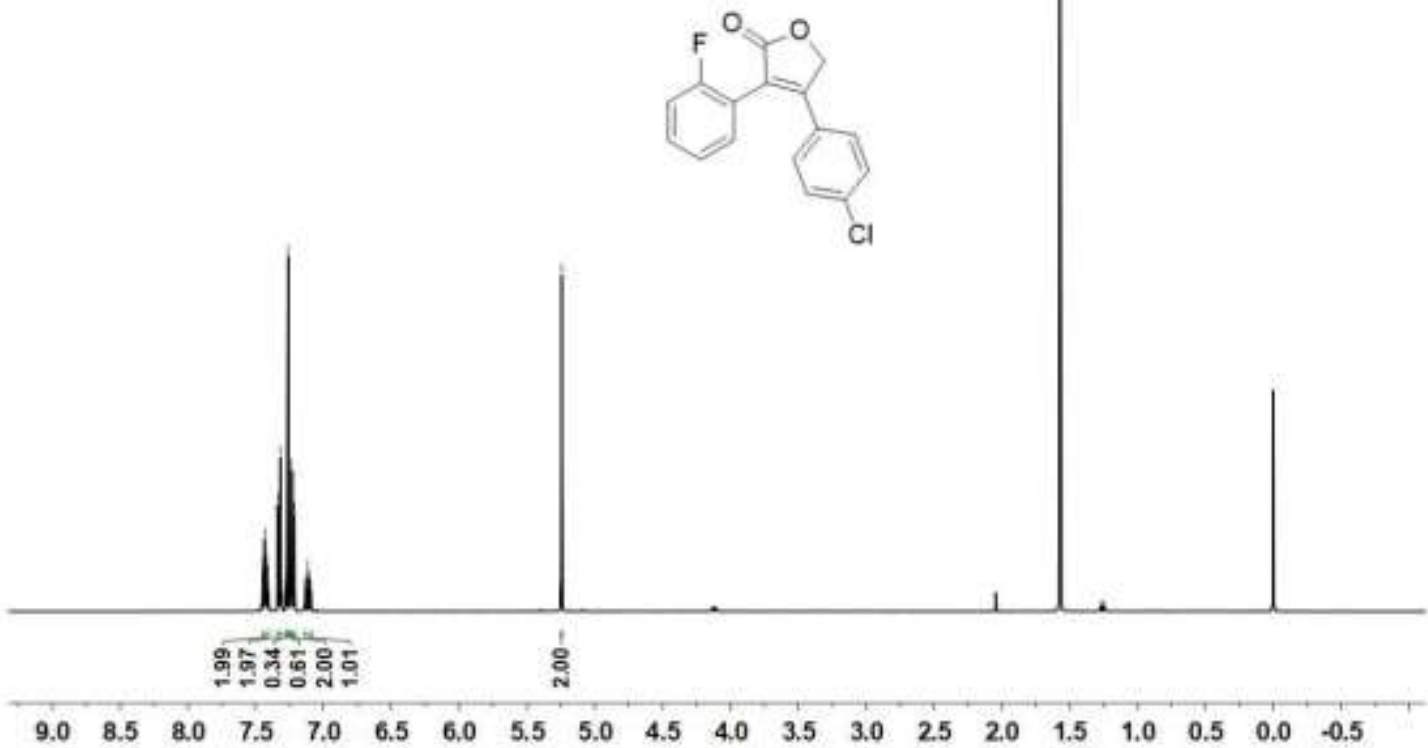

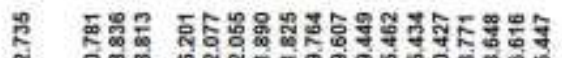

난
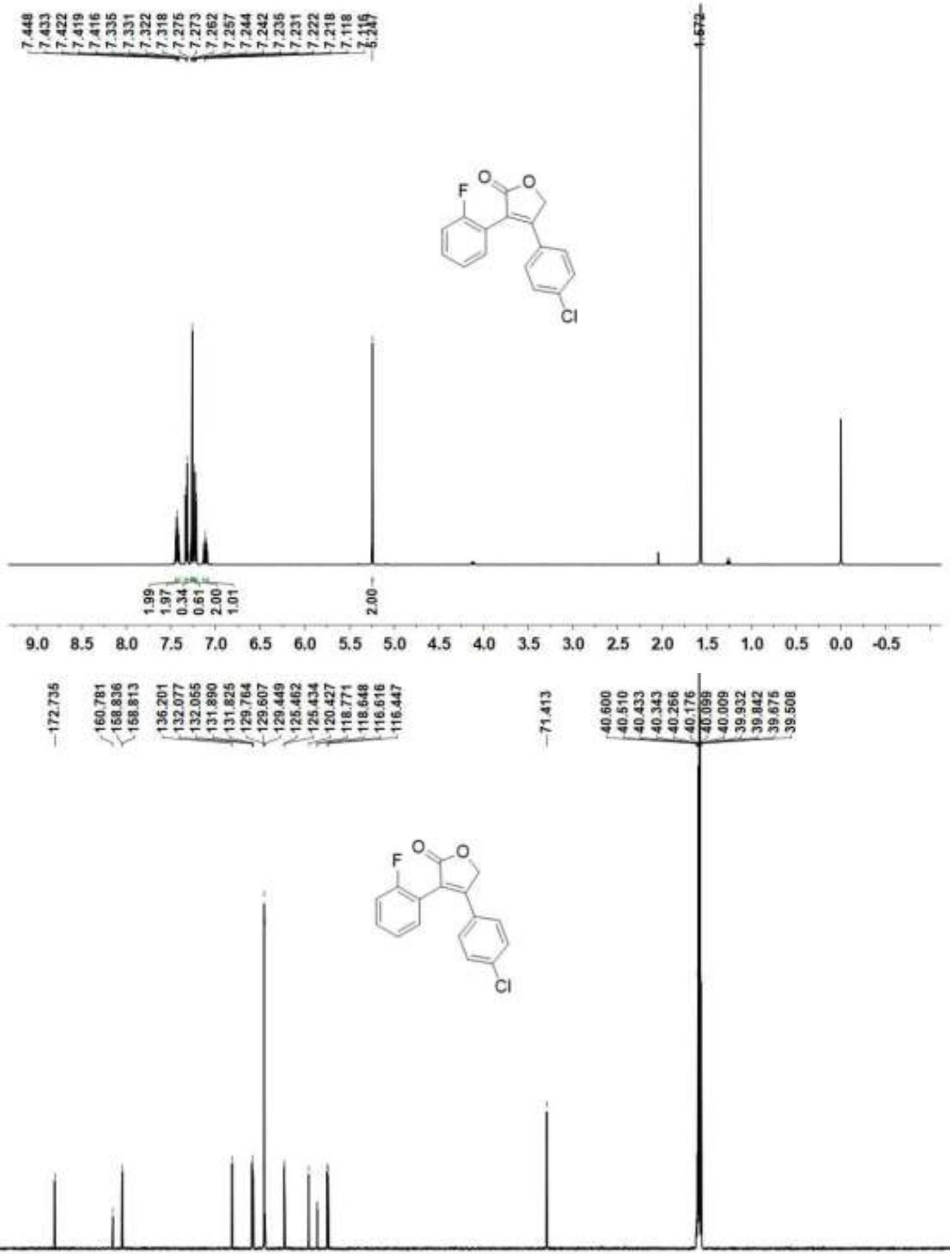

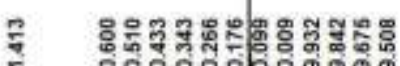

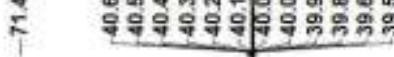

$\begin{array}{llllllllllllllllllll}180 & 170 & 160 & 150 & 140 & 130 & 120 & 110 & 100 & 90 & 80 & 70 & 60 & 50 & 40 & 30 & 20 & 10 & 0 & -10\end{array}$ 
3-(2-Fluorophenyl)-4-(4-isopropoxyphenyl)furan-2(5H)-one (1d)

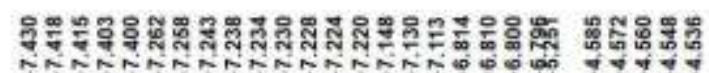

ํㅠㄹㅠ

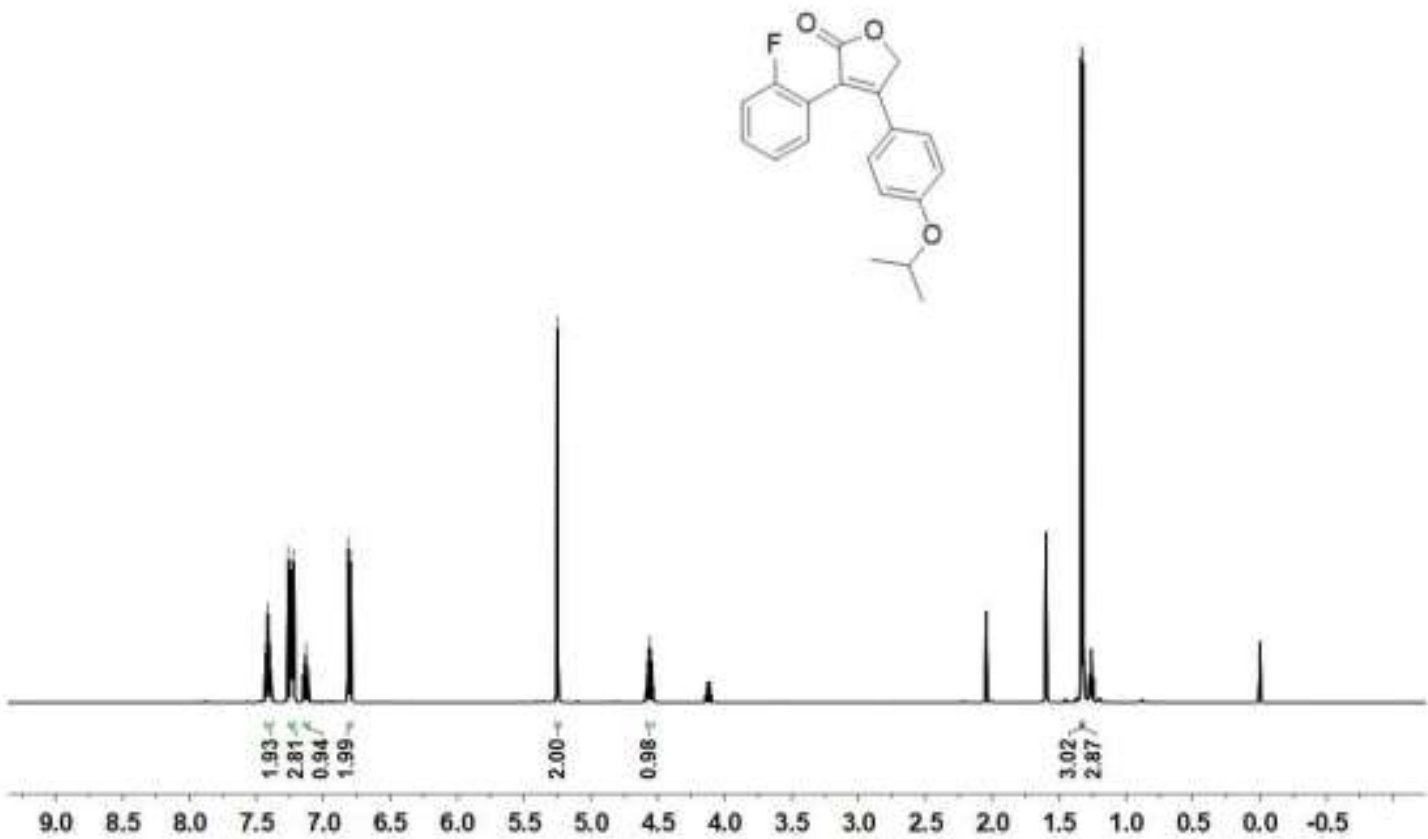

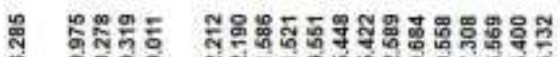

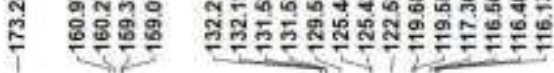

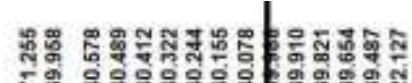

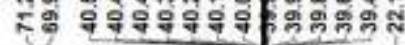

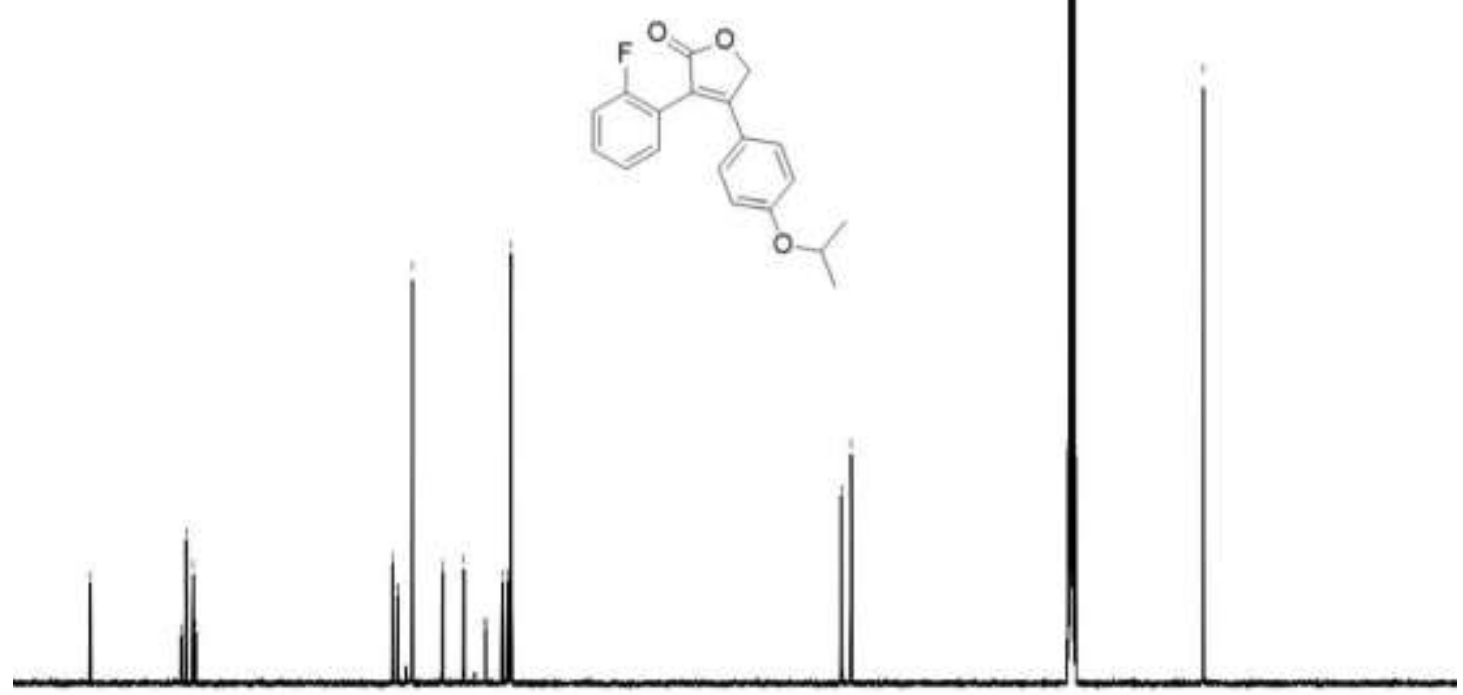

$\begin{array}{llllllllllllllllllll}180 & 170 & 160 & 150 & 140 & 130 & 120 & 110 & 100 & 90 & 80 & 70 & 60 & 50 & 40 & 30 & 20 & 10 & 0 & -10\end{array}$ 
3-(2-Fluorophenyl)-4-(3-methyl-4-propoxyphenyl)furan-2(5H)-one (1e)

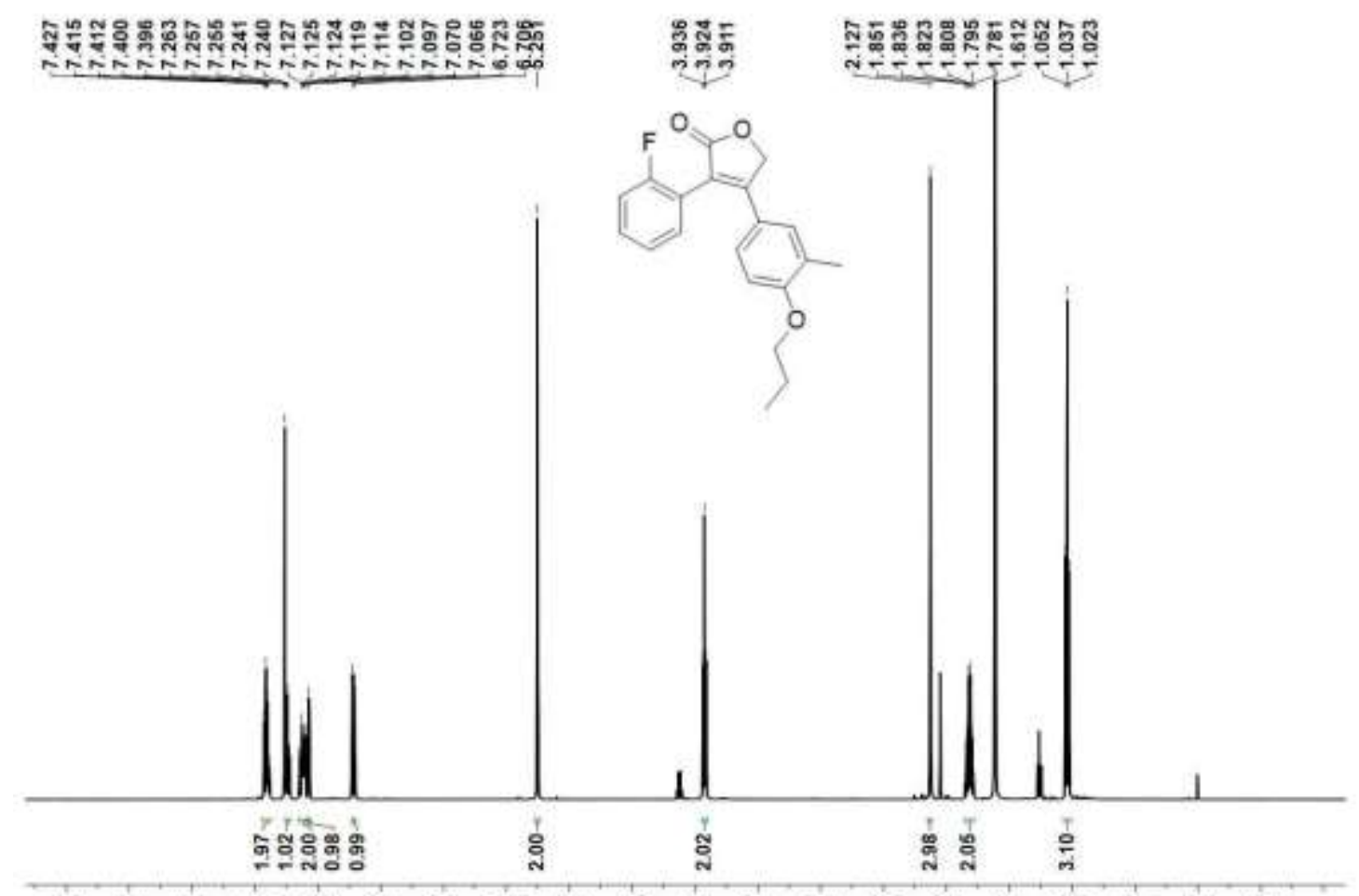

$\begin{array}{llllllllllllllllllll}9.0 & 8.5 & 8.0 & 7.5 & 7.0 & 6.5 & 6.0 & 5.5 & 5.0 & 4.5 & 4.0 & 3.5 & 3.0 & 2.5 & 2.0 & 1.5 & 1.0 & 0.5 & 0.0 & -0.5\end{array}$

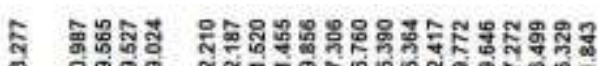

है

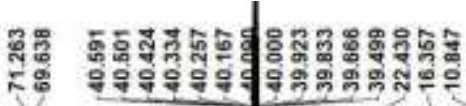

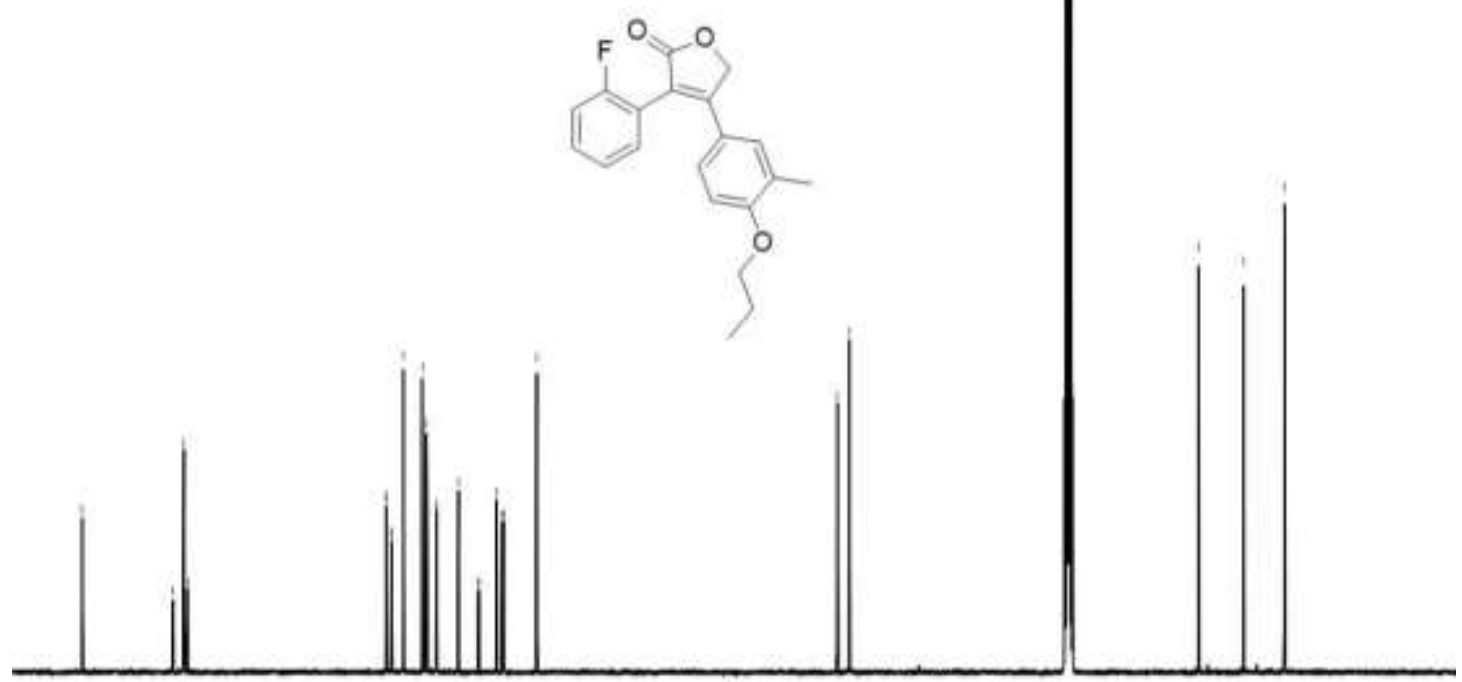

$\begin{array}{llllllllllllllllllll}180 & 170 & 160 & 150 & 140 & 130 & 120 & 110 & 100 & 90 & 80 & 70 & 60 & 50 & 40 & 30 & 20 & 10 & 0 & -10\end{array}$ 
3-(2-Fluorophenyl)-4-(3-methyl-4-(pentyloxy)phenyl)furan-2(5H)-one (1f)

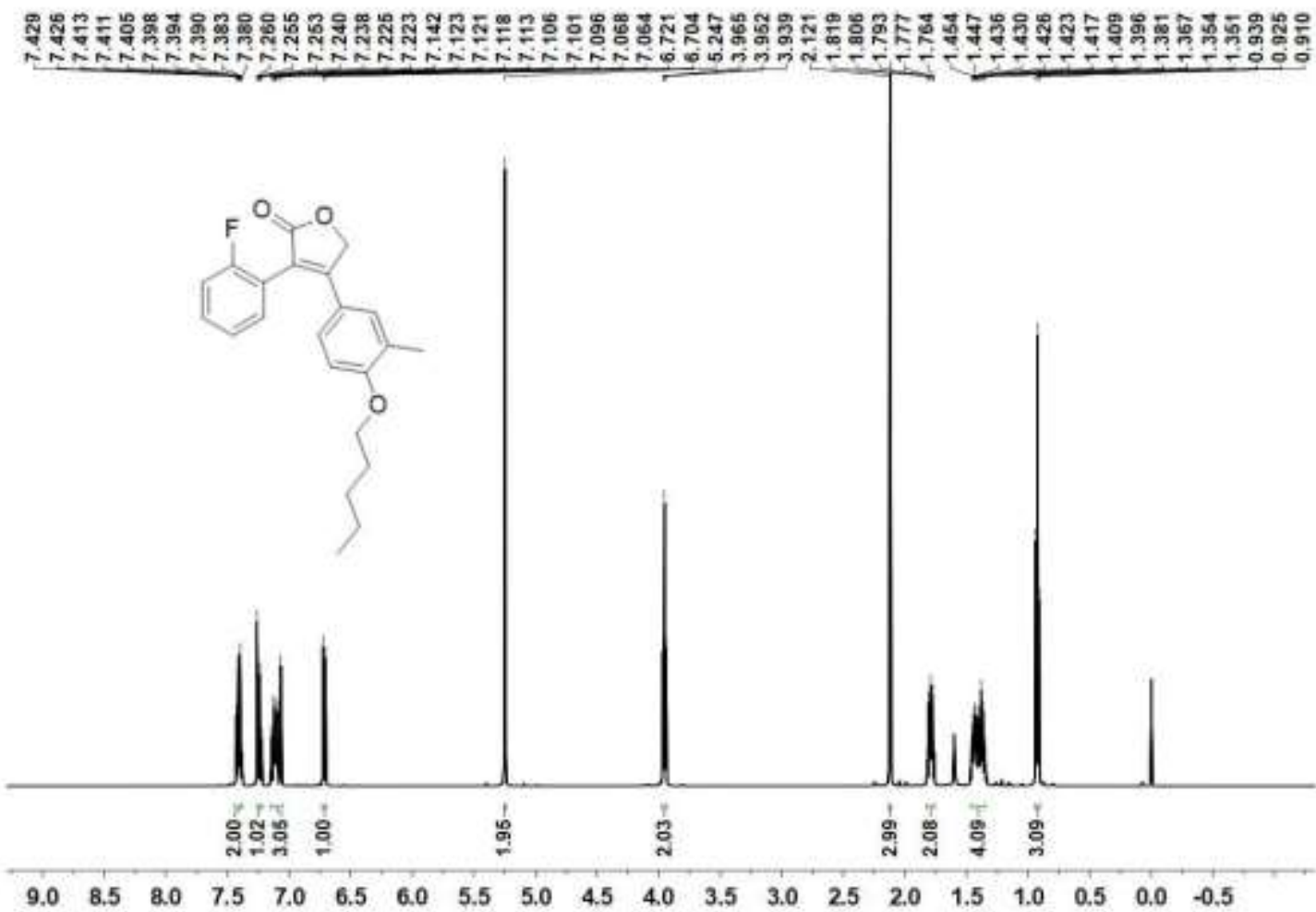

苨

ल
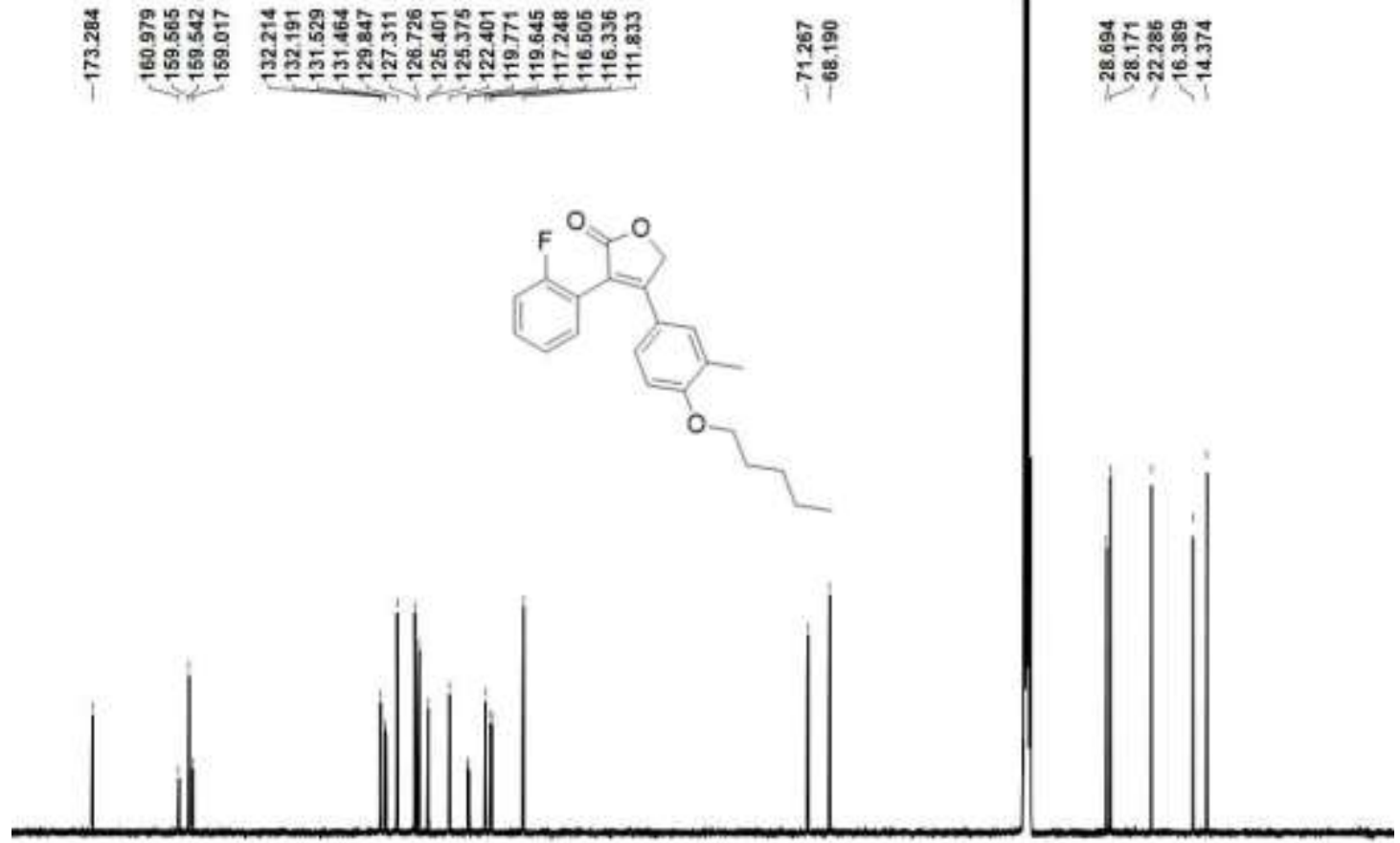

$\begin{array}{llllllllllllllllllll}180 & 170 & 160 & 150 & 140 & 130 & 120 & 110 & 100 & 90 & 80 & 70 & 60 & 50 & 40 & 30 & 20 & 10 & 0 & -10\end{array}$ 
4-(2-Fluorophenyl)-3-(4-methoxyphenyl)furan-2(5H)-one (2a)
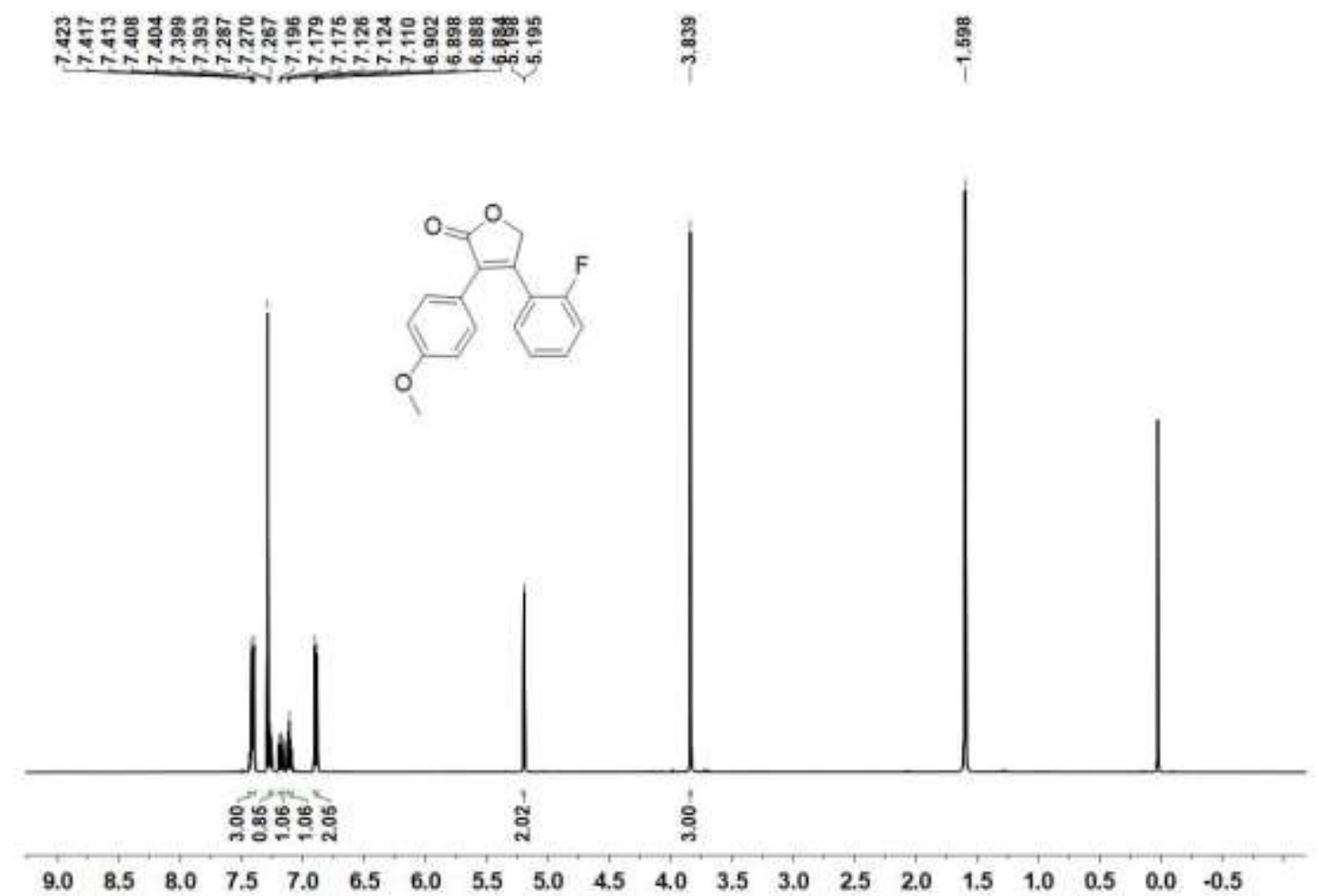

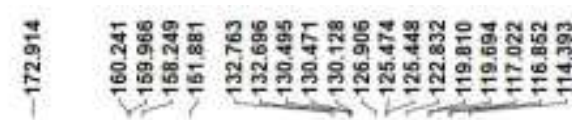

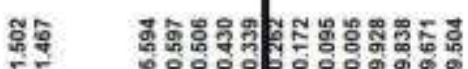

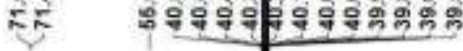

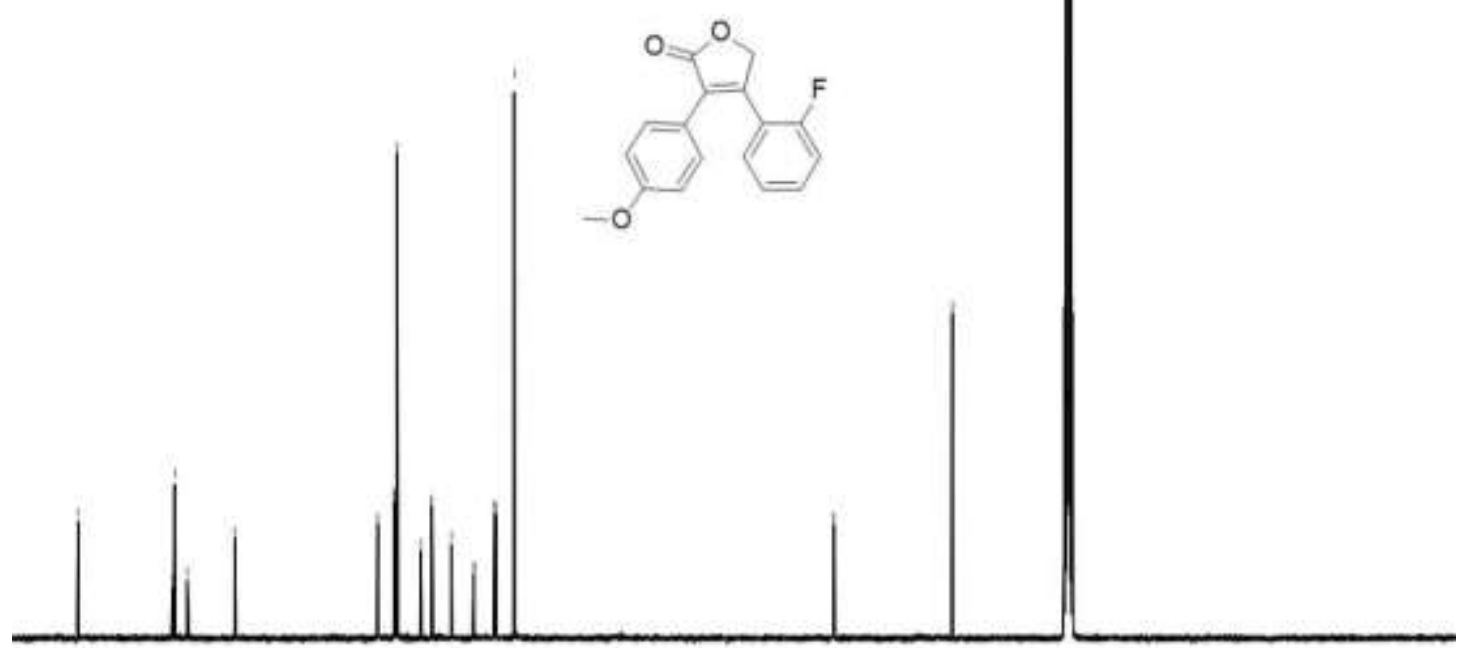

$\begin{array}{llllllllllllllllllll}180 & 170 & 160 & 150 & 140 & 130 & 120 & 110 & 100 & 90 & 80 & 70 & 60 & 50 & 40 & 30 & 20 & 10 & 0 & -1 C\end{array}$ 
4-(2-Fluorophenyl)-3-(1H-indol-3-yl)furan-2(5H)-one (2e)

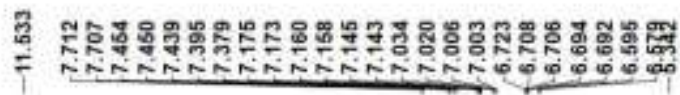
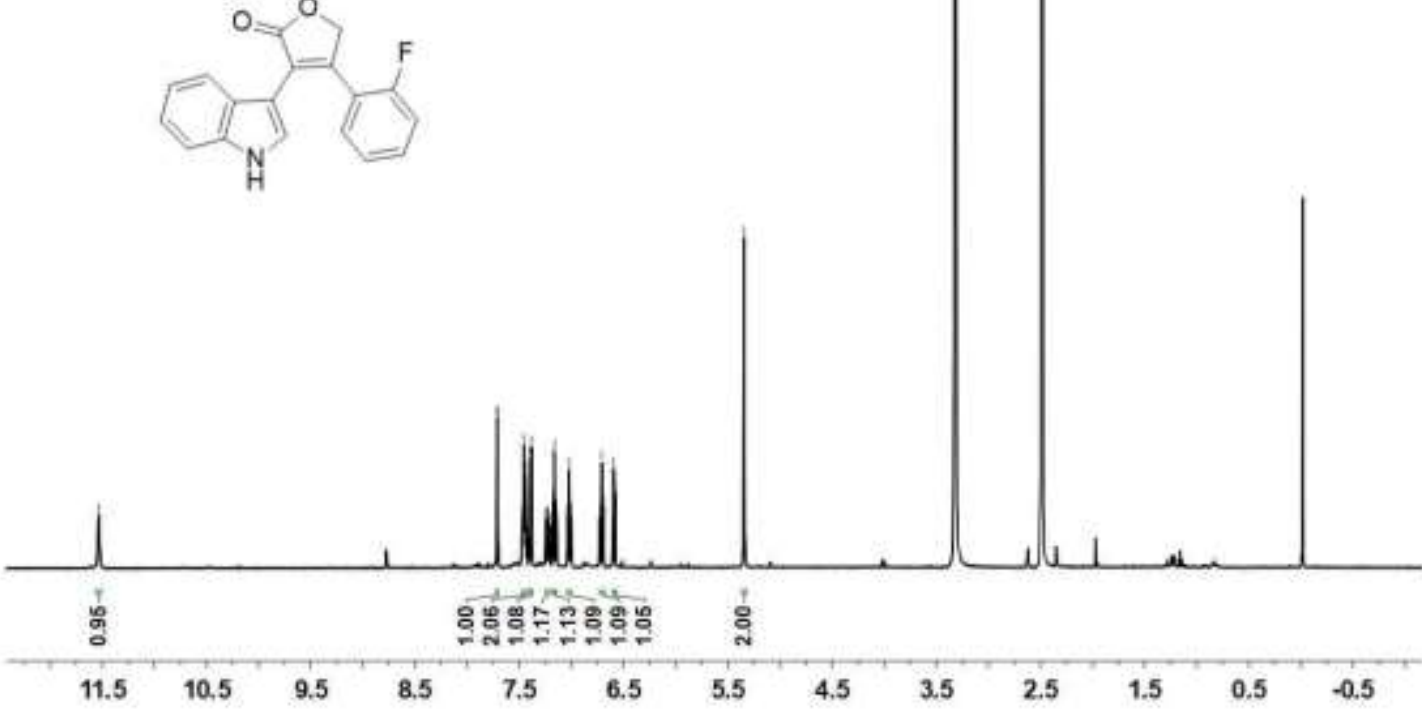

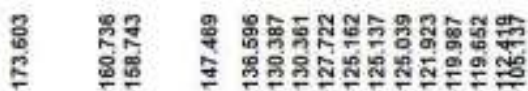

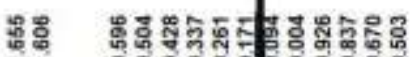

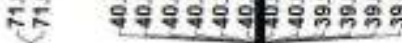
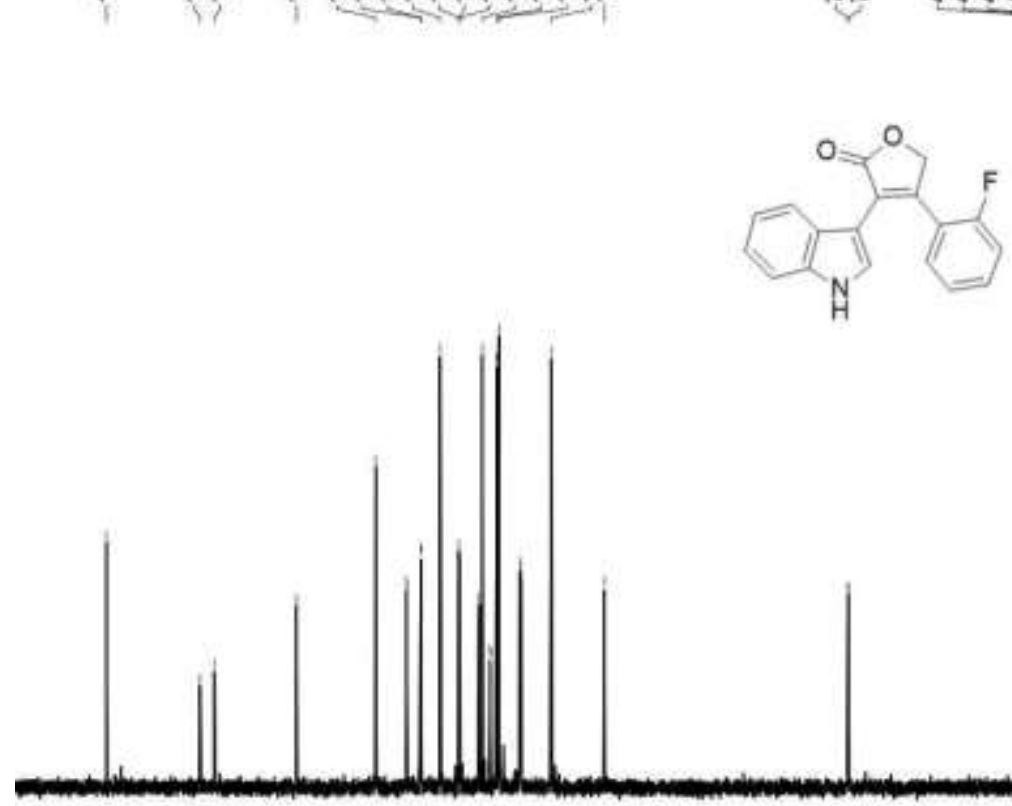

$\begin{array}{llllllllllllllllllll}180 & 170 & 160 & 150 & 140 & 130 & 120 & 110 & 100 & 90 & 80 & 70 & 60 & 50 & 40 & 30 & 20 & 10 & 0 & -10\end{array}$ 
3-(1-Ethyl-1H-indol-3-yl)-4-(2-fluorophenyl)furan-2(5H)-one (2f)

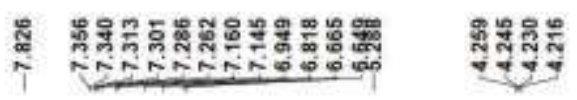

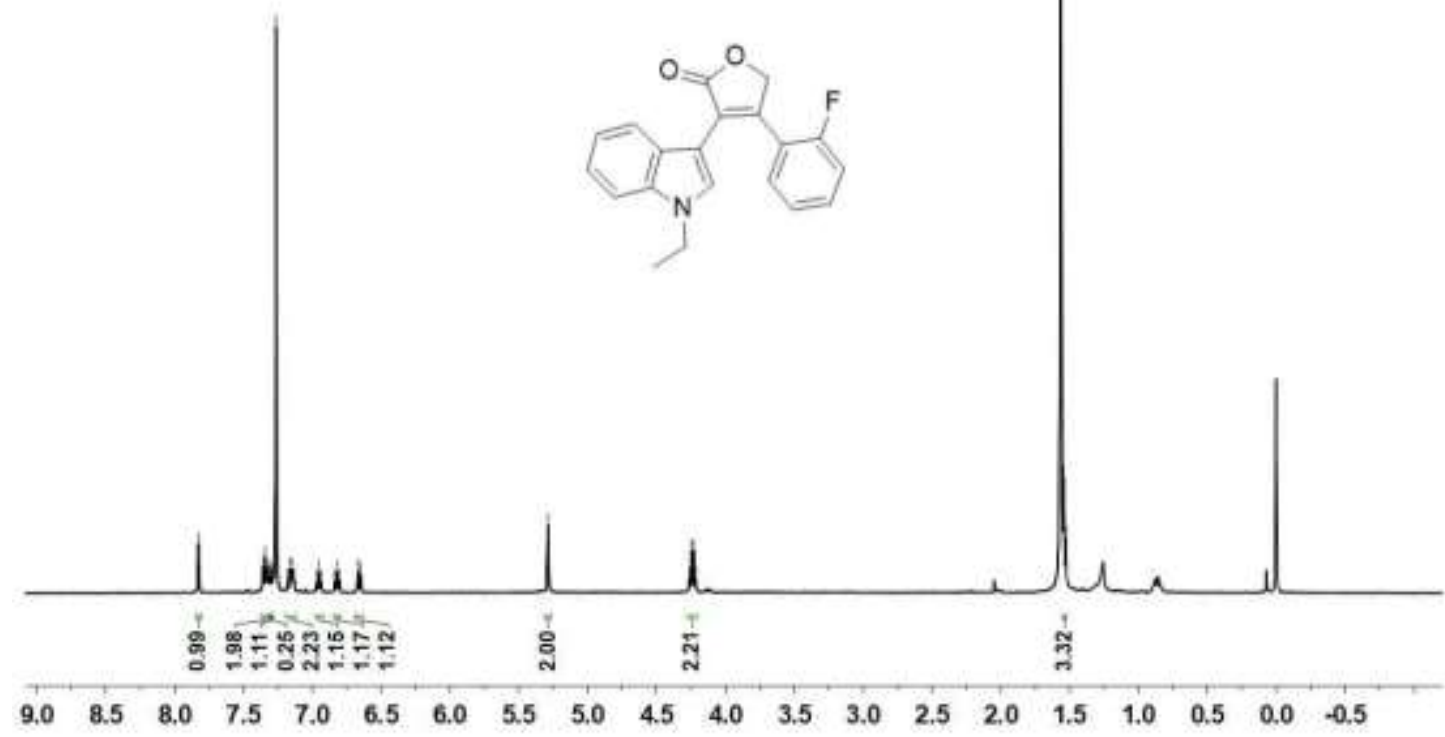

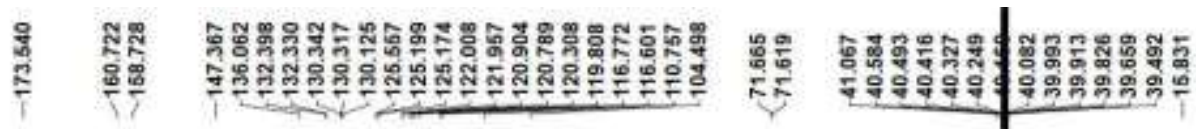

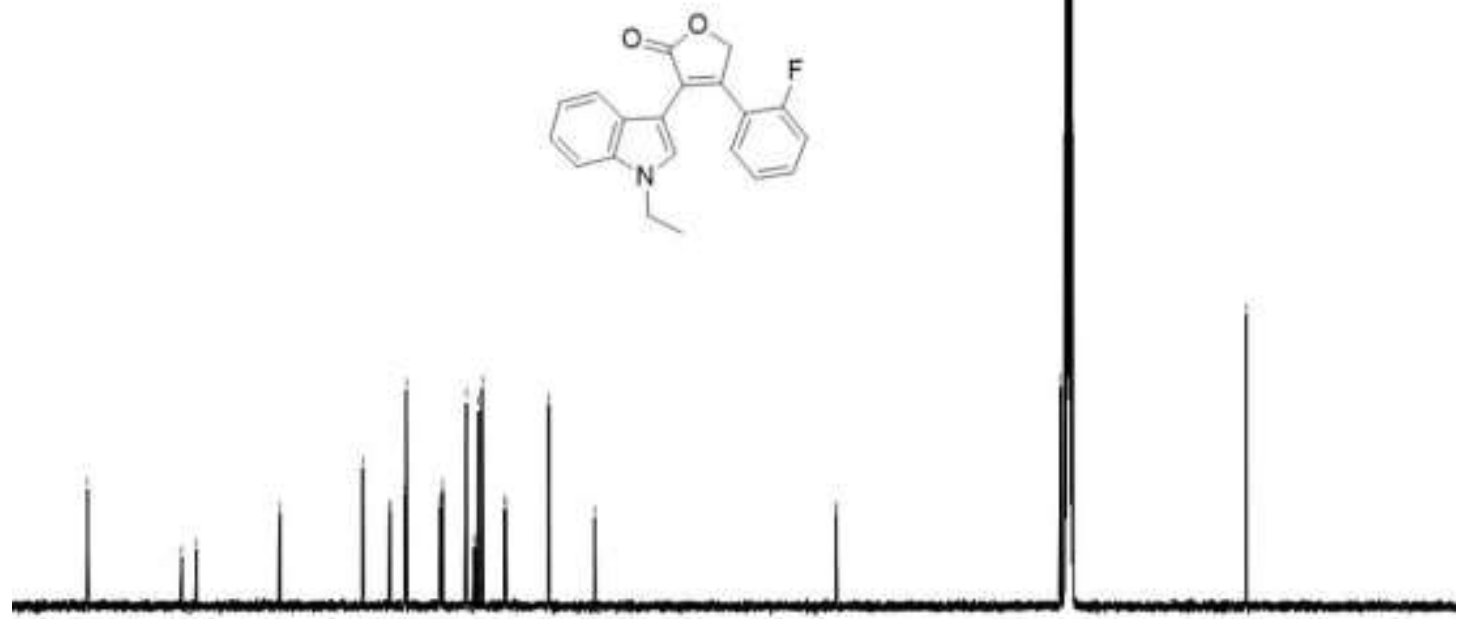

$\begin{array}{llllllllllllllllllll}180 & 170 & 160 & 150 & 140 & 130 & 120 & 110 & 100 & 90 & 80 & 70 & 60 & 50 & 40 & 30 & 20 & 10 & 0 & -10\end{array}$ 
4-(2-Fluorophenyl)-3-(naphthalen-1-yl)furan-2(5H)-one (2g)

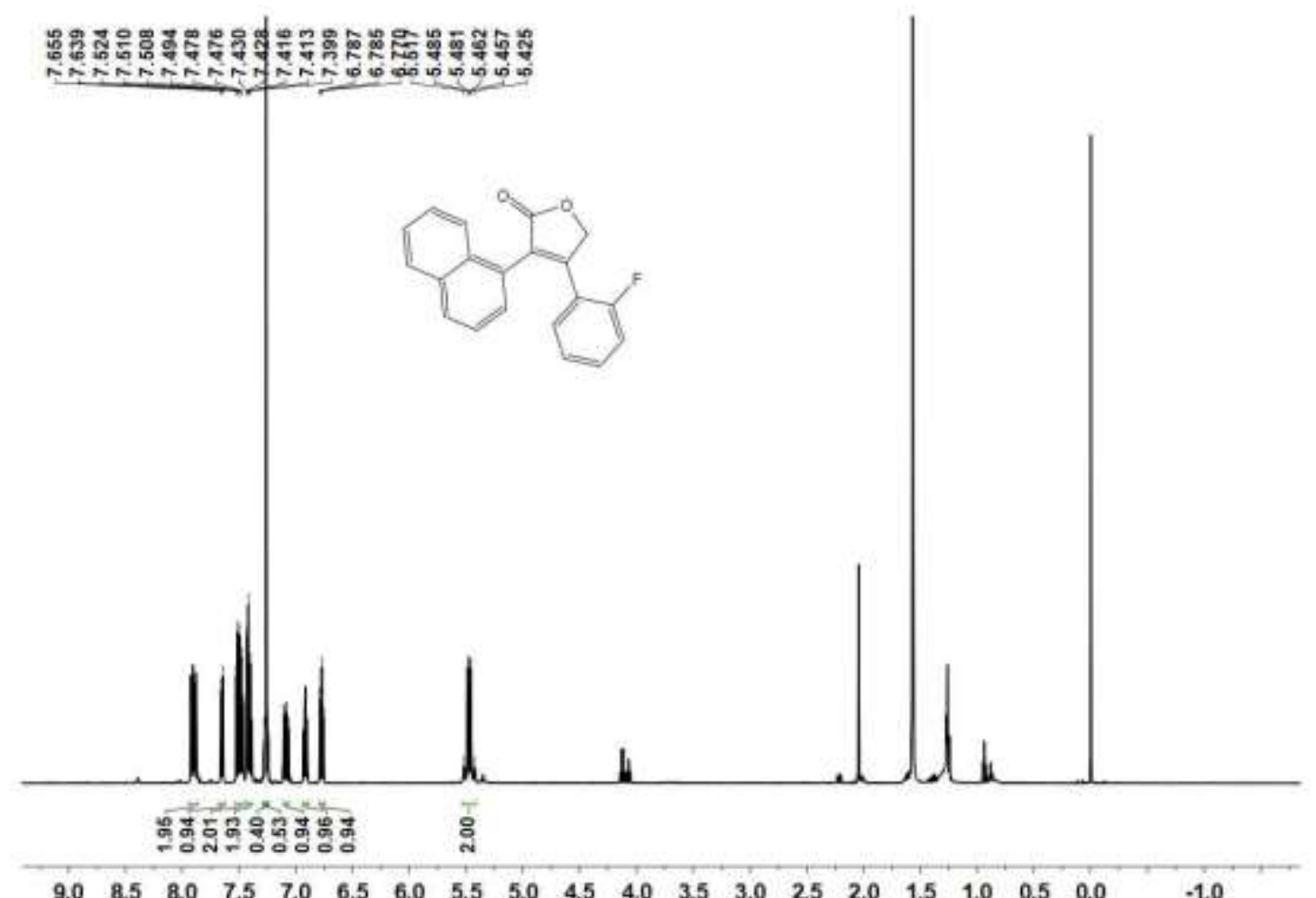

$\begin{array}{lllllllllllll}5.5 & 5.0 & 4.5 & 4.0 & 3.5 & 3.0 & 2.5 & 2.0 & 1.5 & 1.0 & 0.5 & 0.0\end{array}$

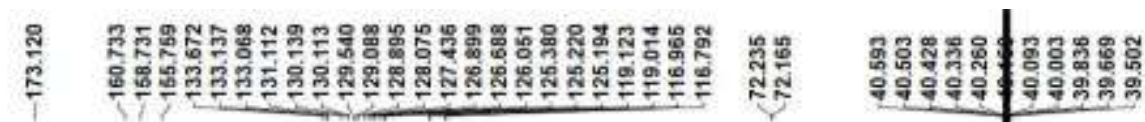

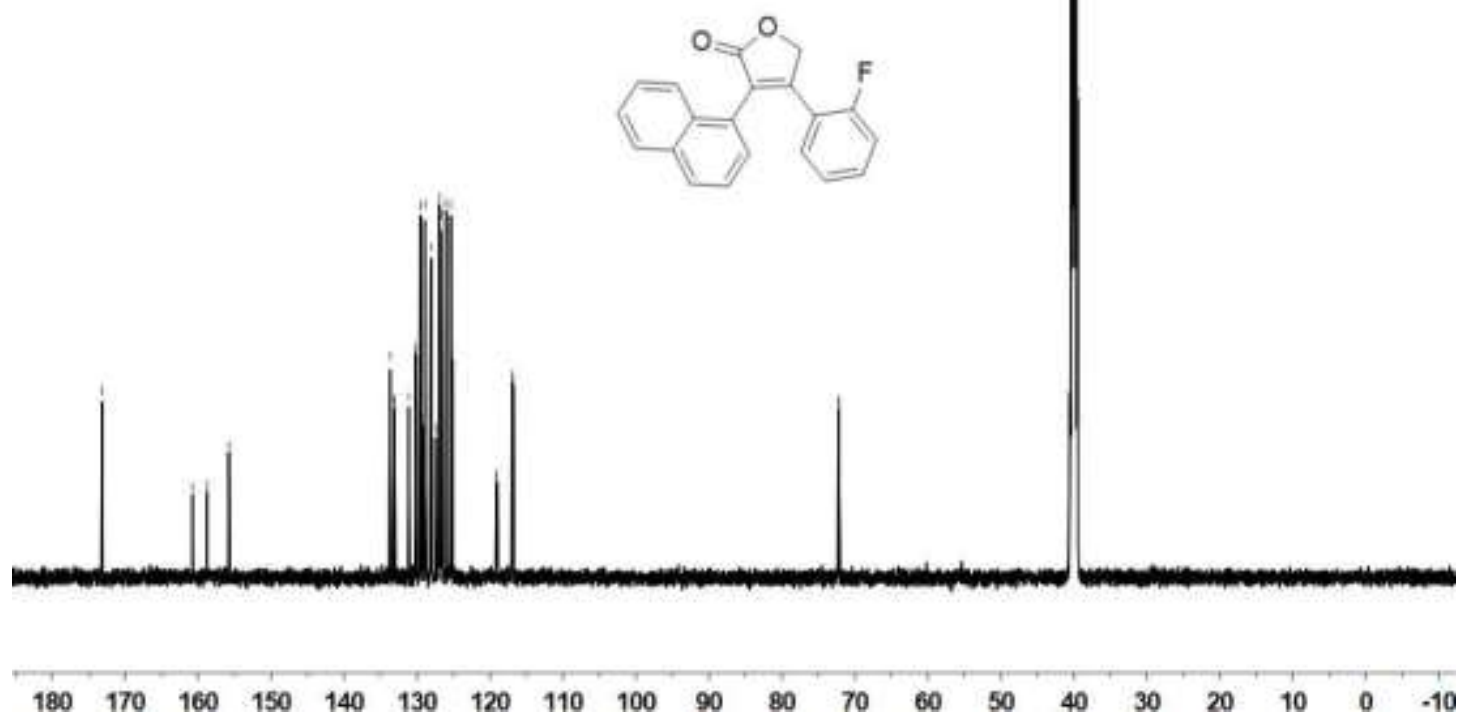


3,4-Bis(2-fluorophenyl)-1H-pyrrole-2,5-dione (3a)
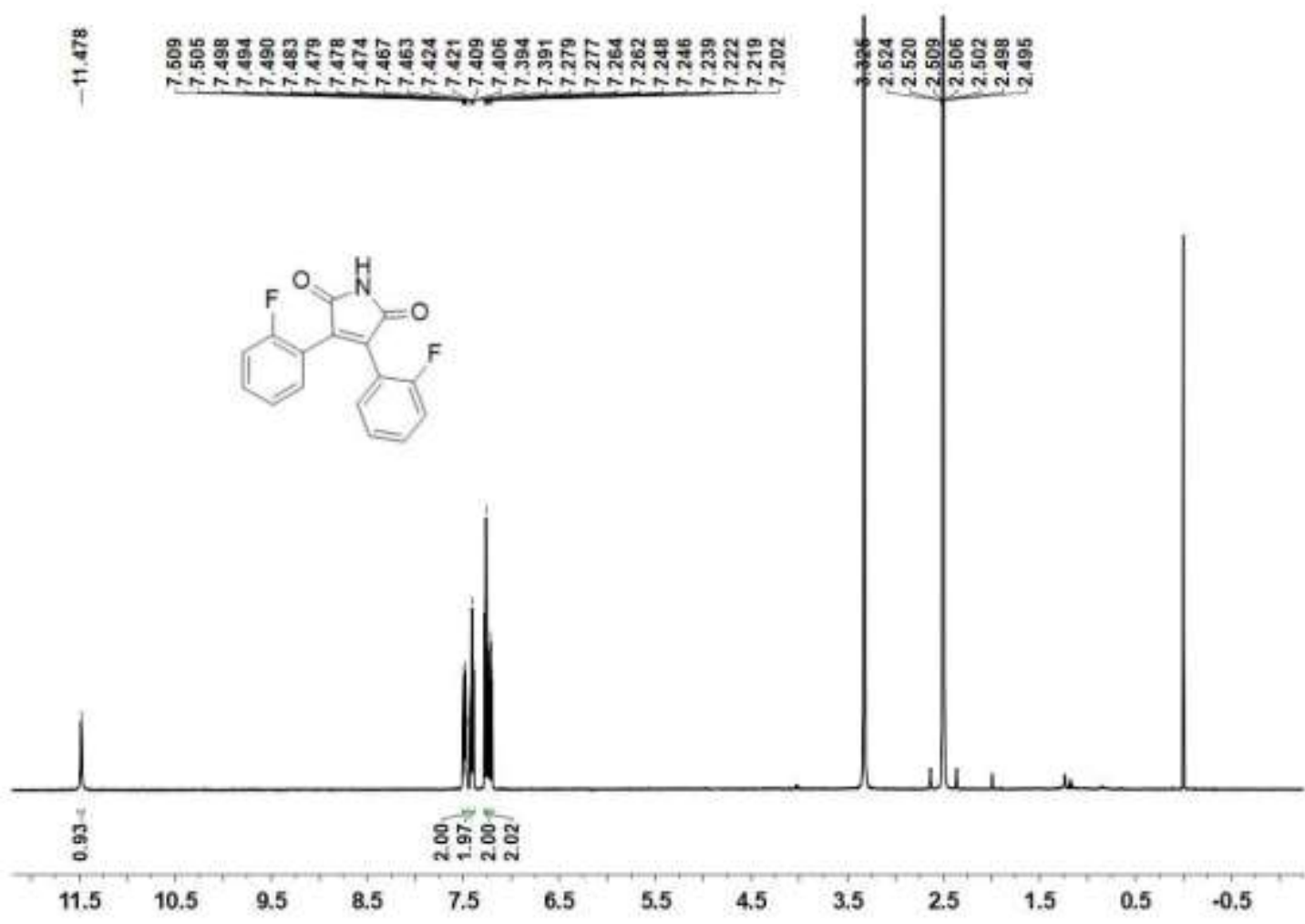

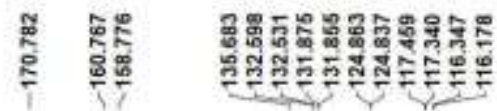
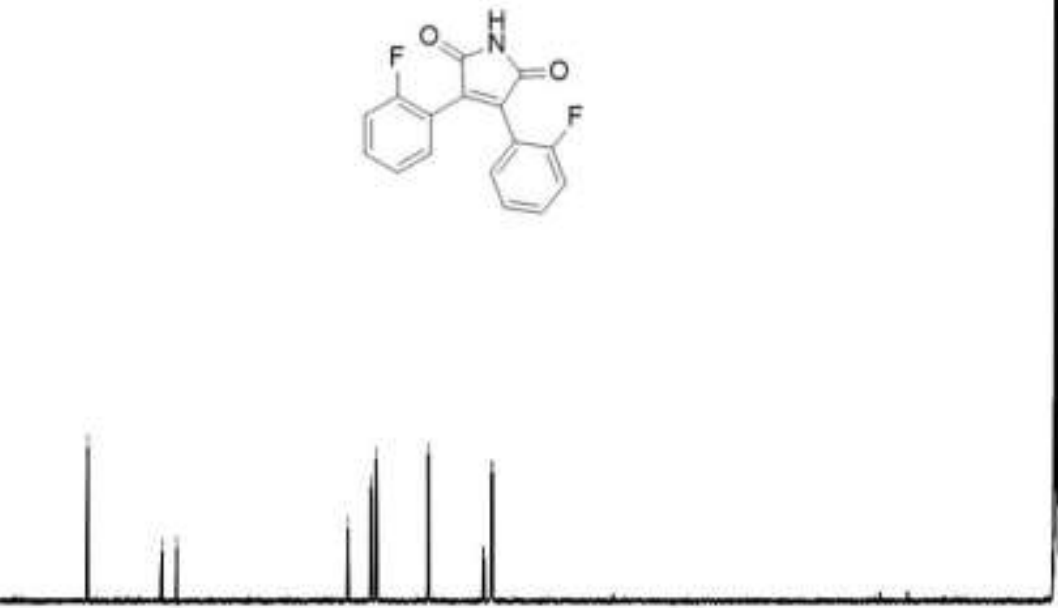

$\begin{array}{llllllllllllllllllll}180 & 170 & 160 & 150 & 140 & 130 & 120 & 110 & 100 & 90 & 80 & 70 & 60 & 50 & 40 & 30 & 20 & 10 & 0 & -10\end{array}$ 
3-(2-Fluorophenyl)-4-(4-methoxyphenyl)-1H-pyrrole-2,5-dione (3b)

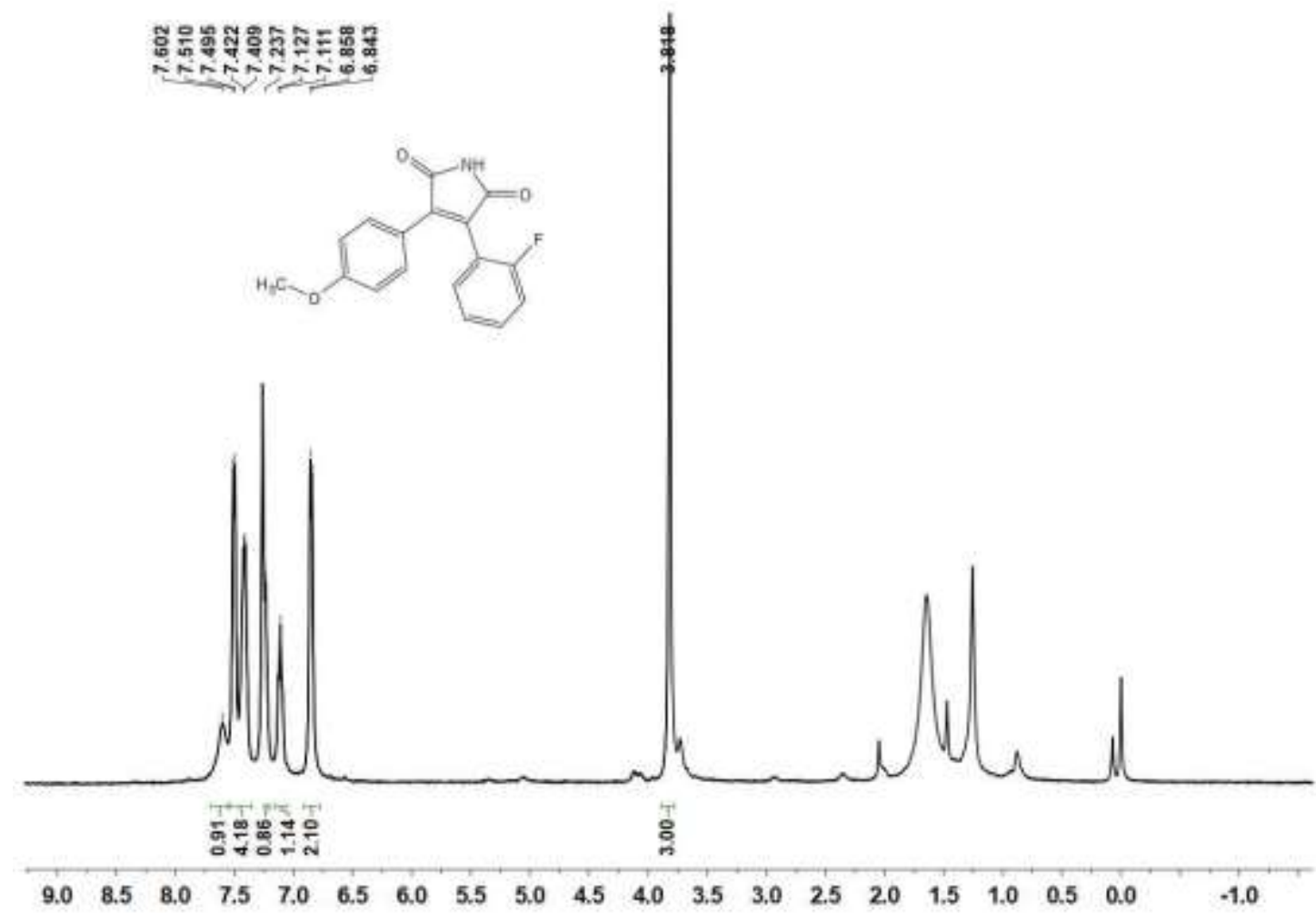

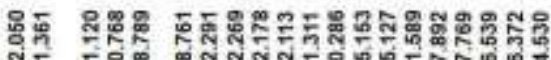

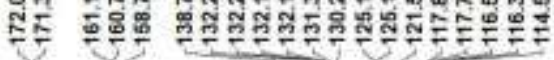

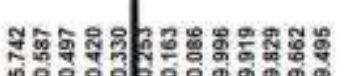

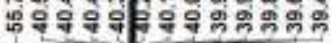

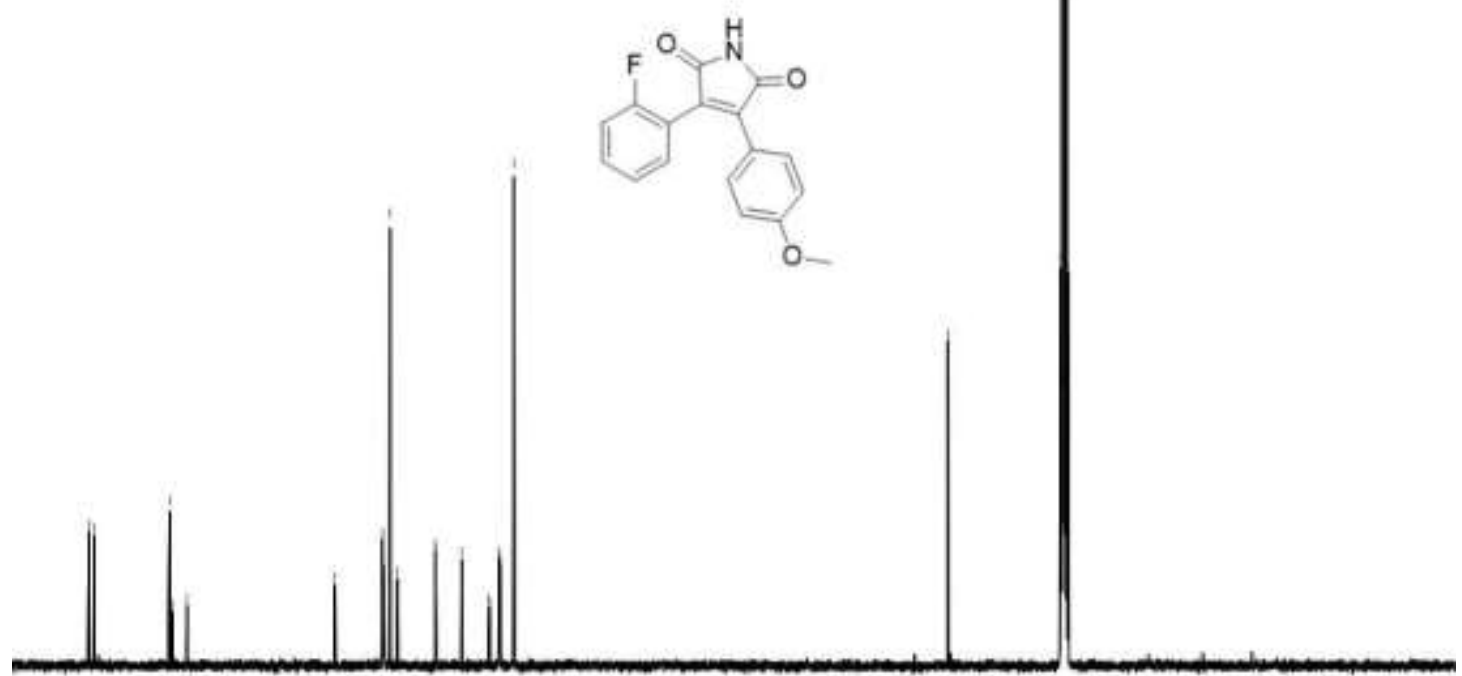

$\begin{array}{llllllllllllllllllll}180 & 170 & 160 & 150 & 140 & 130 & 120 & 110 & 100 & 90 & 80 & 70 & 60 & 50 & 40 & 30 & 20 & 10 & 0 & -10\end{array}$ 
3-(2-Fluorophenyl)-4-(4-methoxy-3-methylphenyl)-1H-pyrrole-2,5-dione (3c)

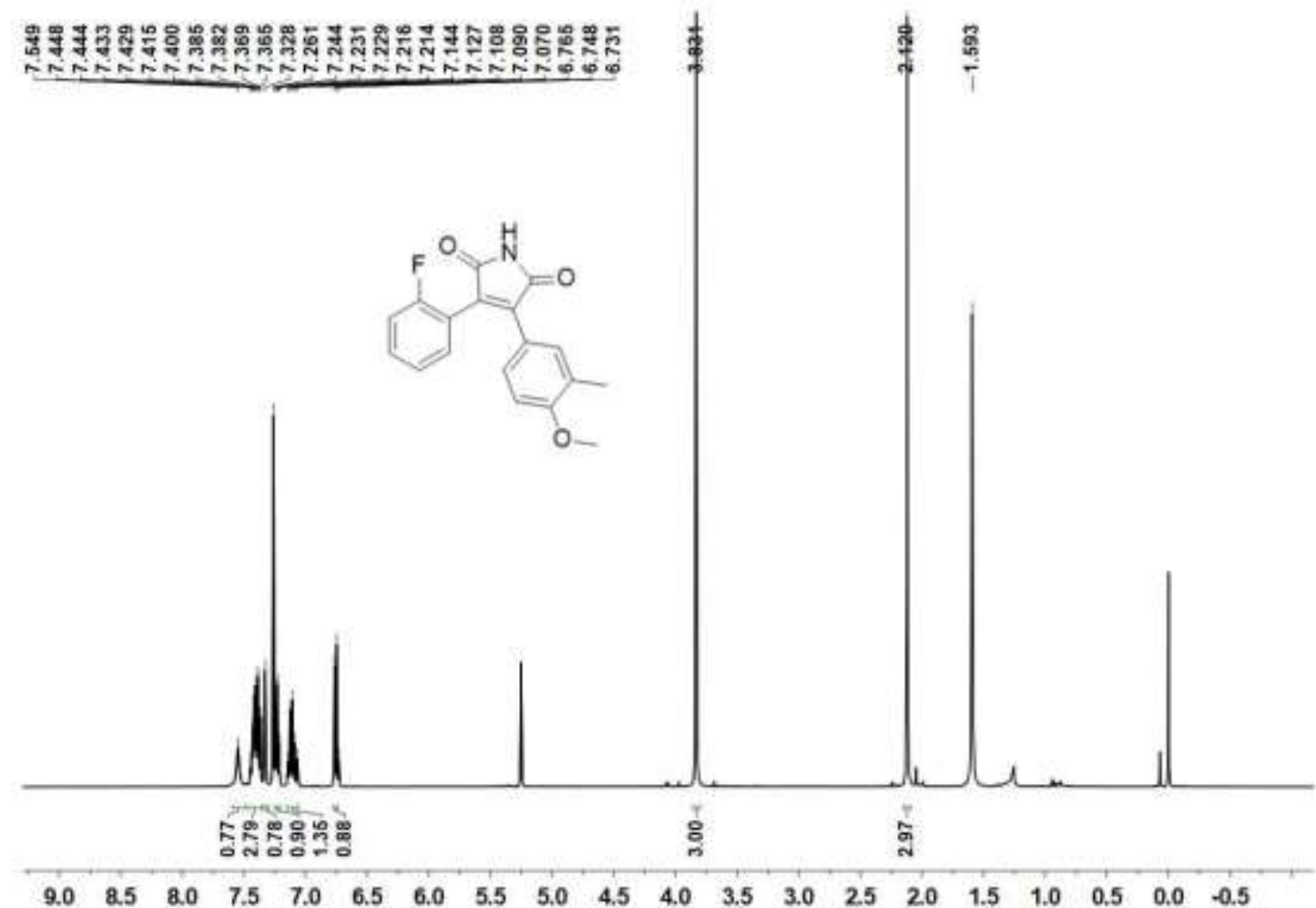

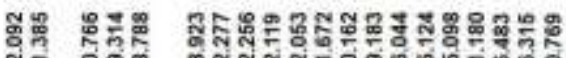 \\ E}

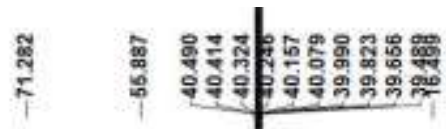
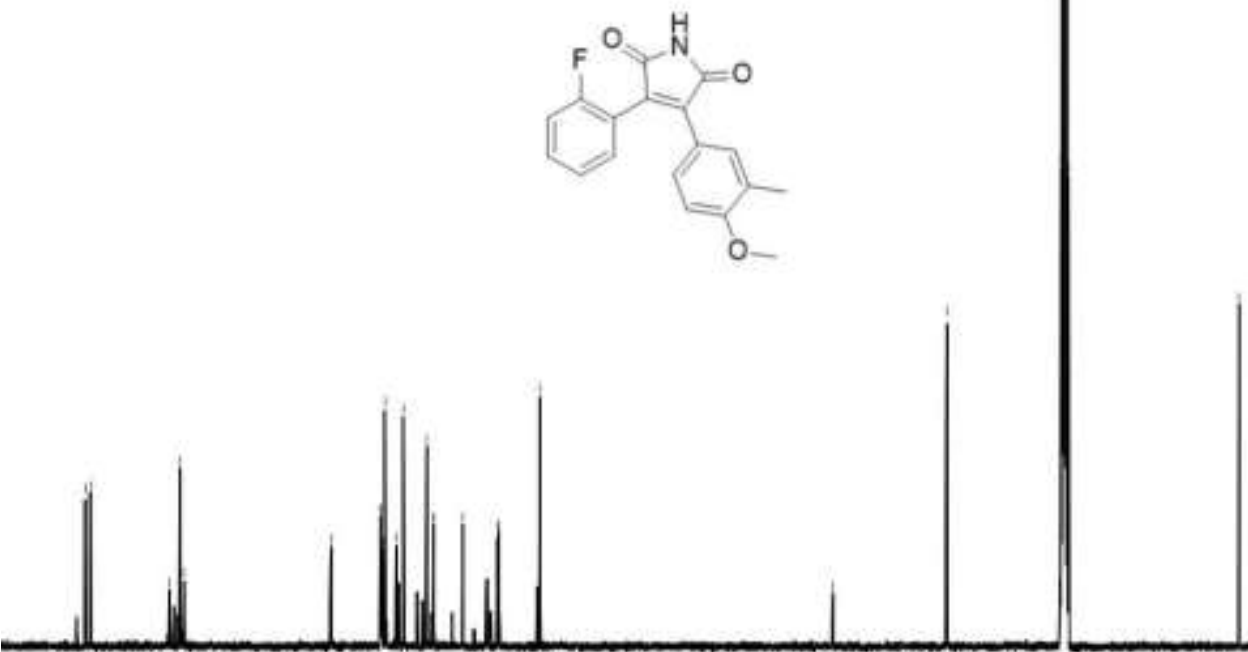

$\begin{array}{llllllllllllllllllll}180 & 170 & 160 & 150 & 140 & 130 & 120 & 110 & 100 & 90 & 80 & 70 & 60 & 50 & 40 & 30 & 20 & 10 & 0 & -11\end{array}$ 
5,6-Bis(4-methoxy-3-methylphenyl)pyridin-2-amine (4)

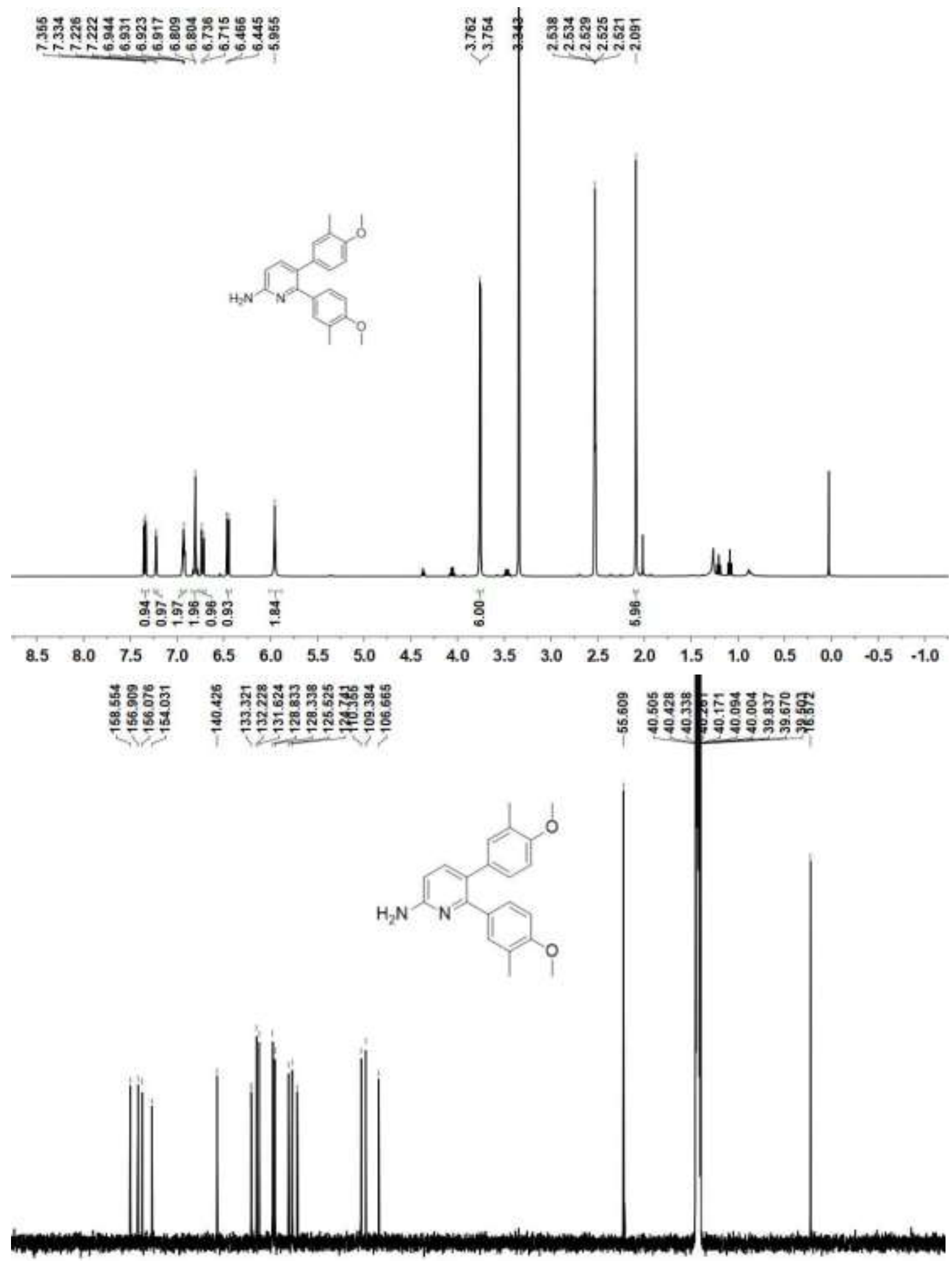

$\begin{array}{llllllllllllllllllll}180 & 170 & 160 & 150 & 140 & 130 & 120 & 110 & 100 & 90 & 80 & 70 & 60 & 50 & 40 & 30 & 20 & 10 & 0 & -1 C\end{array}$ 
5-(4-Methoxy-3-methylphenyl)-6-phenylpyridin-2-amine (5a)

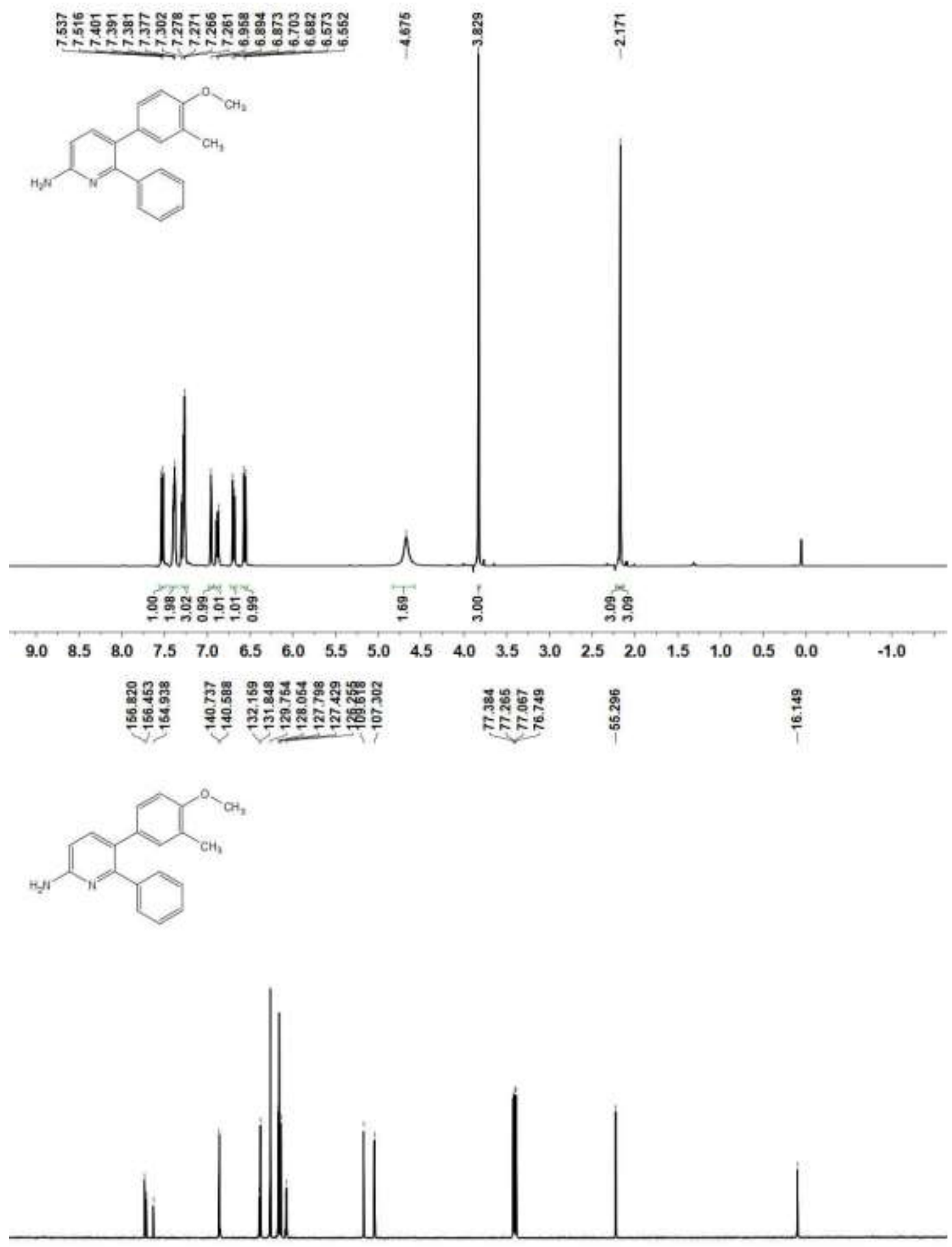

$\begin{array}{llllllllllllllllllll}180 & 170 & 160 & 150 & 140 & 130 & 120 & 110 & 100 & 90 & 80 & 70 & 60 & 50 & 40 & 30 & 20 & 10 & 0 & -10\end{array}$ 
6-(4-Isopropoxyphenyl)-5-(4-methoxy-3-methylphenyl)pyridin-2-amine (5b)
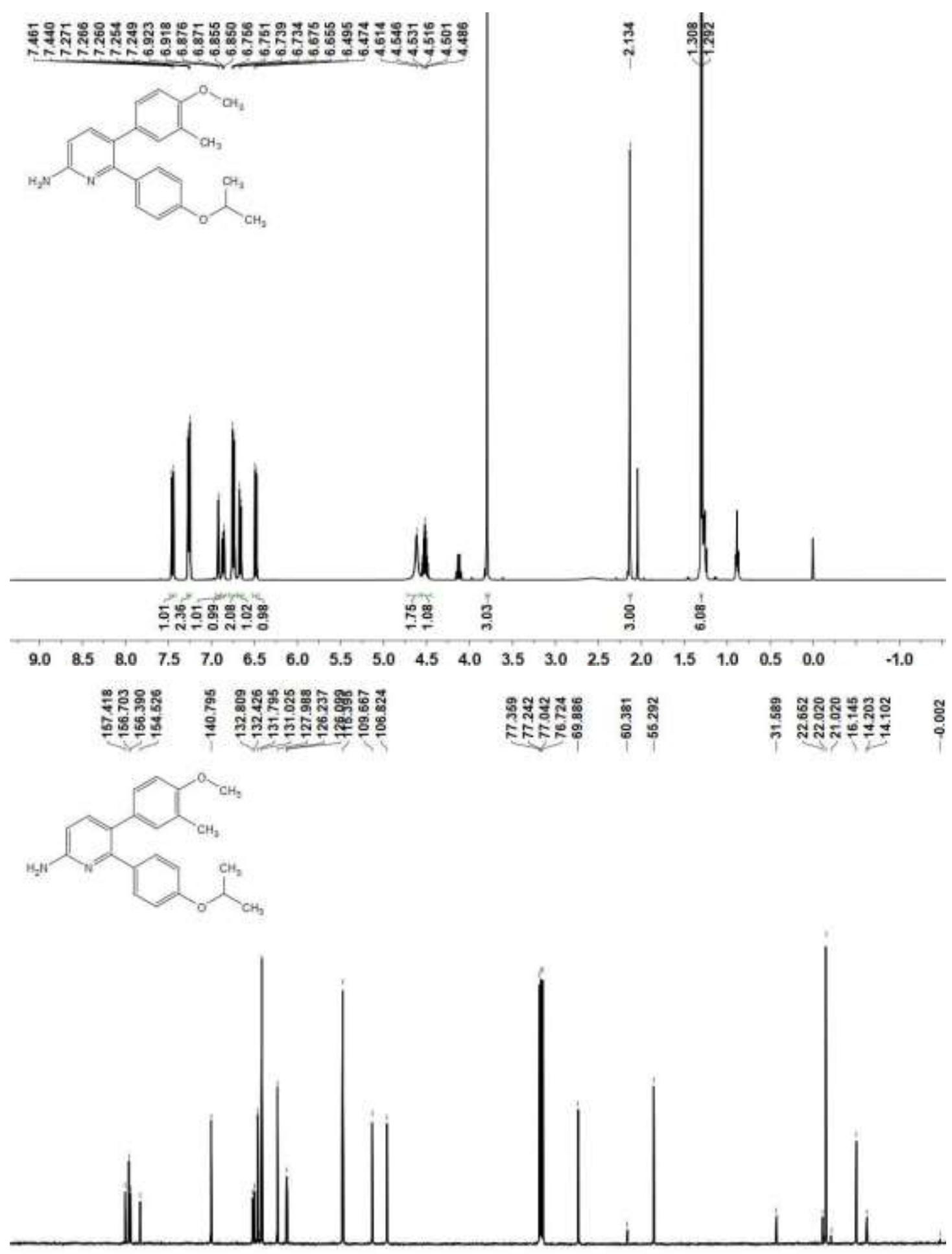

$\begin{array}{llllllllllllllllll}170 & 160 & 150 & 140 & 130 & 120 & 110 & 100 & 90 & 80 & 70 & 60 & 50 & 40 & 30 & 20 & 10 & 0\end{array}$ 
5-(4-Methoxy-3-methylphenyl)-6-(4-(trifluoromethyl)phenyl)pyridin-2-amine (5c)

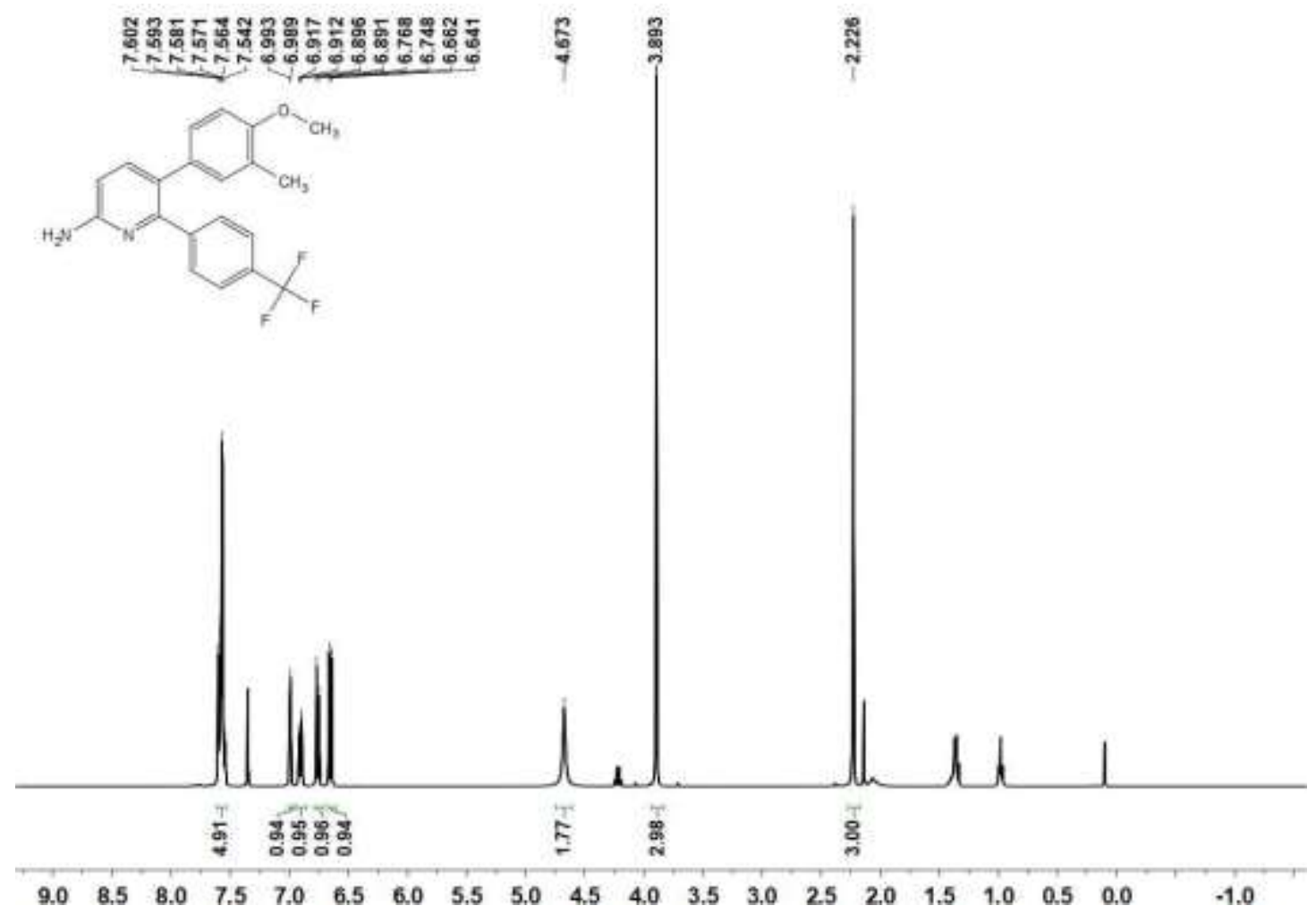

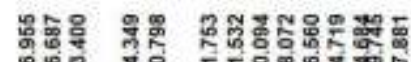

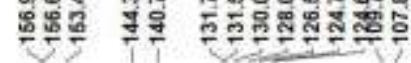

ลั.

$\stackrel{\text { : }}{\circ}$
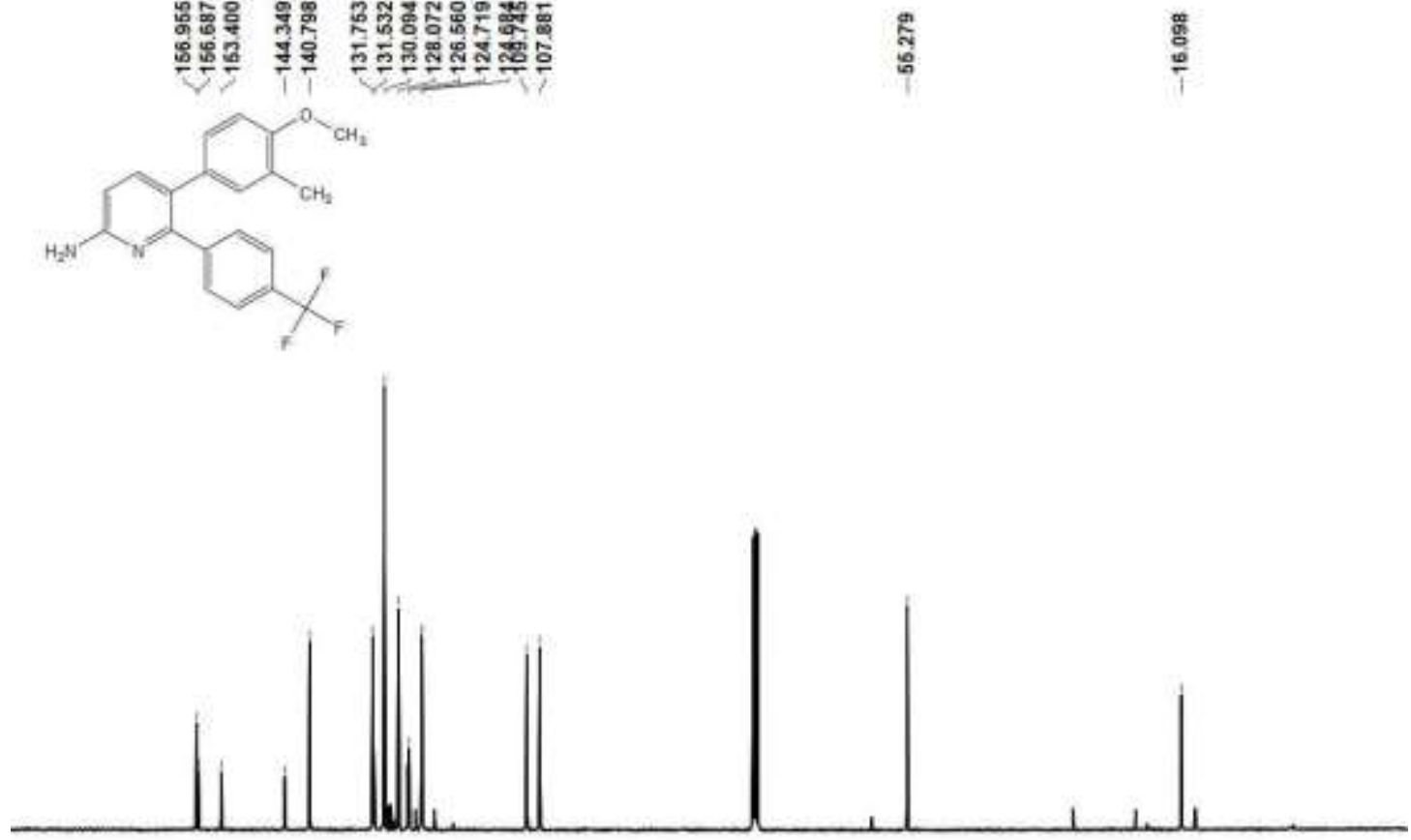

$\begin{array}{llllllllllllllllllll}180 & 170 & 160 & 150 & 140 & 130 & 120 & 110 & 100 & 90 & 80 & 70 & 60 & 50 & 40 & 30 & 20 & 10 & 0 & -10\end{array}$ 
6-(4-Methoxy-3-methylphenyl)-5-phenylpyridin-2-amine (5d)
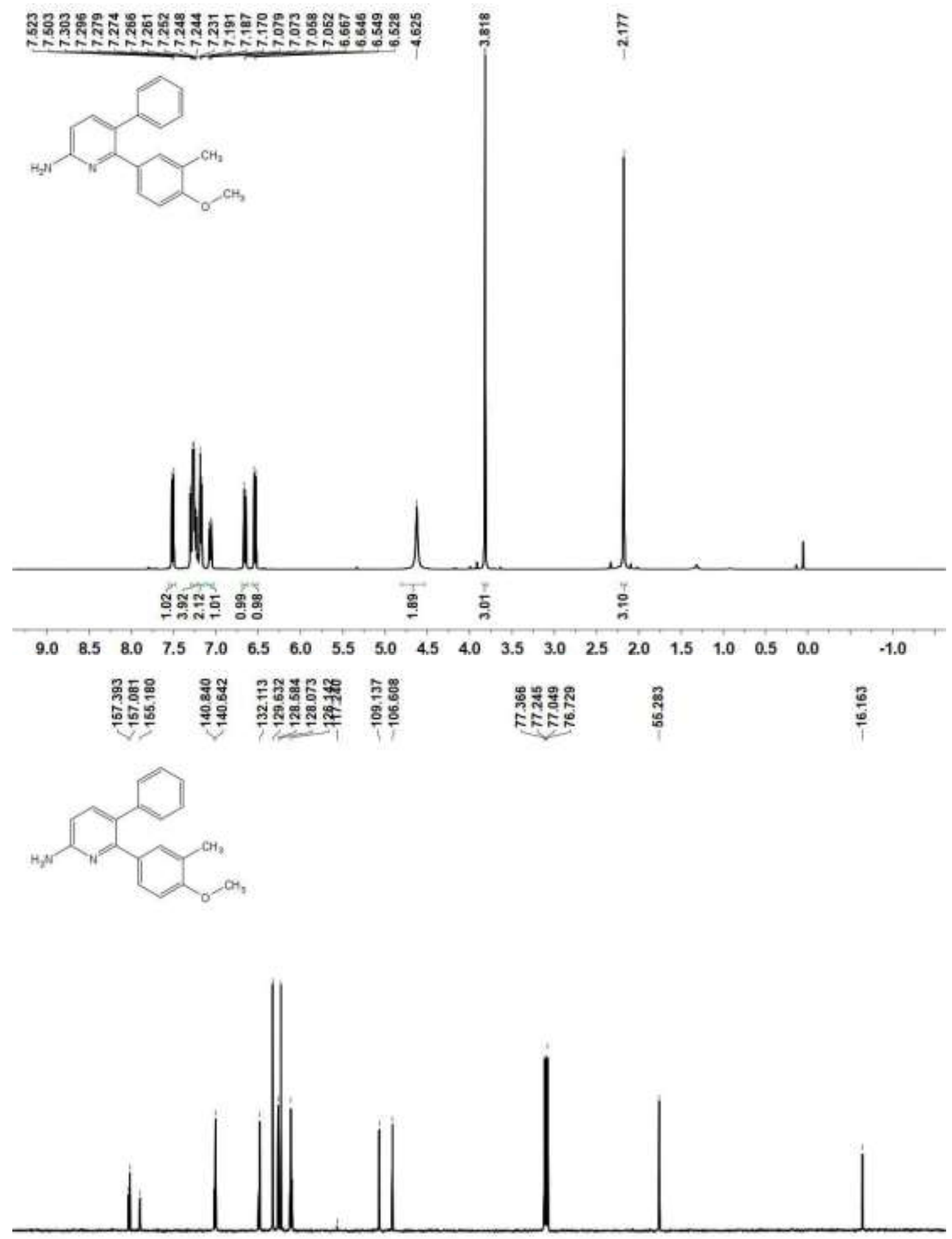

$\begin{array}{lllllllllllllllll}170 & 160 & 150 & 140 & 130 & 120 & 110 & 100 & 90 & 80 & 70 & 60 & 50 & 40 & 30 & 20 & 10\end{array}$ 
5-(4-Isopropoxyphenyl)-6-(4-methoxy-3-methylphenyl)pyridin-2-amine (5e)

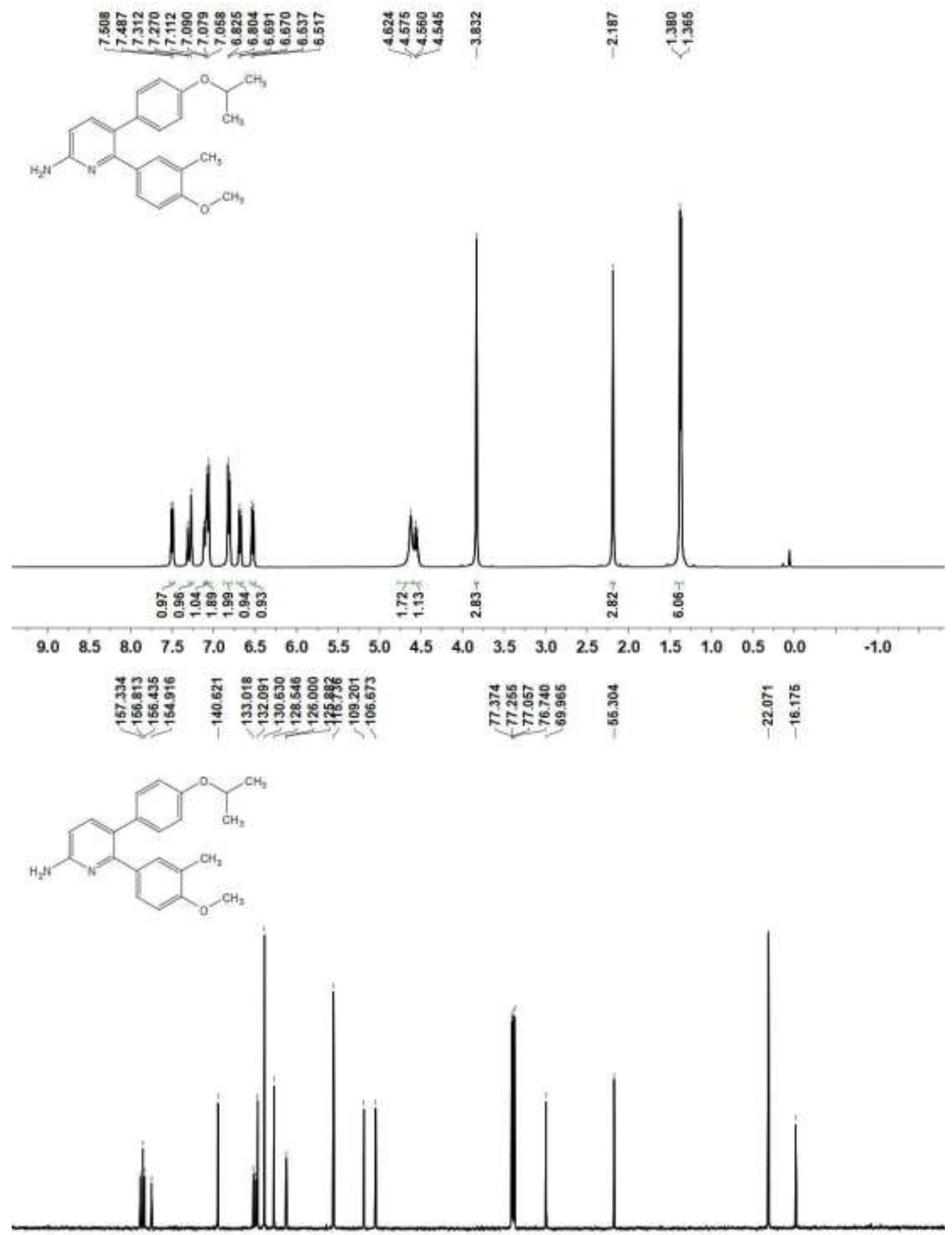

$\begin{array}{llllllllllllllllllll}180 & 170 & 160 & 150 & 140 & 130 & 120 & 110 & 100 & 90 & 80 & 70 & 60 & 50 & 40 & 30 & 20 & 10 & 0 & -10\end{array}$ 
6-(4-Methoxy-3-methylphenyl)-5-(4-(trifluoromethyl)phenyl)pyridin-2-amine (5f)

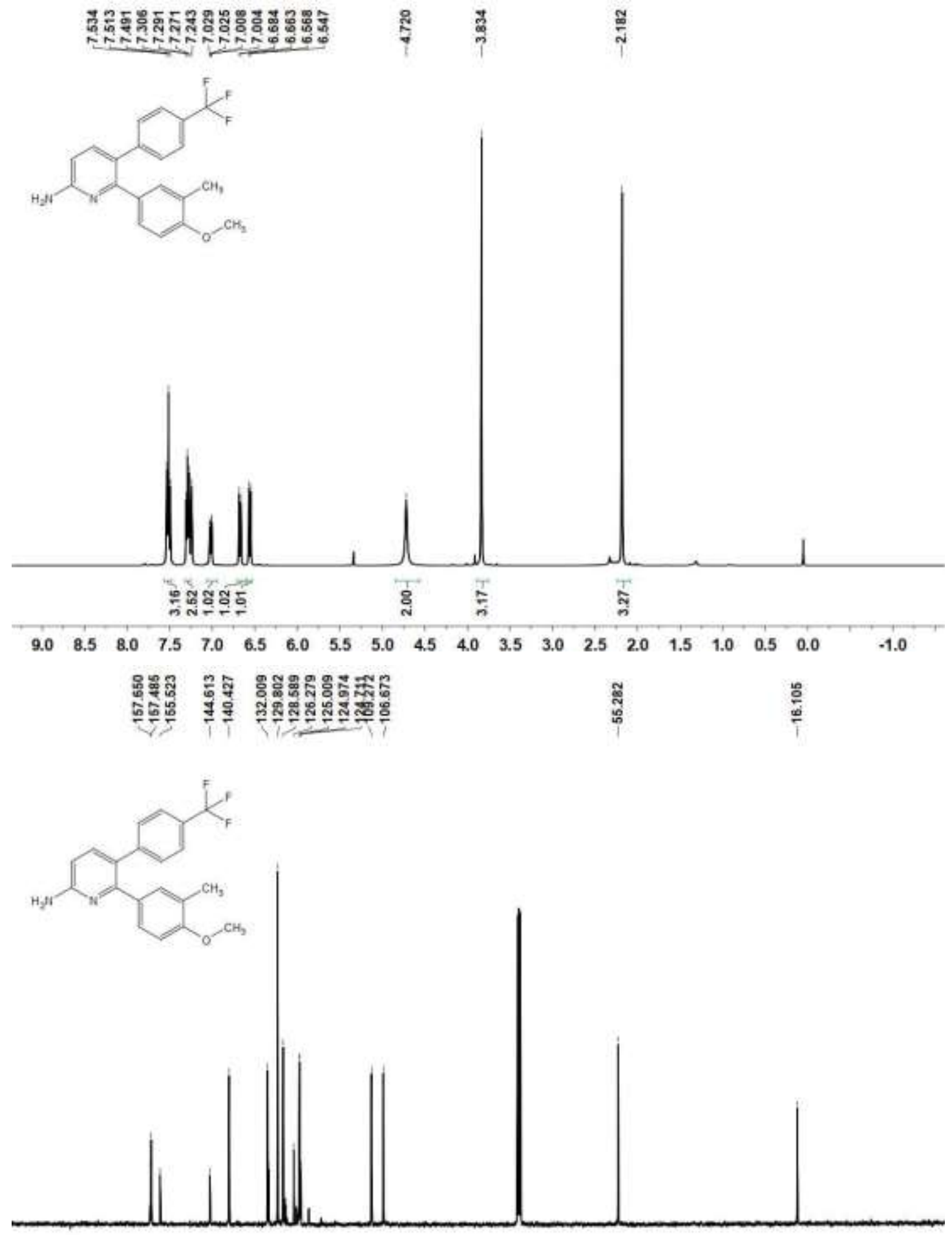

$\begin{array}{llllllllllllllllllll}180 & 170 & 160 & 150 & 140 & 130 & 120 & 110 & 100 & 90 & 80 & 70 & 60 & 50 & 40 & 30 & 20 & 10 & 0 & -10\end{array}$ 
6-(4-Methoxy-3-methylphenoxy)-5-phenylpyridin-2-amine (6a)

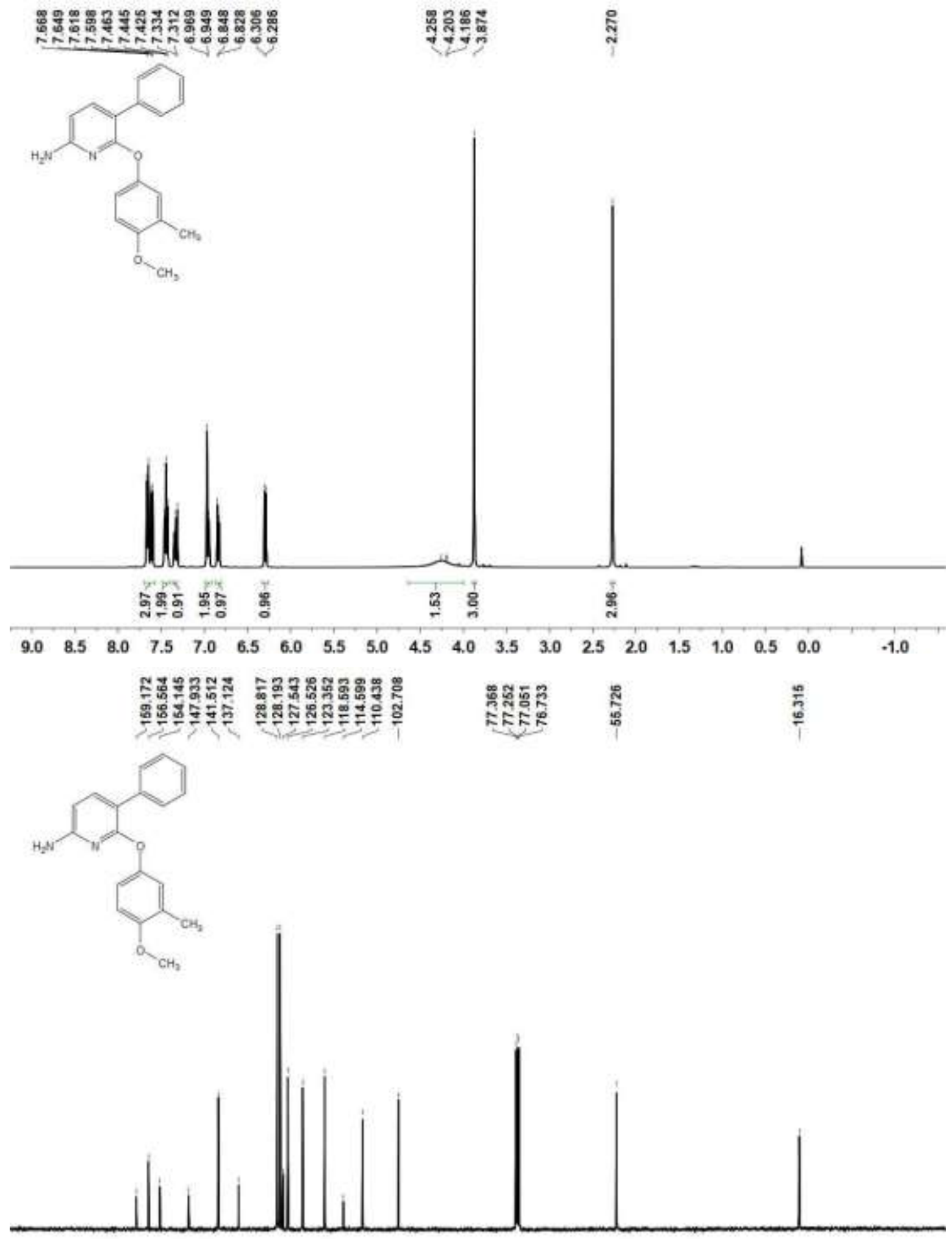

$\begin{array}{llllllllllllllllllll}180 & 170 & 160 & 150 & 140 & 130 & 120 & 110 & 100 & 90 & 80 & 70 & 60 & 50 & 40 & 30 & 20 & 10 & 0 & -10\end{array}$ 
5-(4-Isopropoxyphenyl)-6-(4-methoxy-3-methylphenoxy)pyridin-2-amine (6b)
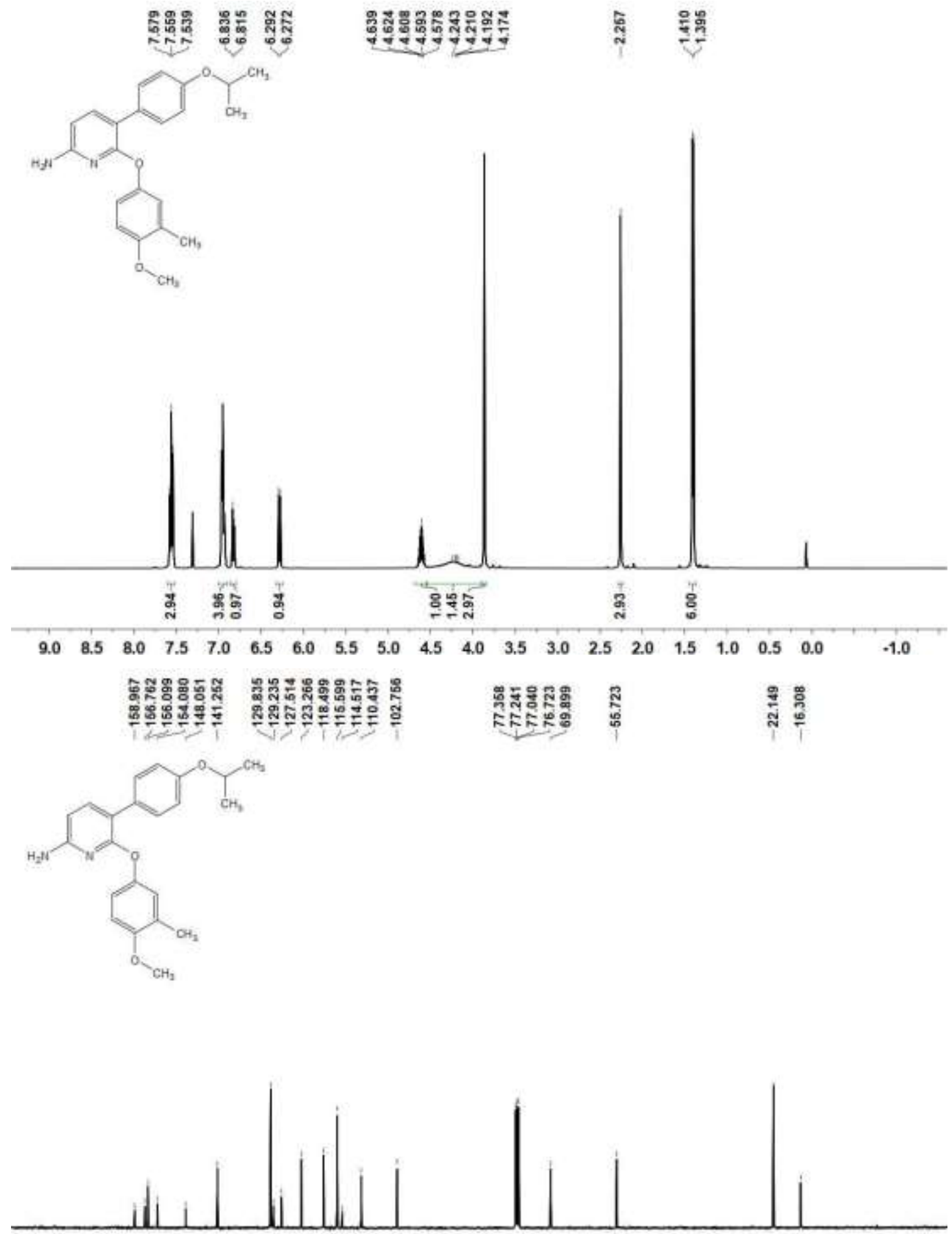

$\begin{array}{llllllllllllllllllll}180 & 170 & 160 & 150 & 140 & 130 & 120 & 110 & 100 & 90 & 80 & 70 & 60 & 50 & 40 & 30 & 20 & 10 & 0 & -10\end{array}$ 
6-(4-Methoxy-3-methylphenoxy)-5-(4-methoxy-3-methylphenyl)pyridin-2-amine (6c)
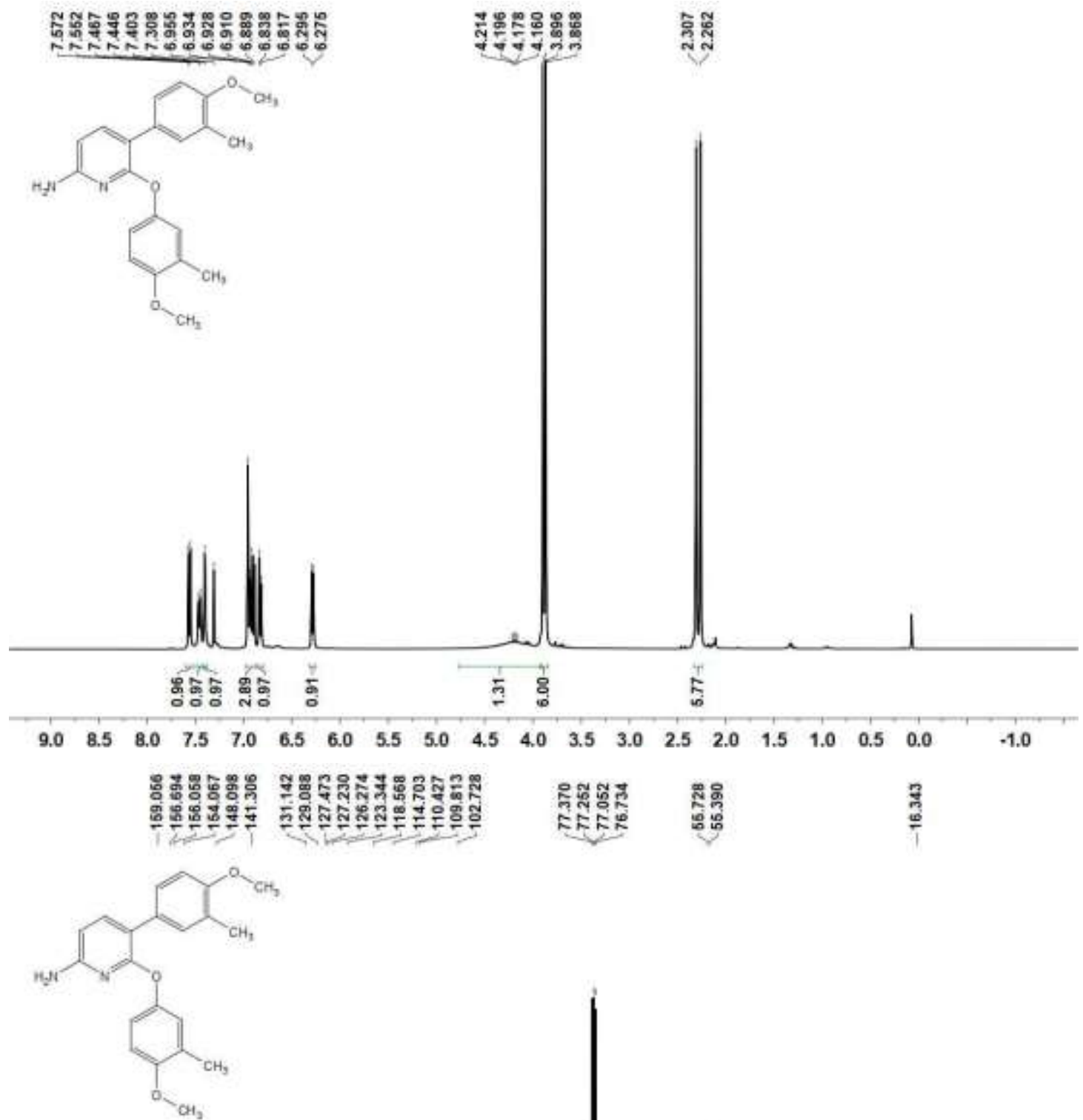

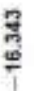

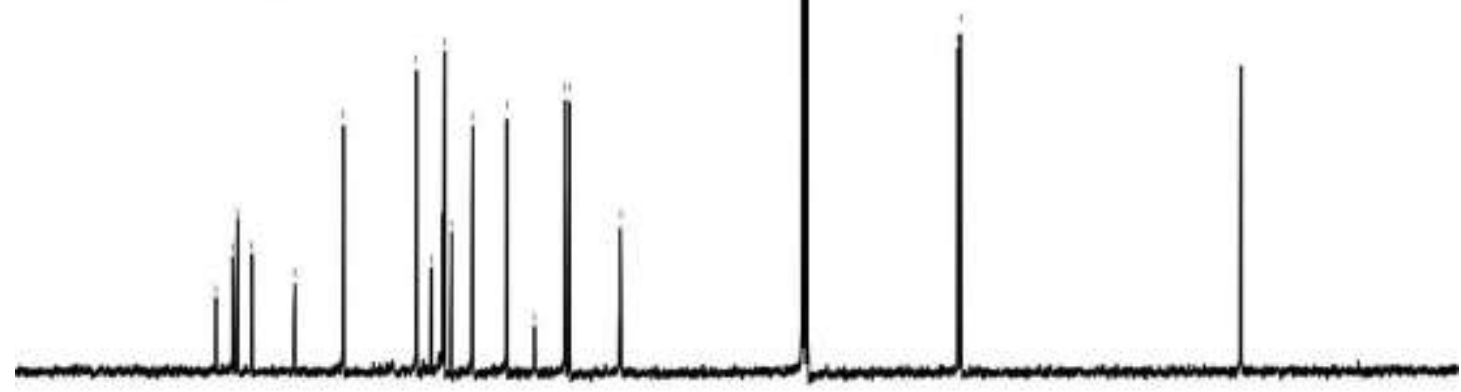

$\begin{array}{llllllllllllllllllll}180 & 170 & 160 & 150 & 140 & 130 & 120 & 110 & 100 & 90 & 80 & 70 & 60 & 50 & 40 & 30 & 20 & 10 & 0 & -10\end{array}$ 
6-(4-Methoxy-3-methylphenoxy)-5-(4-(trifluoromethyl)phenyl)pyridin-2-amine (6d)

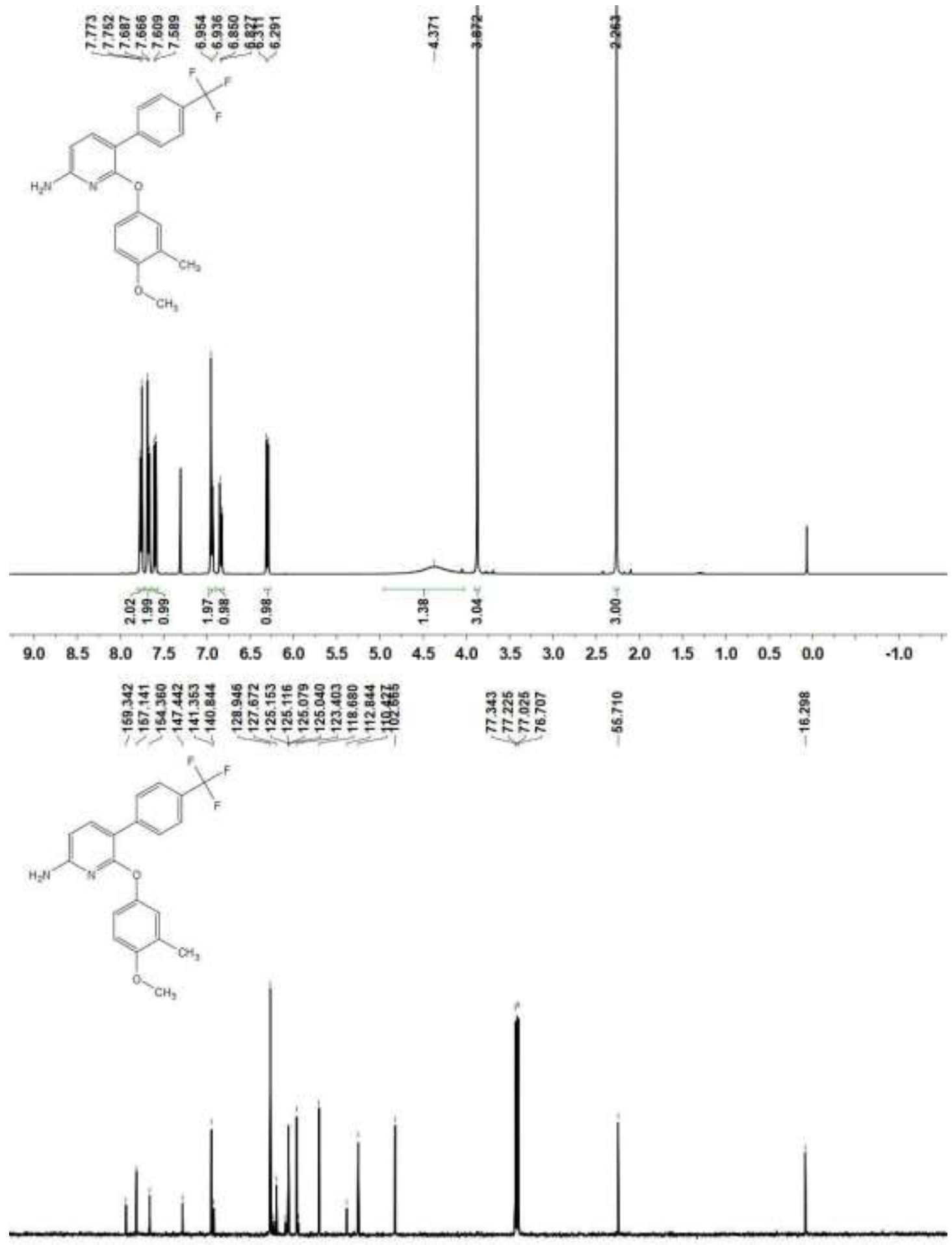

$\begin{array}{llllllllllllllllllll}180 & 170 & 160 & 150 & 140 & 130 & 120 & 110 & 100 & 90 & 80 & 70 & 60 & 50 & 40 & 30 & 20 & 10 & 0 & -10\end{array}$ 
5-(4-Methoxy-3-methylphenyl)-6-phenoxypyridin-2-amine (6e)

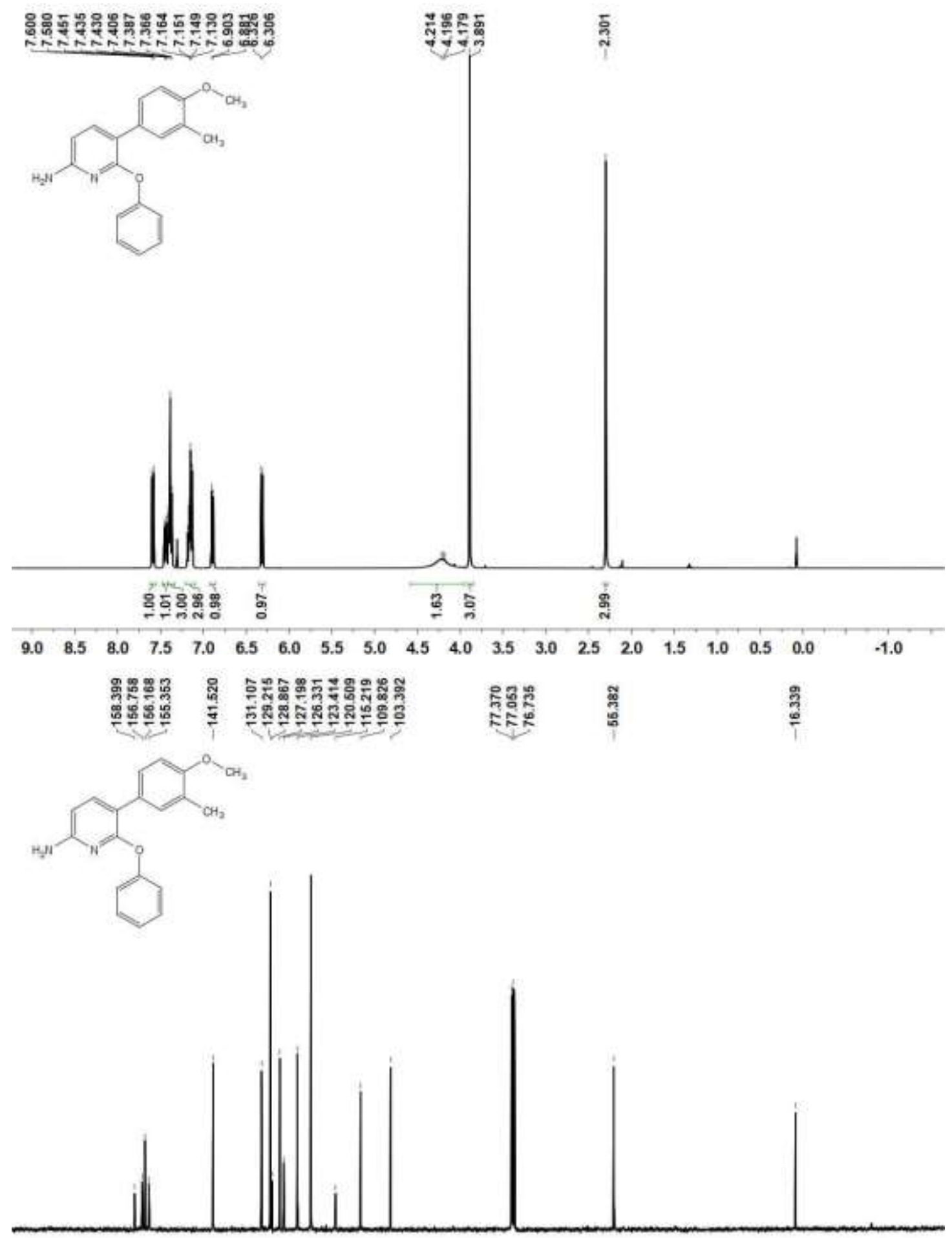

$\begin{array}{llllllllllllllllllll}180 & 170 & 160 & 150 & 140 & 130 & 120 & 110 & 100 & 90 & 80 & 70 & 60 & 50 & 40 & 30 & 20 & 10 & 0 & -10\end{array}$ 
6-(4-Isopropoxyphenoxy)-5-(4-methoxy-3-methylphenyl)pyridin-2-amine (6f)

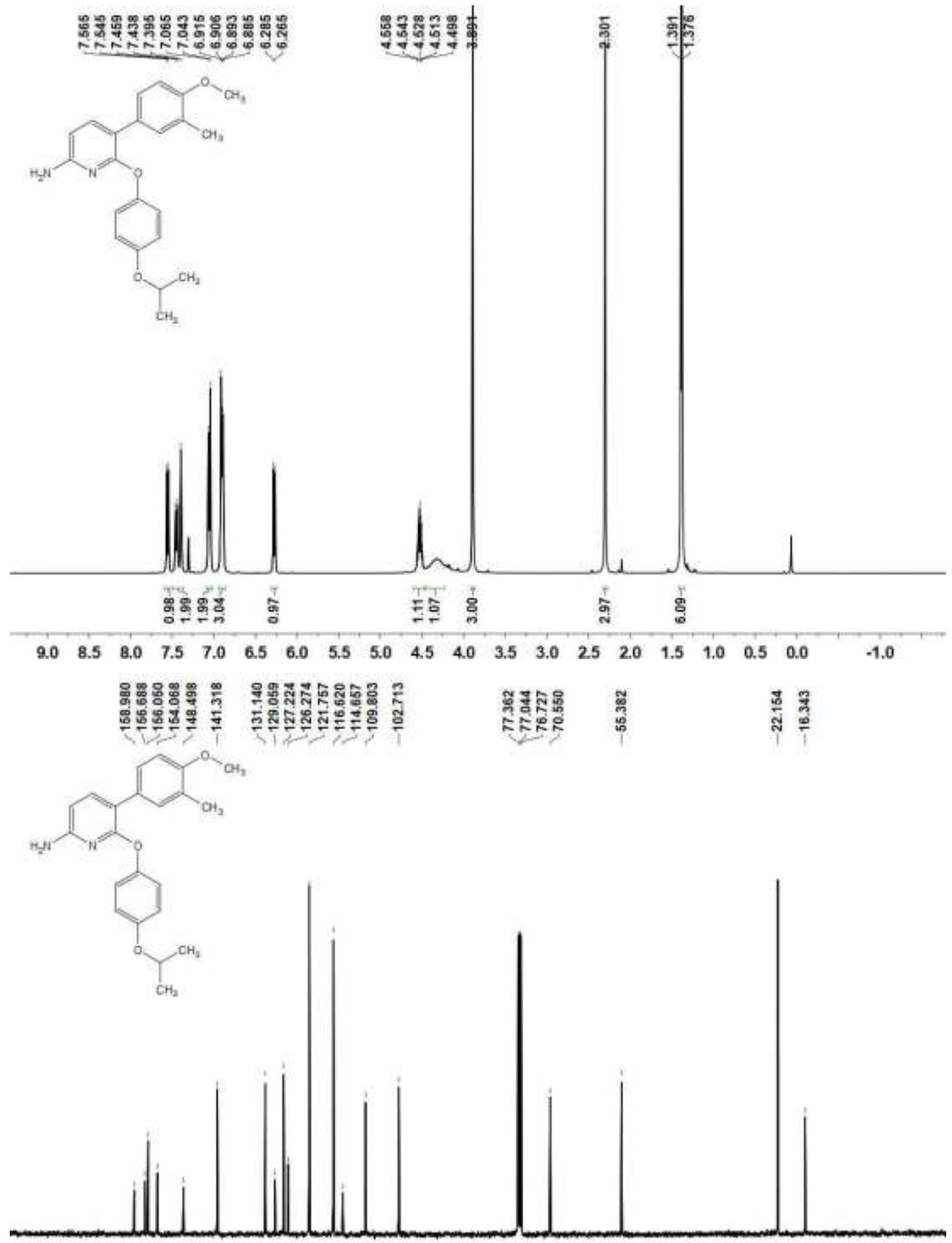

$\begin{array}{llllllllllllllllllll}180 & 170 & 160 & 150 & 140 & 130 & 120 & 110 & 100 & 90 & 80 & 70 & 60 & 50 & 40 & 30 & 20 & 10 & 0 & -10\end{array}$ 
$\mathrm{N}^{2}$-(4-methoxy-3-methylphenyl)-3-phenylpyridine-2,6-diamine (6g)

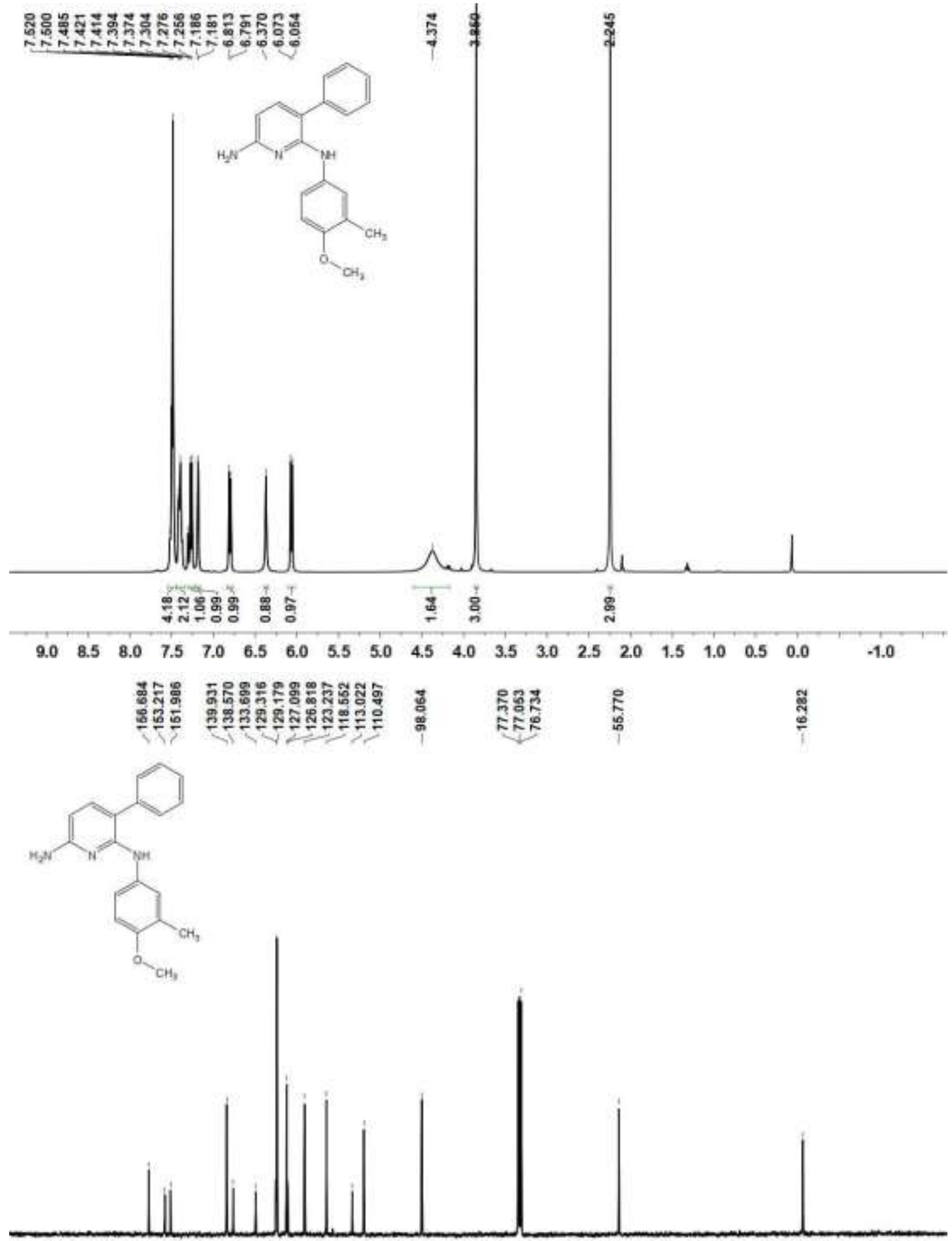

$\begin{array}{llllllllllllllllllll}180 & 170 & 160 & 150 & 140 & 130 & 120 & 110 & 100 & 90 & 80 & 70 & 60 & 50 & 40 & 30 & 20 & 10 & 0 & -10\end{array}$ 
3-(4-Isopropoxyphenyl)- $\mathrm{N}^{2}$-(4-methoxy-3-methylphenyl)pyridine-2,6-diamine (6h)
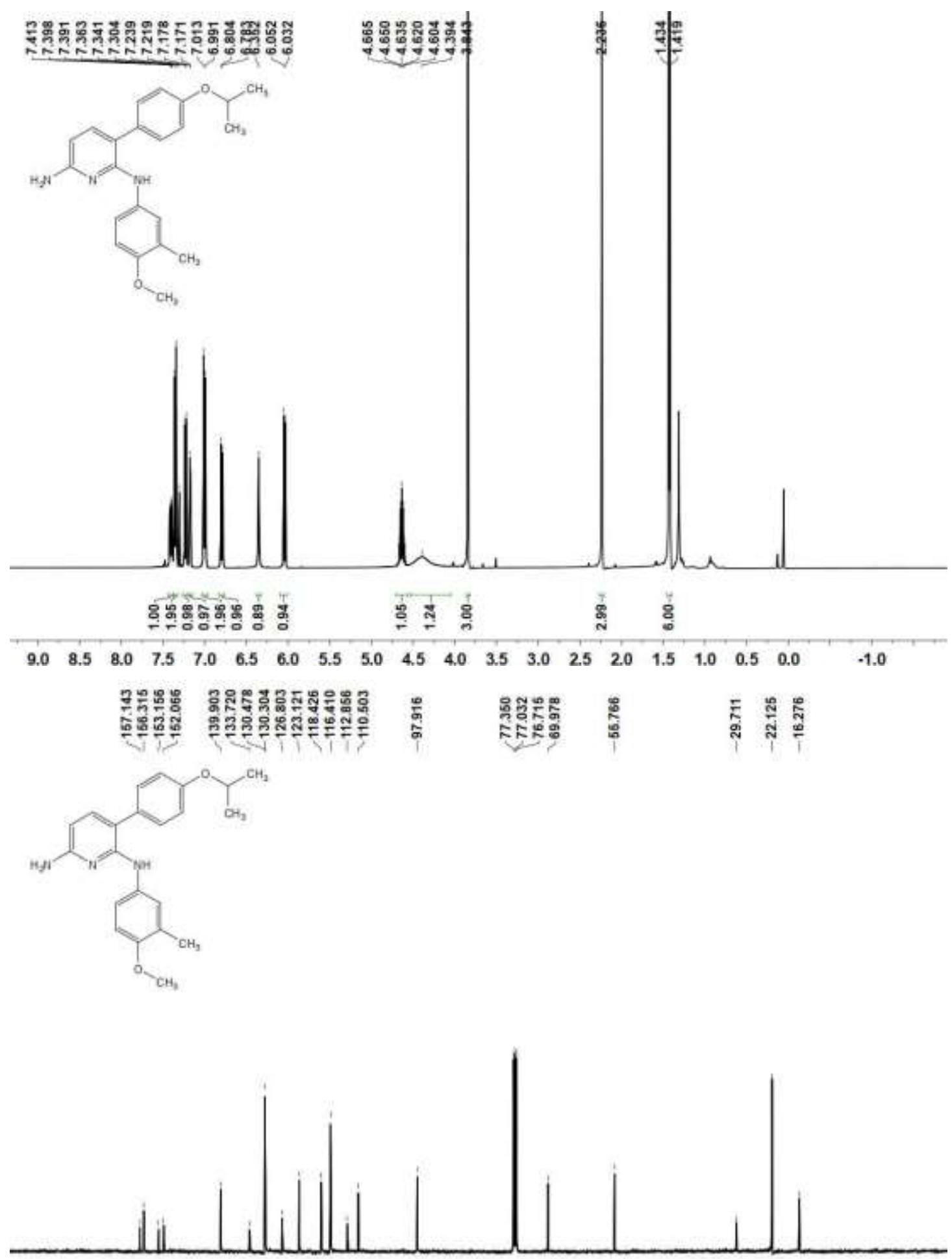

$\begin{array}{llllllllllllllllllll}180 & 170 & 160 & 150 & 140 & 130 & 120 & 110 & 100 & 90 & 80 & 70 & 60 & 50 & 40 & 30 & 20 & 10 & 0 & -10\end{array}$ 
$\mathrm{N}^{2}$,3-bis(4-methoxy-3-methylphenyl)pyridine-2,6-diamine (6i)
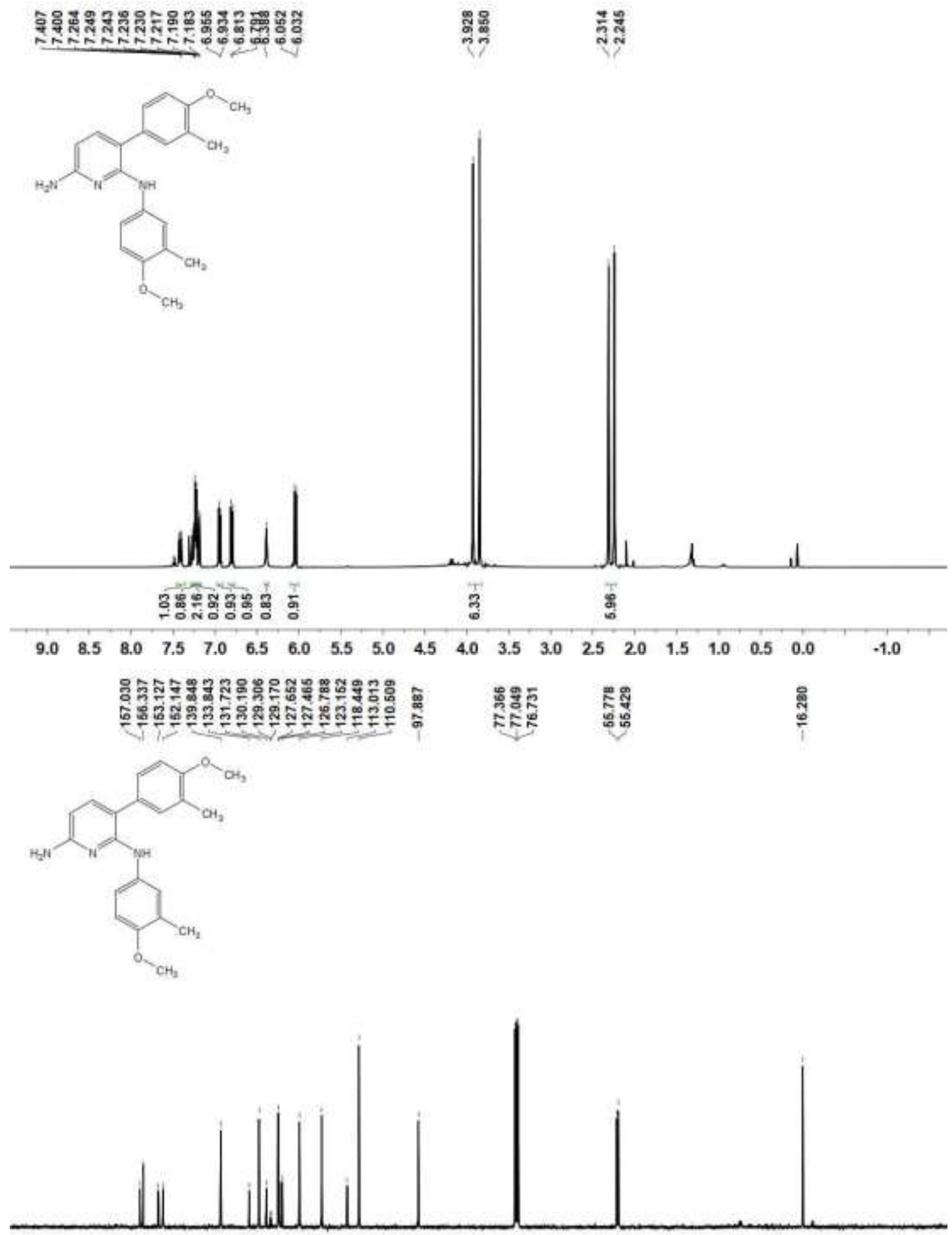

$\begin{array}{llllllllllllllllllll}180 & 170 & 160 & 150 & 140 & 130 & 120 & 110 & 100 & 90 & 80 & 70 & 60 & 50 & 40 & 30 & 20 & 10 & 0 & -10\end{array}$ 
$\mathrm{N}^{2}$-(4-methoxy-3-methylphenyl)-3-(4-(trifluoromethyl)phenyl)pyridine-2,6-diamine (6j)

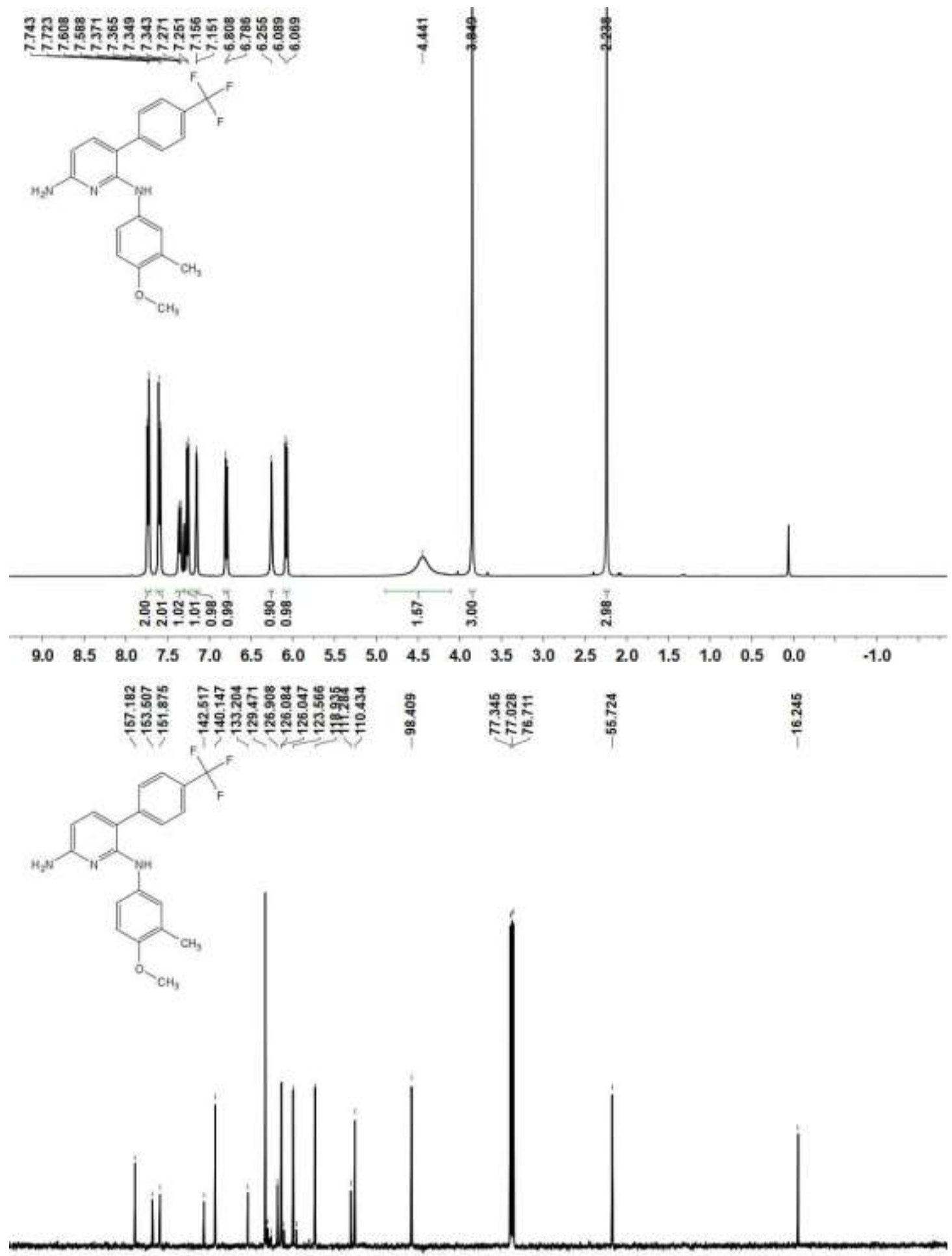

$\begin{array}{llllllllllllllllllll}180 & 170 & 160 & 150 & 140 & 130 & 120 & 110 & 100 & 90 & 80 & 70 & 60 & 50 & 40 & 30 & 20 & 10 & 0 & -10\end{array}$ 
3-(4-Methoxy-3-methylphenyl)- $\mathrm{N}^{2}$-phenylpyridine-2,6-diamine (6k)

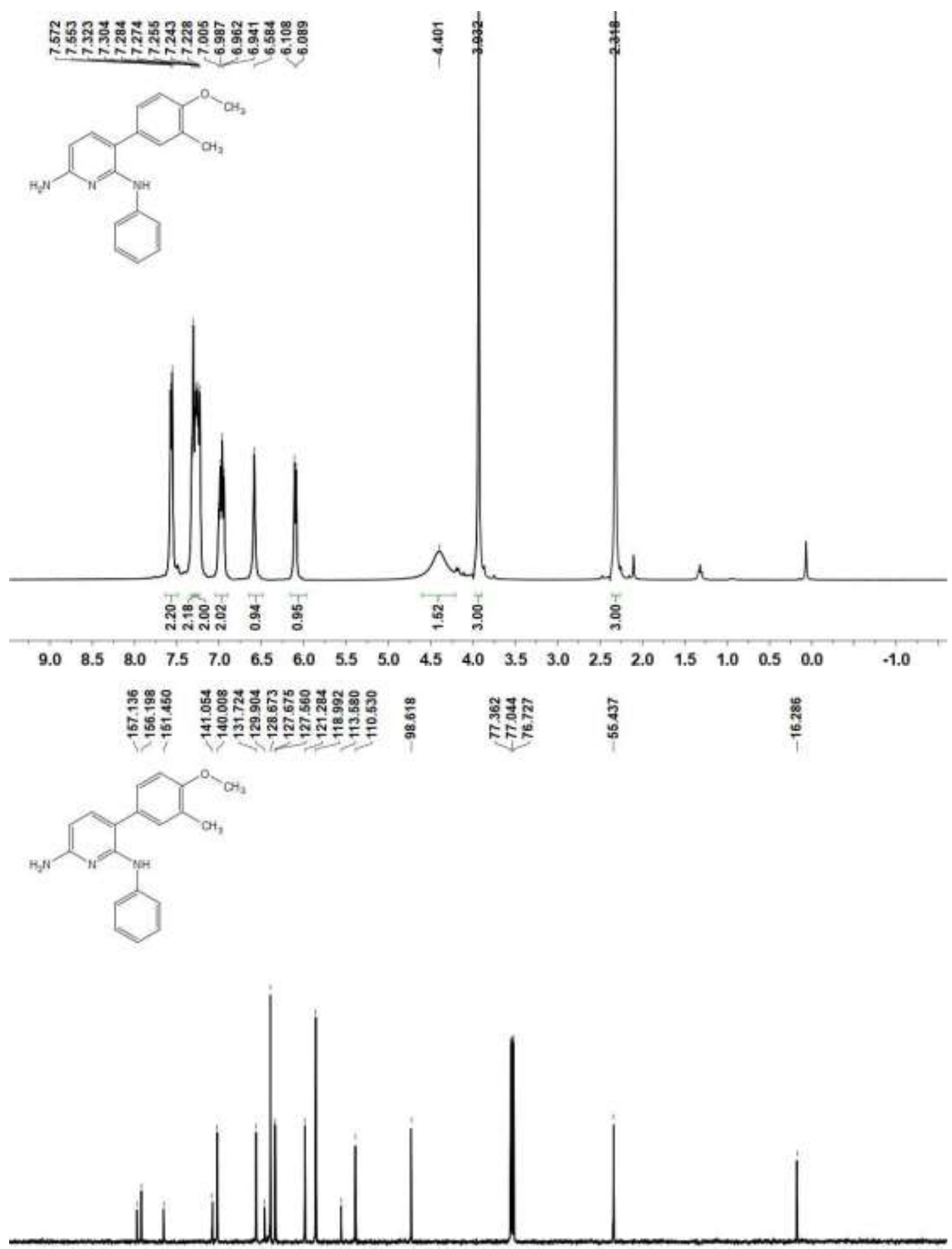

$\begin{array}{llllllllllllllllllll}180 & 170 & 160 & 150 & 140 & 130 & 120 & 110 & 100 & 90 & 80 & 70 & 60 & 50 & 40 & 30 & 20 & 10 & 0 & -10\end{array}$ 
$\mathrm{N}^{2}$-(4-isopropoxyphenyl)-3-(4-methoxy-3-methylphenyl)pyridine-2,6-diamine (6l)

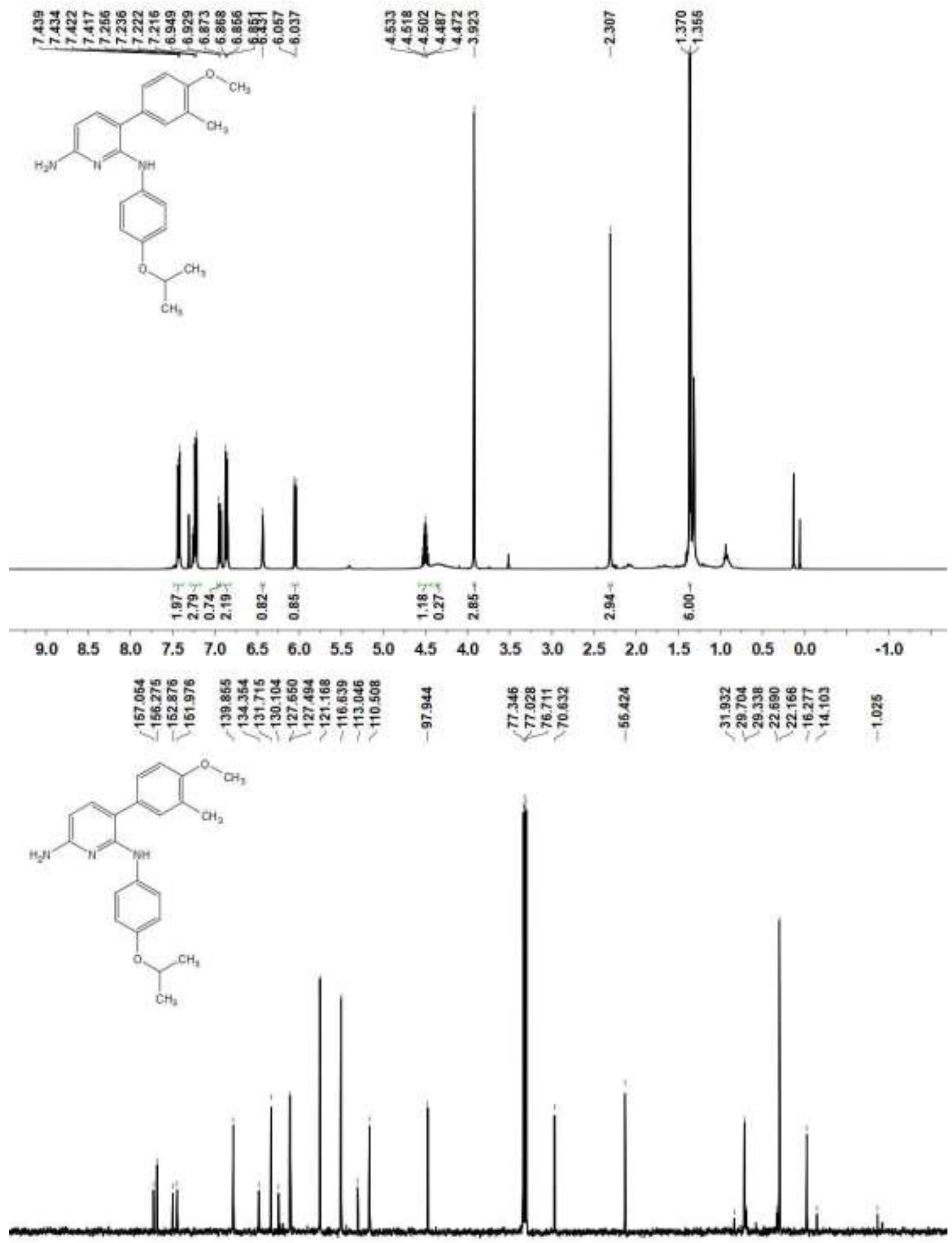

$\begin{array}{llllllllllllllllllll}180 & 170 & 160 & 150 & 140 & 130 & 120 & 110 & 100 & 90 & 80 & 70 & 60 & 50 & 40 & 30 & 20 & 10 & 0 & -10\end{array}$ 
3-((5,6-Bis(4-methoxy-3-methylphenyl)pyridin-2-yl)amino)propan-1-ol (7a)

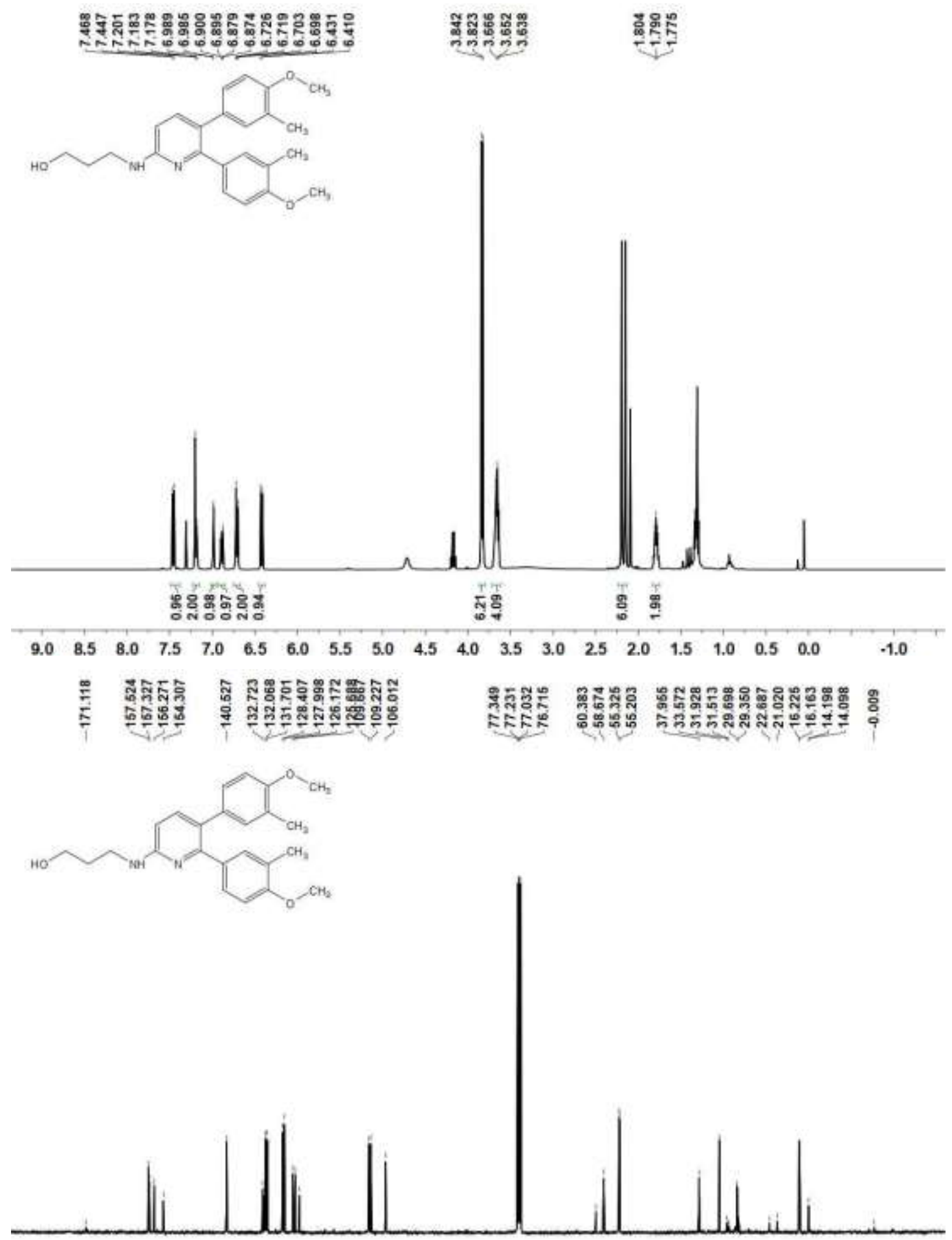

$\begin{array}{llllllllllllllllllll}180 & 170 & 160 & 150 & 140 & 130 & 120 & 110 & 100 & 90 & 80 & 70 & 60 & 50 & 40 & 30 & 20 & 10 & 0 & -10\end{array}$ 
1-((5,6-bis(4-methoxy-3-methylphenyl)pyridin-2-yl)amino)propan-2-ol (7b)
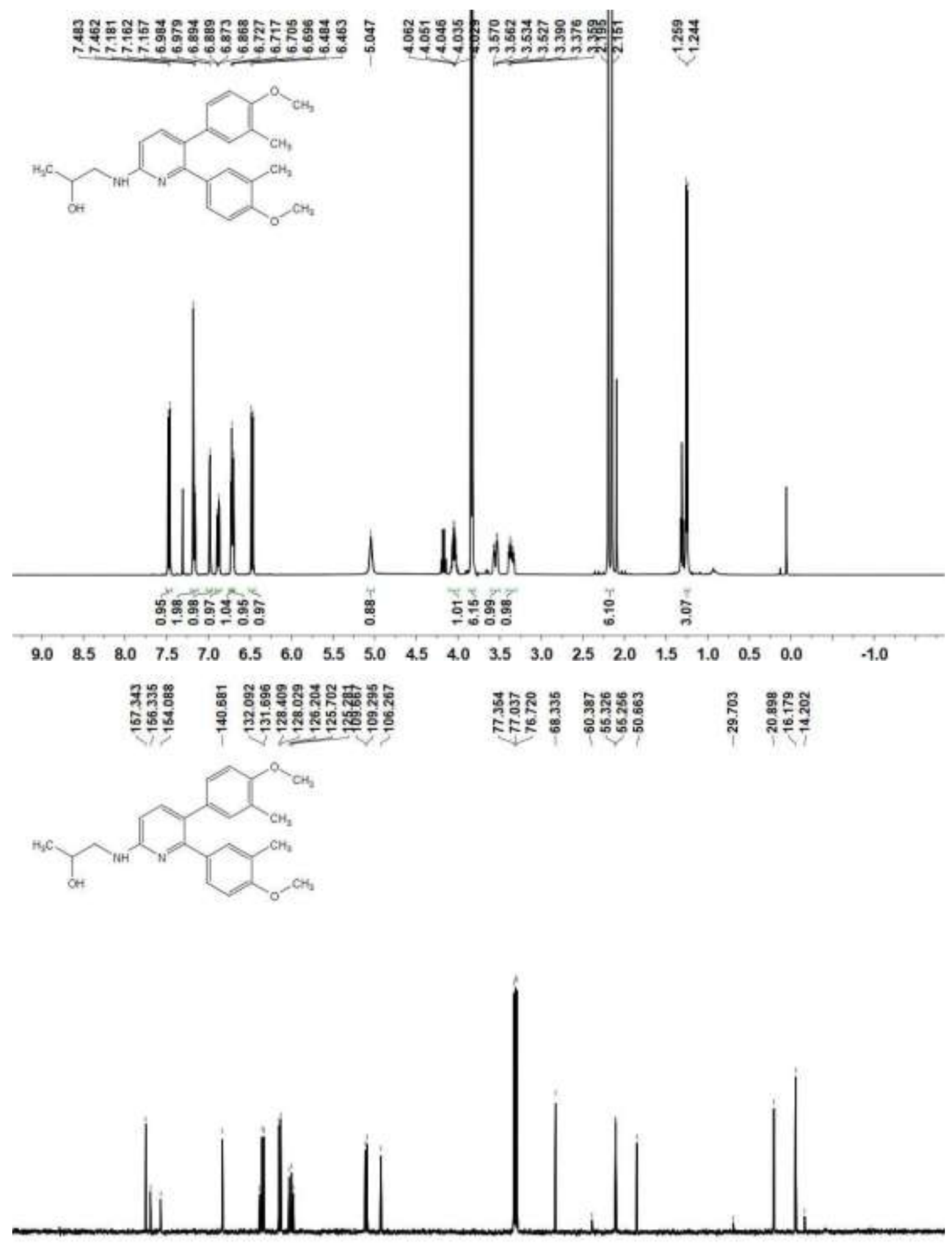

$\begin{array}{llllllllllllllllllll}180 & 170 & 160 & 150 & 140 & 130 & 120 & 110 & 100 & 90 & 80 & 70 & 60 & 50 & 40 & 30 & 20 & 10 & 0 & -10\end{array}$ 
N-(5,6-bis(4-methoxy-3-methylphenyl)pyridin-2-yl)-3-(4-hydroxypiperidin-1-yl)propenamide (7c)
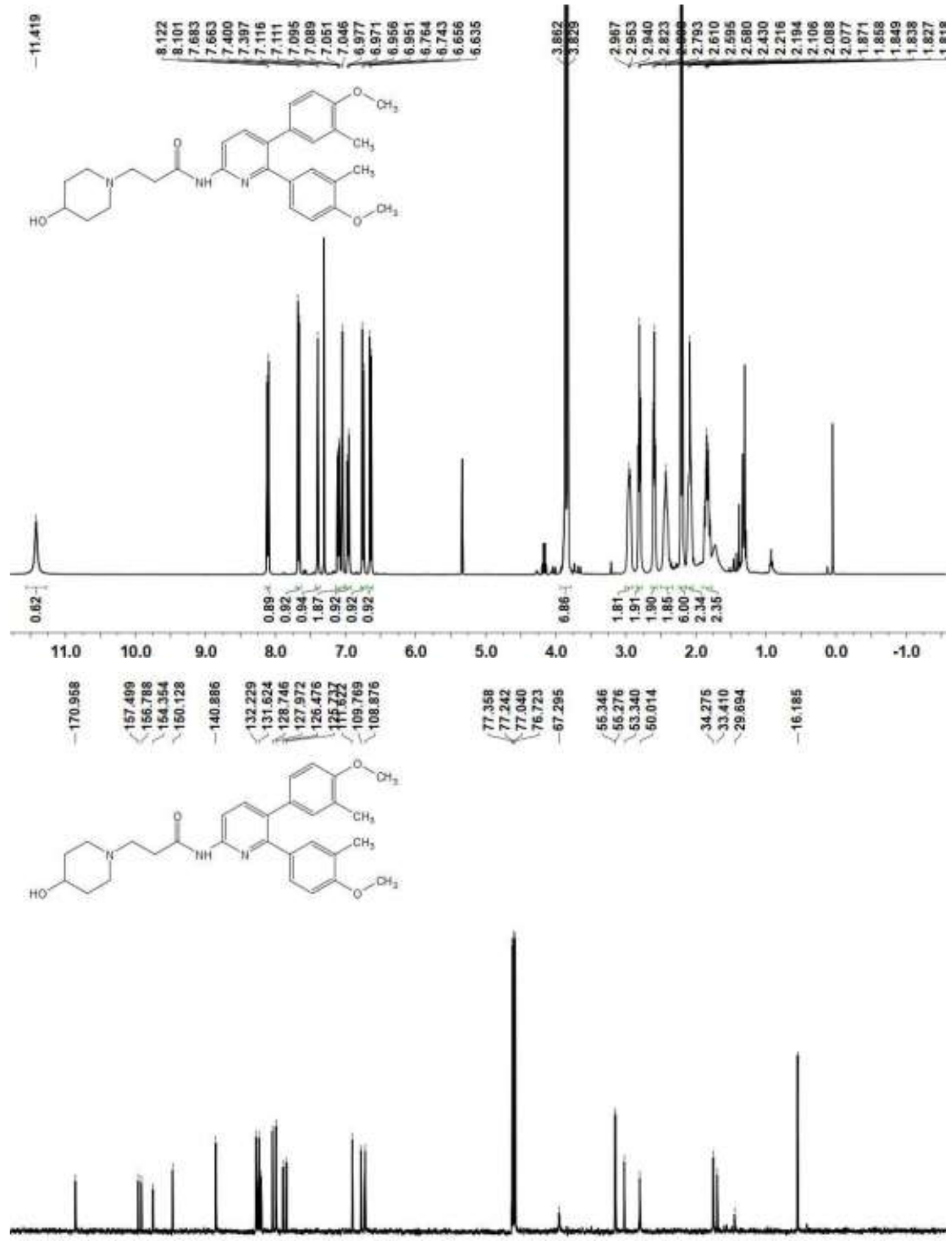

$\begin{array}{llllllllllllllllllll}180 & 170 & 160 & 150 & 140 & 130 & 120 & 110 & 100 & 90 & 80 & 70 & 60 & 50 & 40 & 30 & 20 & 10 & 0 & -10\end{array}$ 
N-(5,6-bis(4-methoxy-3-methylphenyl)pyridin-2-yl)-3-morpholinopropanamide (7d)

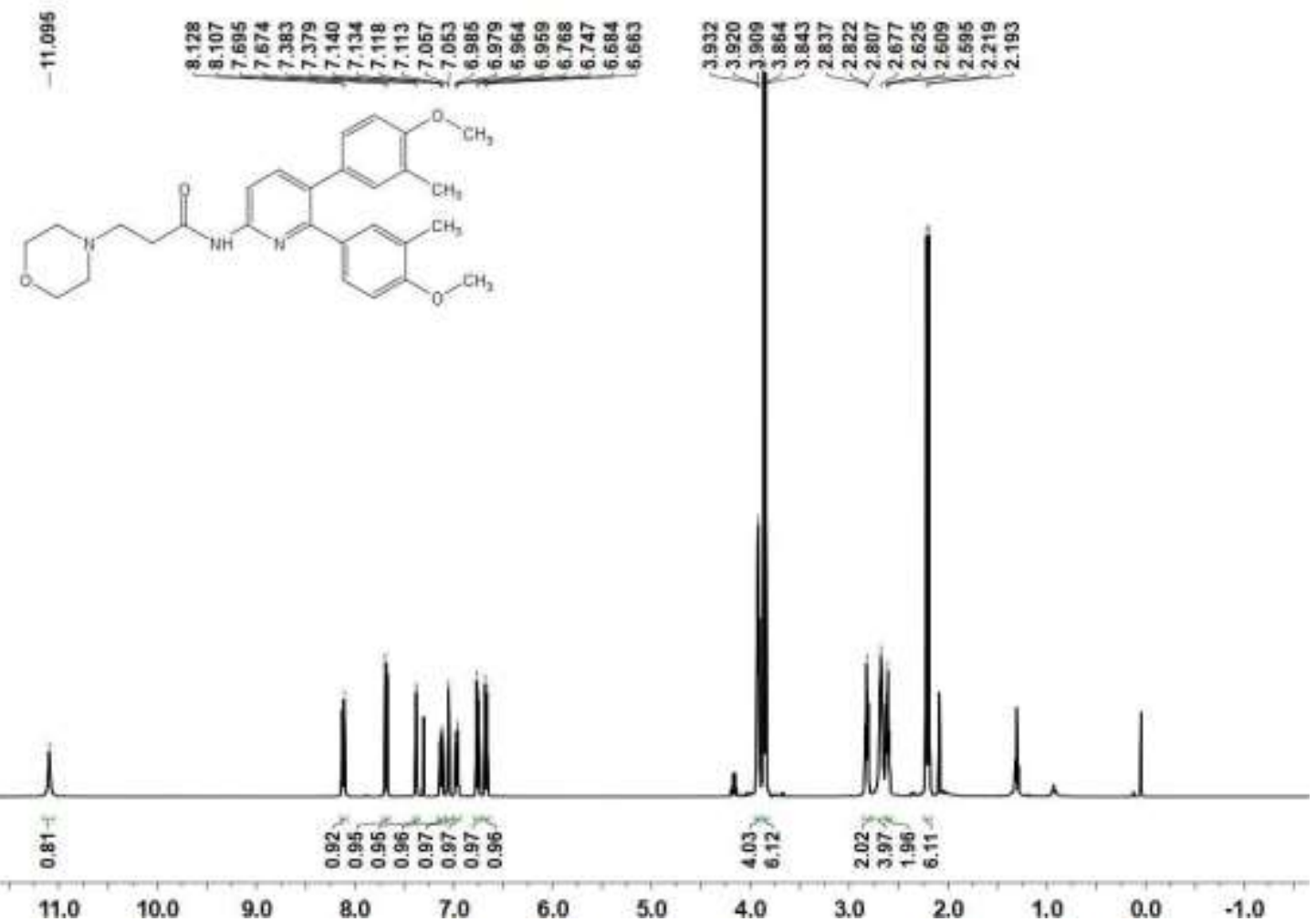

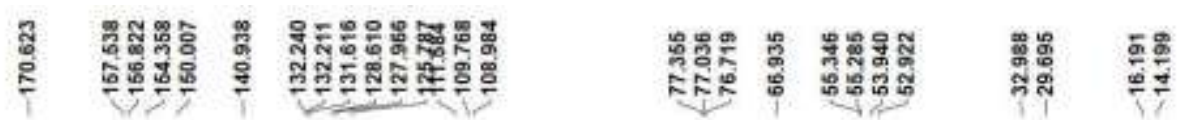

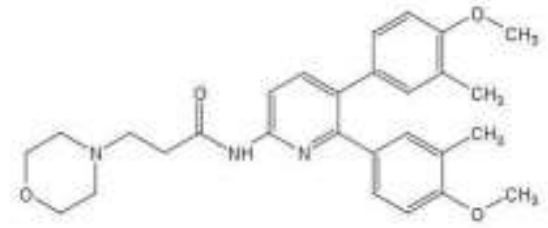

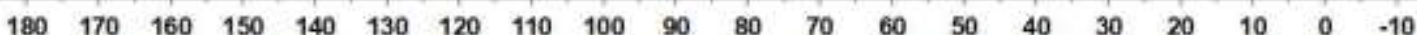


N-(5,6-bis(4-methoxy-3-methylphenyl)pyridin-2-yl)-3-(1H-1,2,4-triazol-1-yl)propenamide (7e)
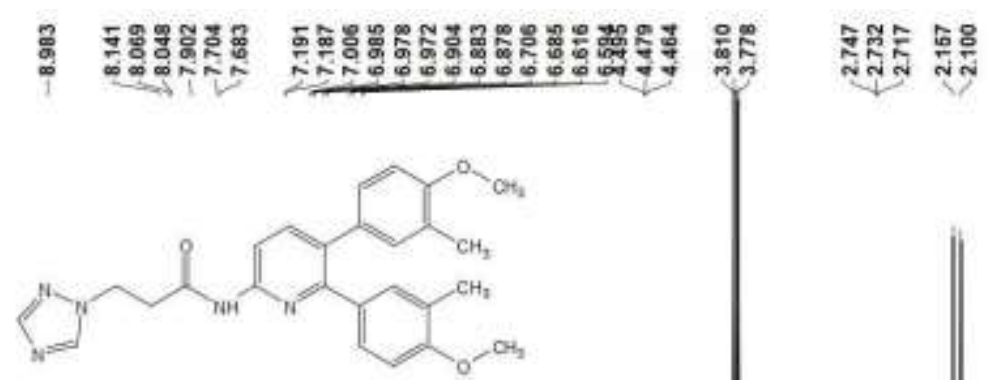

กิ่

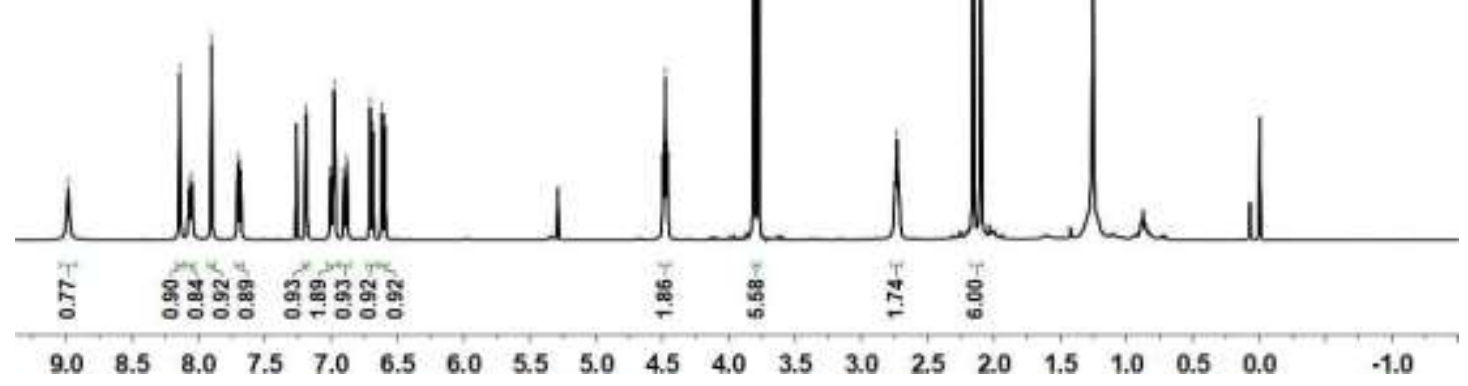

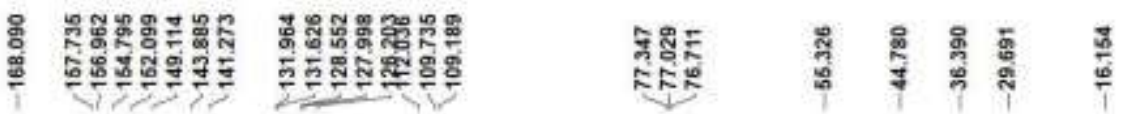

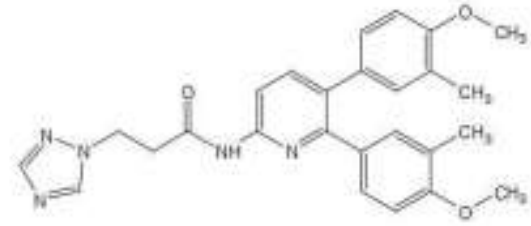

$\frac{\mathrm{g}}{6}$

$\begin{array}{llllllllllllllllllll}180 & 170 & 160 & 150 & 140 & 130 & 120 & 110 & 100 & 90 & 80 & 70 & 60 & 50 & 40 & 30 & 20 & 10 & 0 & -10\end{array}$ 
5,6-Bis(4-methoxy-3-methylphenyl)-N-(3-morpholinopropyl)pyridin-2-amine (7f)

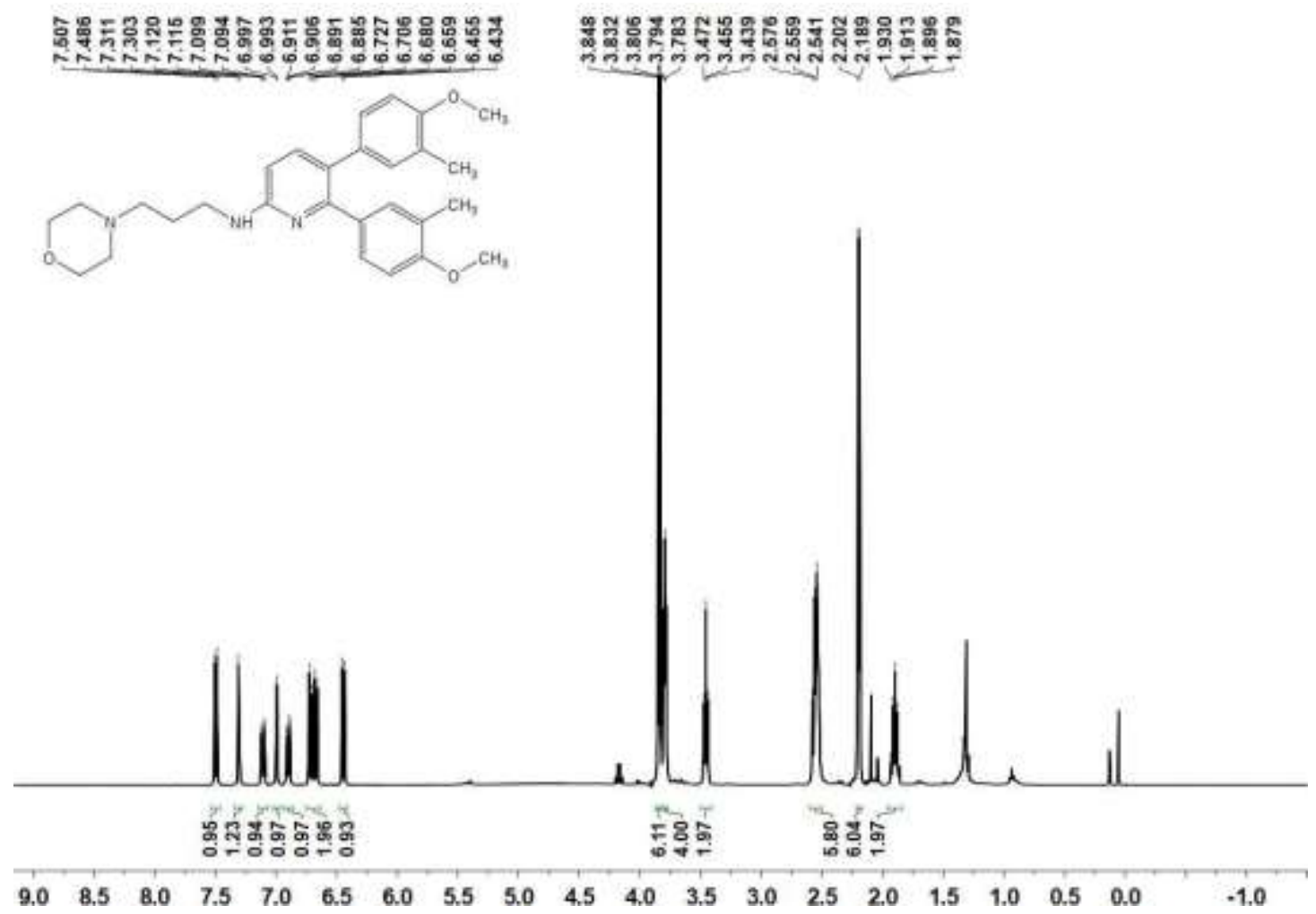

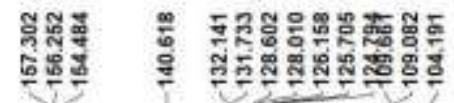

品哭
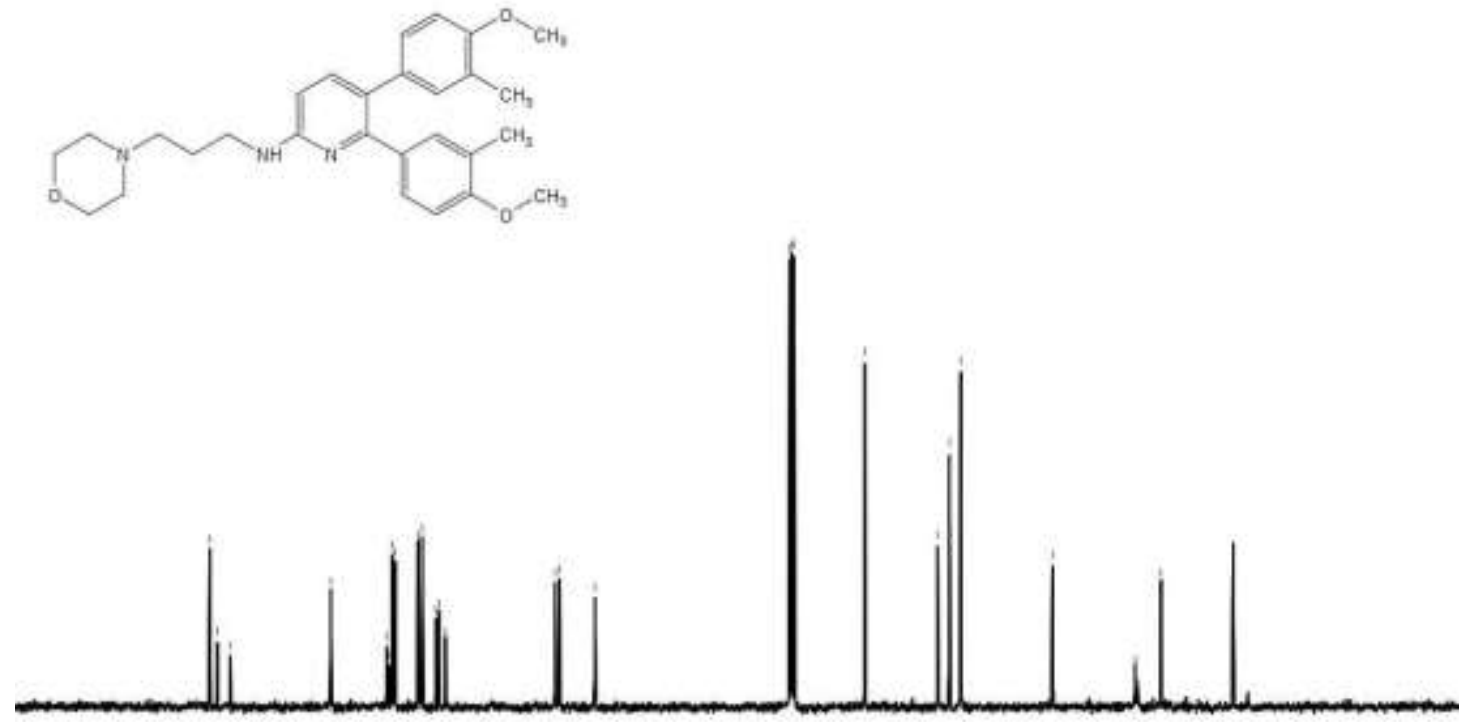

$\begin{array}{llllllllllllllllllll}180 & 170 & 160 & 150 & 140 & 130 & 120 & 110 & 100 & 90 & 80 & 70 & 60 & 50 & 40 & 30 & 20 & 10 & 0 & -10\end{array}$ 
N-(2-(4-hydroxypiperidin-1-yl)-5-nitrophenyl)-4-methoxy-3-methylbenzamide (8a)

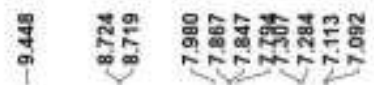

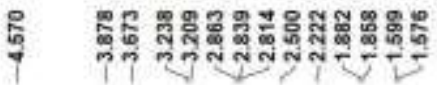
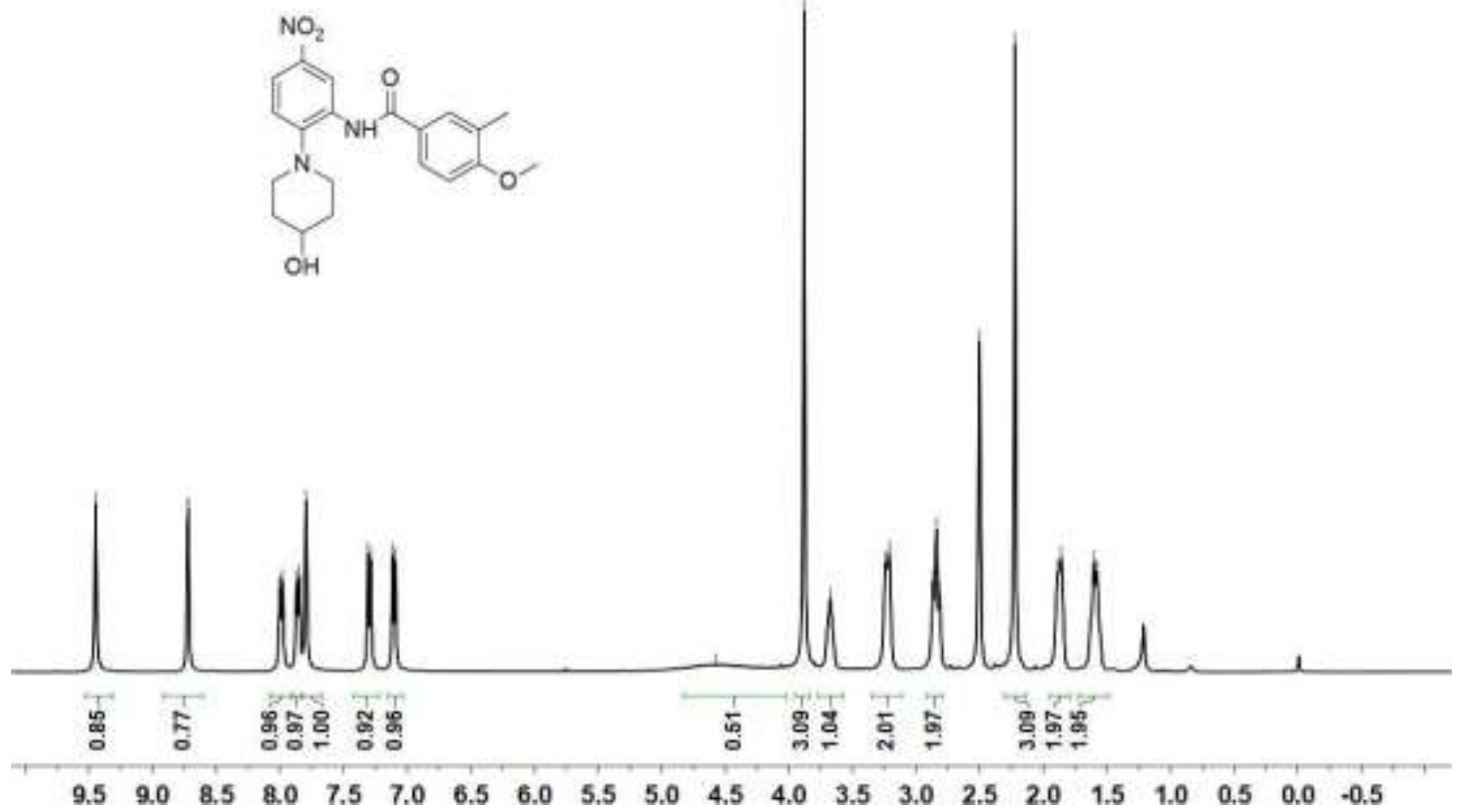

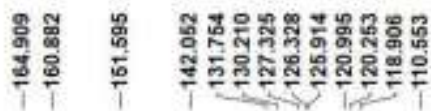

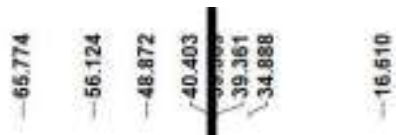

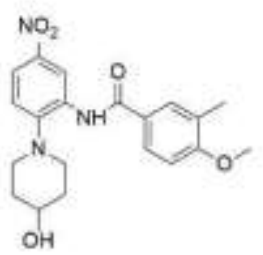

$\begin{array}{llllllllllllllllllll}180 & 170 & 160 & 150 & 140 & 130 & 120 & 110 & 100 & 90 & 80 & 70 & 60 & 50 & 40 & 30 & 20 & 10 & 0 & -10\end{array}$ 
4-Methoxy-3-methyl-N-(2-(4-methylpiperazin-1-yl)-5-nitrophenyl)benzamide (8b)
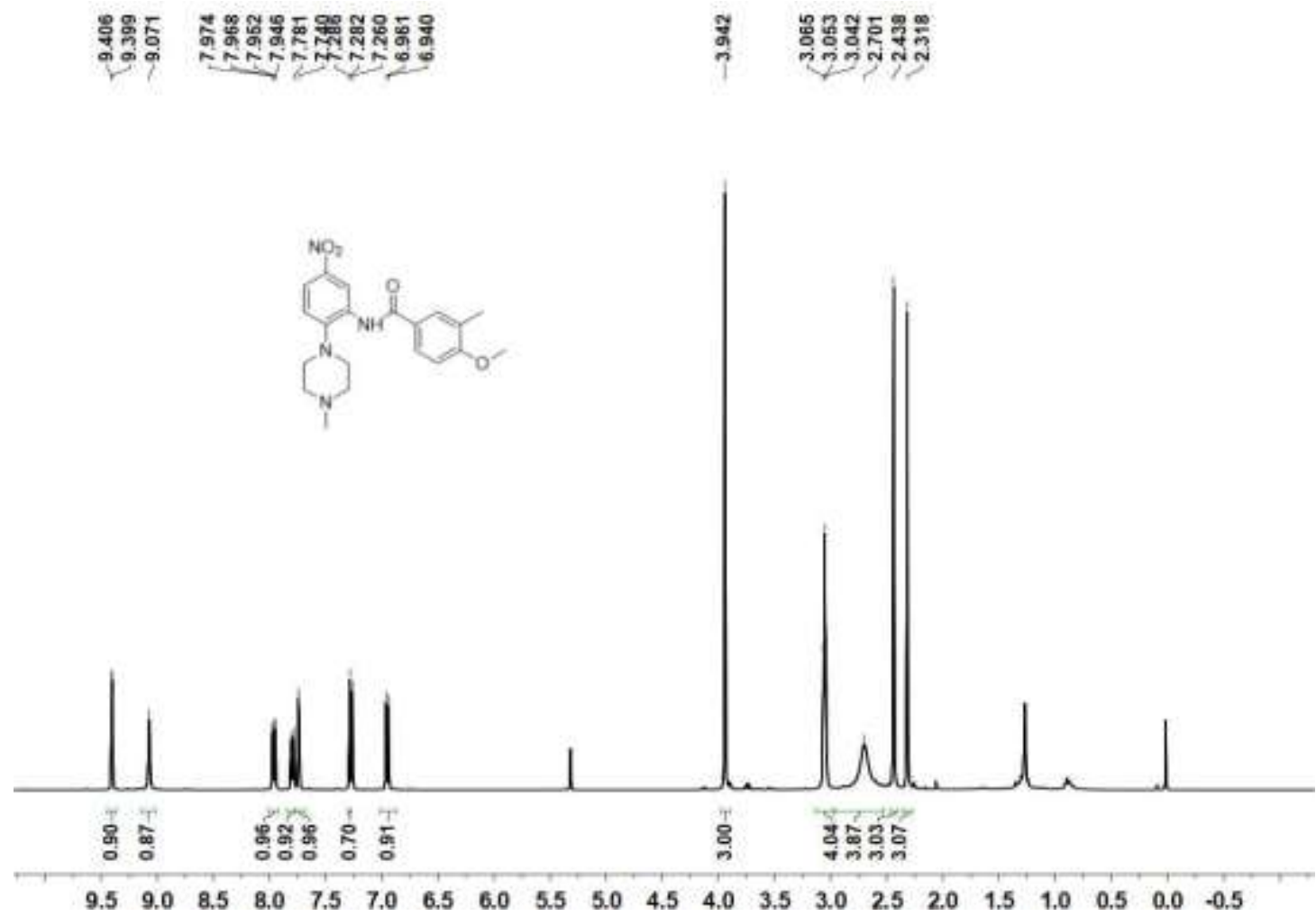

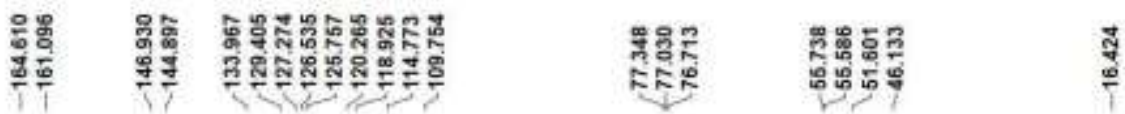
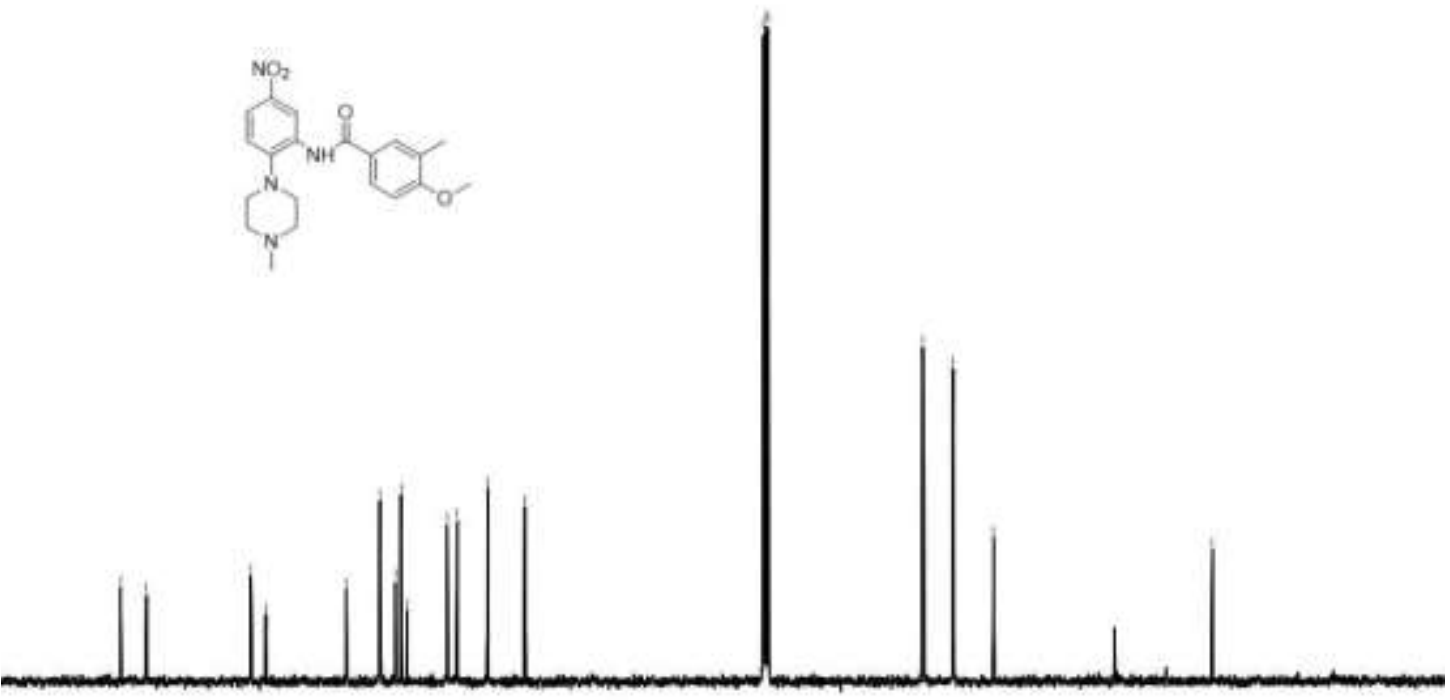

$\begin{array}{llllllllllllllllllll}80 & 170 & 160 & 150 & 140 & 130 & 120 & 110 & 100 & 90 & 80 & 70 & 60 & 50 & 40 & 30 & 20 & 10 & 0 & -10\end{array}$ 
4-Methoxy-3-methyl-N-(2-morpholino-5-nitrophenyl)benzamide (8c)

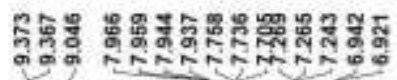

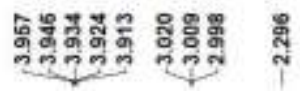

:

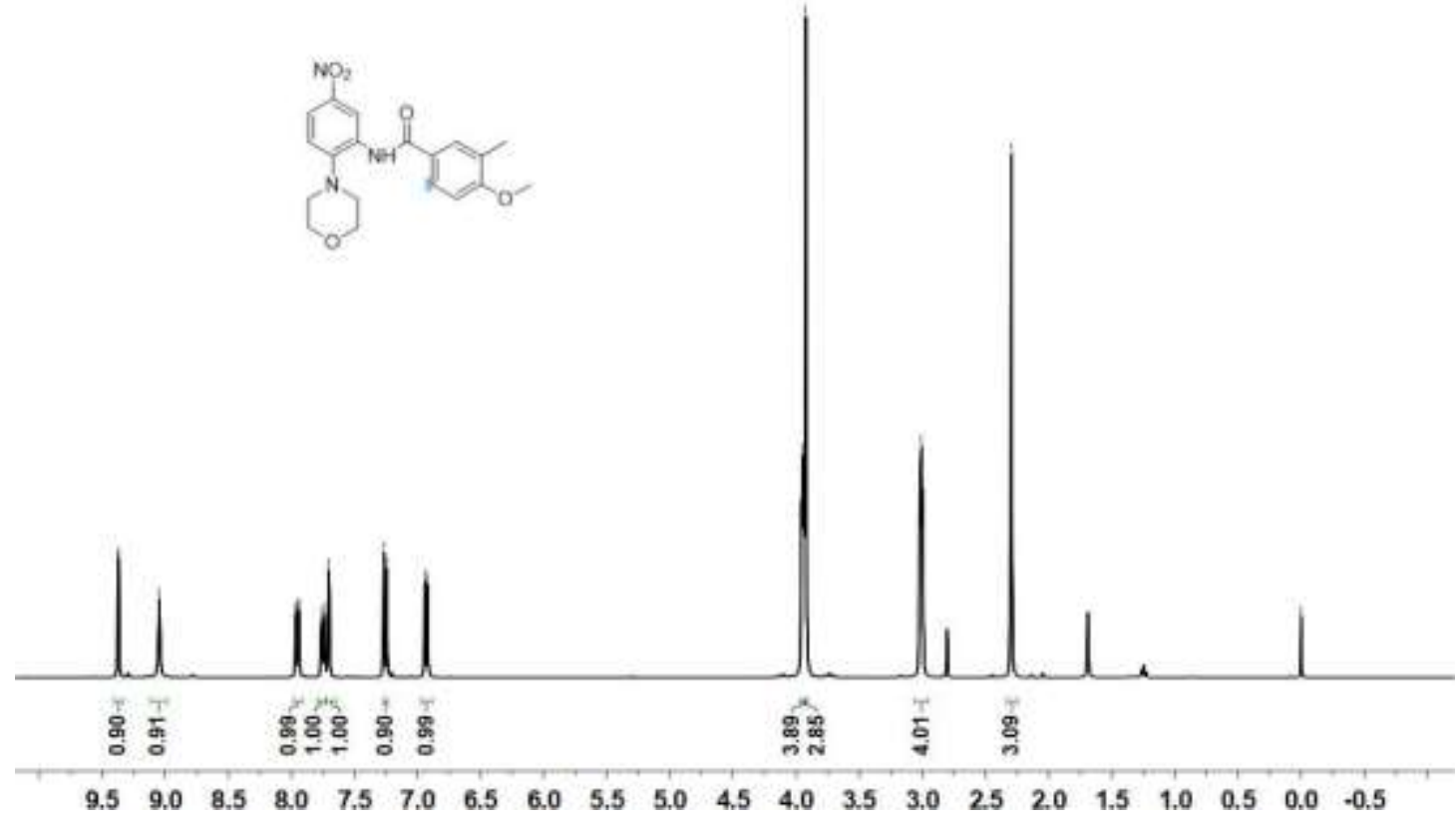

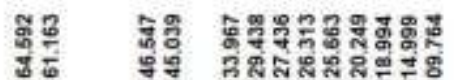

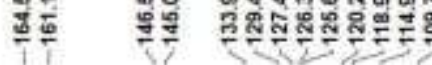

路

$\underset{0}{\stackrel{0}{0}}$
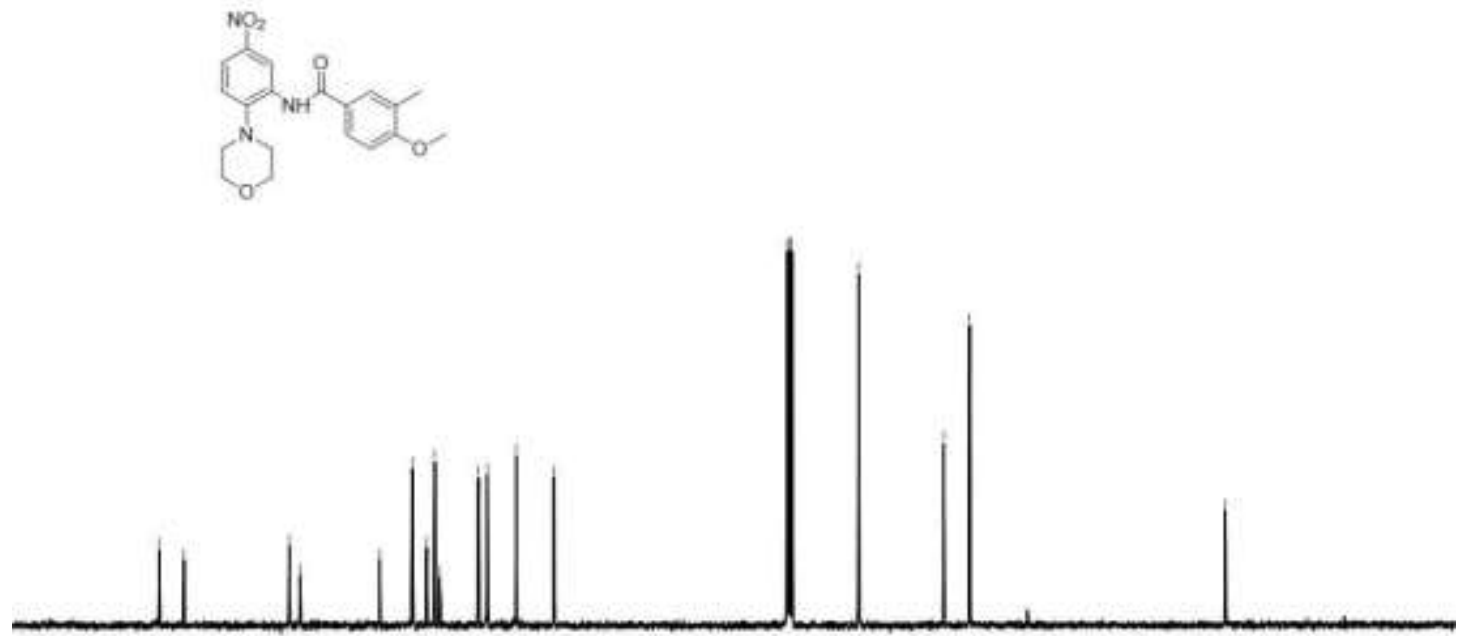

$\begin{array}{llllllllllllllllllll}180 & 170 & 160 & 150 & 140 & 130 & 120 & 110 & 100 & 90 & 80 & 70 & 60 & 50 & 40 & 30 & 20 & 10 & 0 & -10\end{array}$ 
N-(2-(4-hydroxypiperidin-1-yl)-5-nitrophenyl)benzamide (8d)

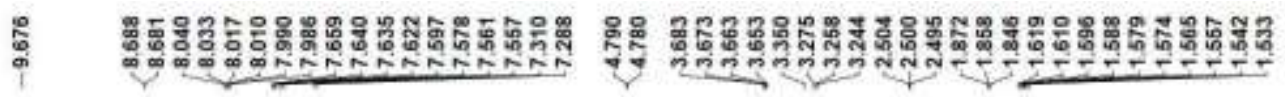

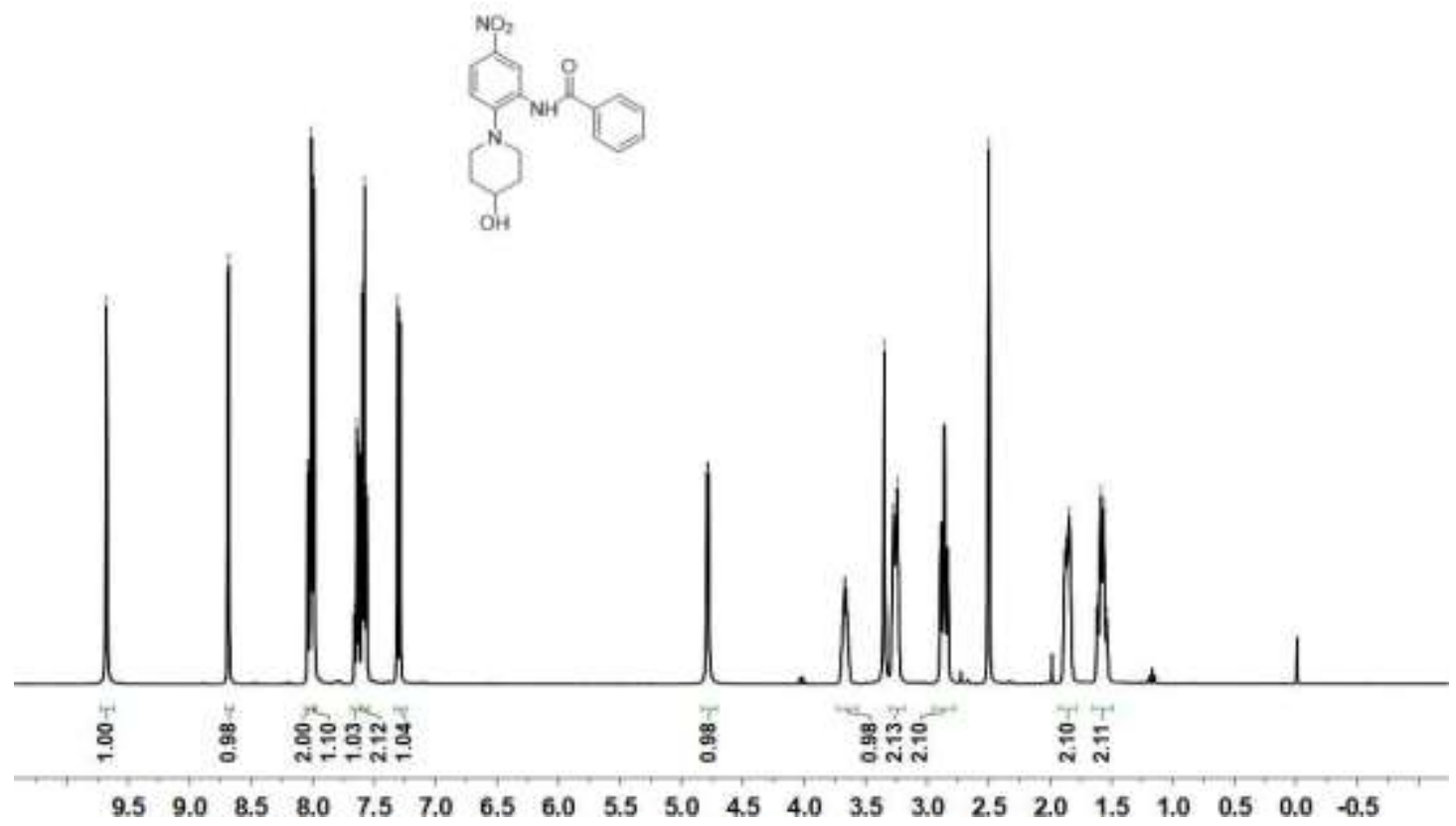

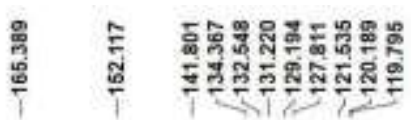
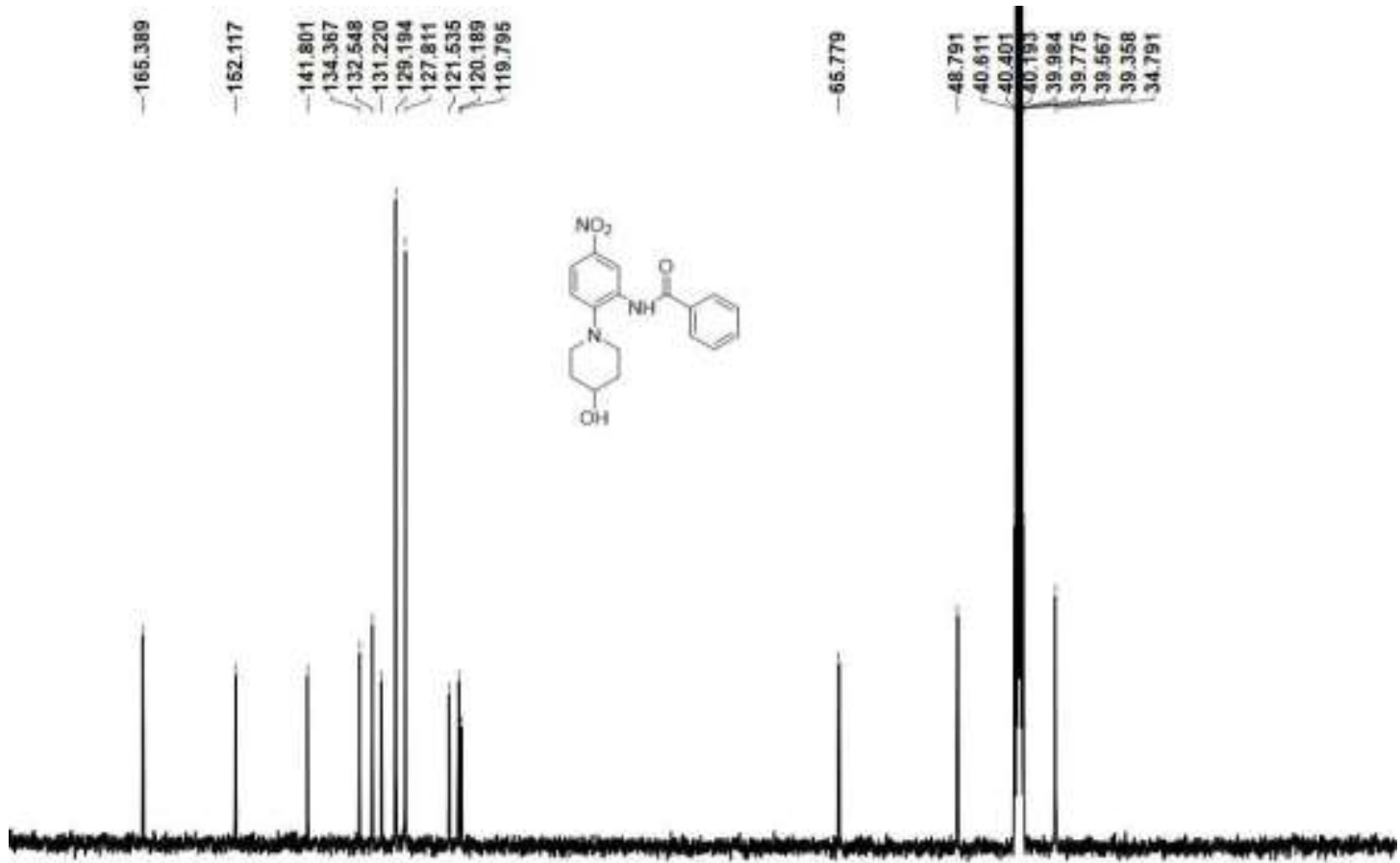

$\begin{array}{llllllllllllllllllll}180 & 170 & 160 & 150 & 140 & 130 & 120 & 110 & 100 & 90 & 80 & 70 & 60 & 50 & 40 & 30 & 20 & 10 & 0 & -10\end{array}$ 
N-(2-(4-methylpiperazin-1-yl)-5-nitrophenyl)benzamide (8e)

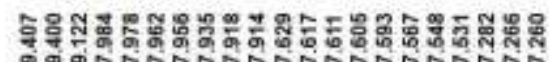

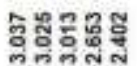
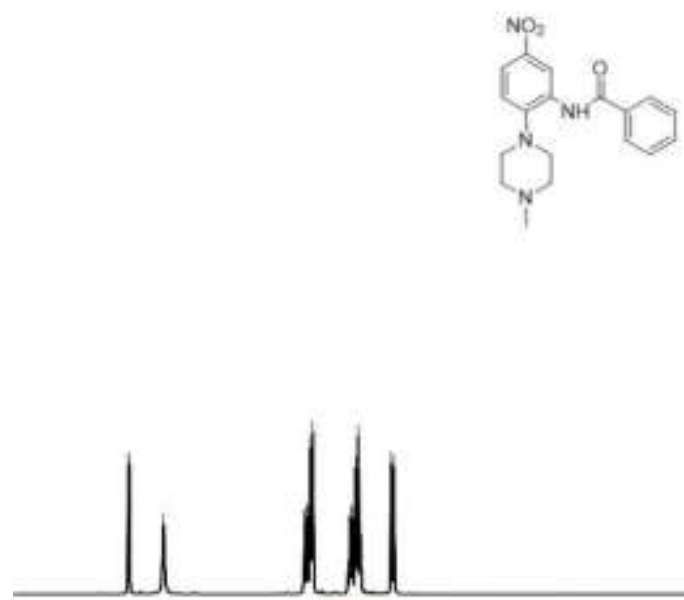

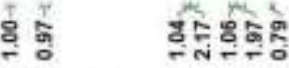

สูสซ్

$\begin{array}{lllllllllllllllllllll}9.5 & 9.0 & 8.5 & 8.0 & 7.5 & 7.0 & 6.5 & 6.0 & 5.5 & 5.0 & 4.5 & 4.0 & 3.5 & 3.0 & 2.5 & 2.0 & 1.5 & 1.0 & 0.5 & 0.0 & -0.5\end{array}$

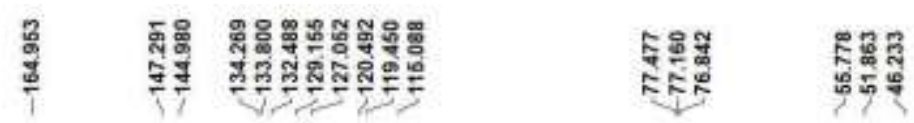

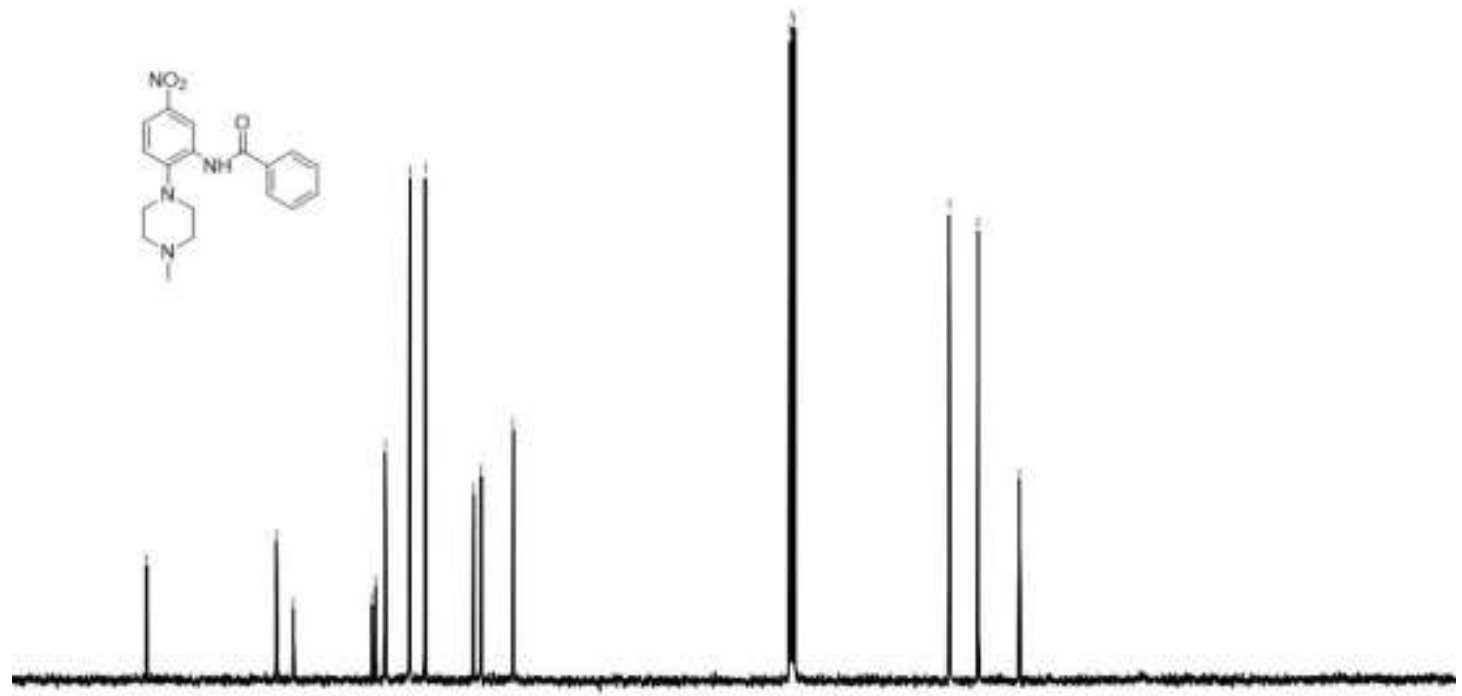

$\begin{array}{llllllllllllllllllll}180 & 170 & 160 & 150 & 140 & 130 & 120 & 110 & 100 & 90 & 80 & 70 & 60 & 50 & 40 & 30 & 20 & 10 & 0 & -10\end{array}$ 
N-(2-morpholino-5-nitrophenyl)benzamide (8f)

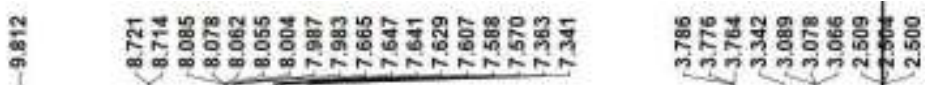

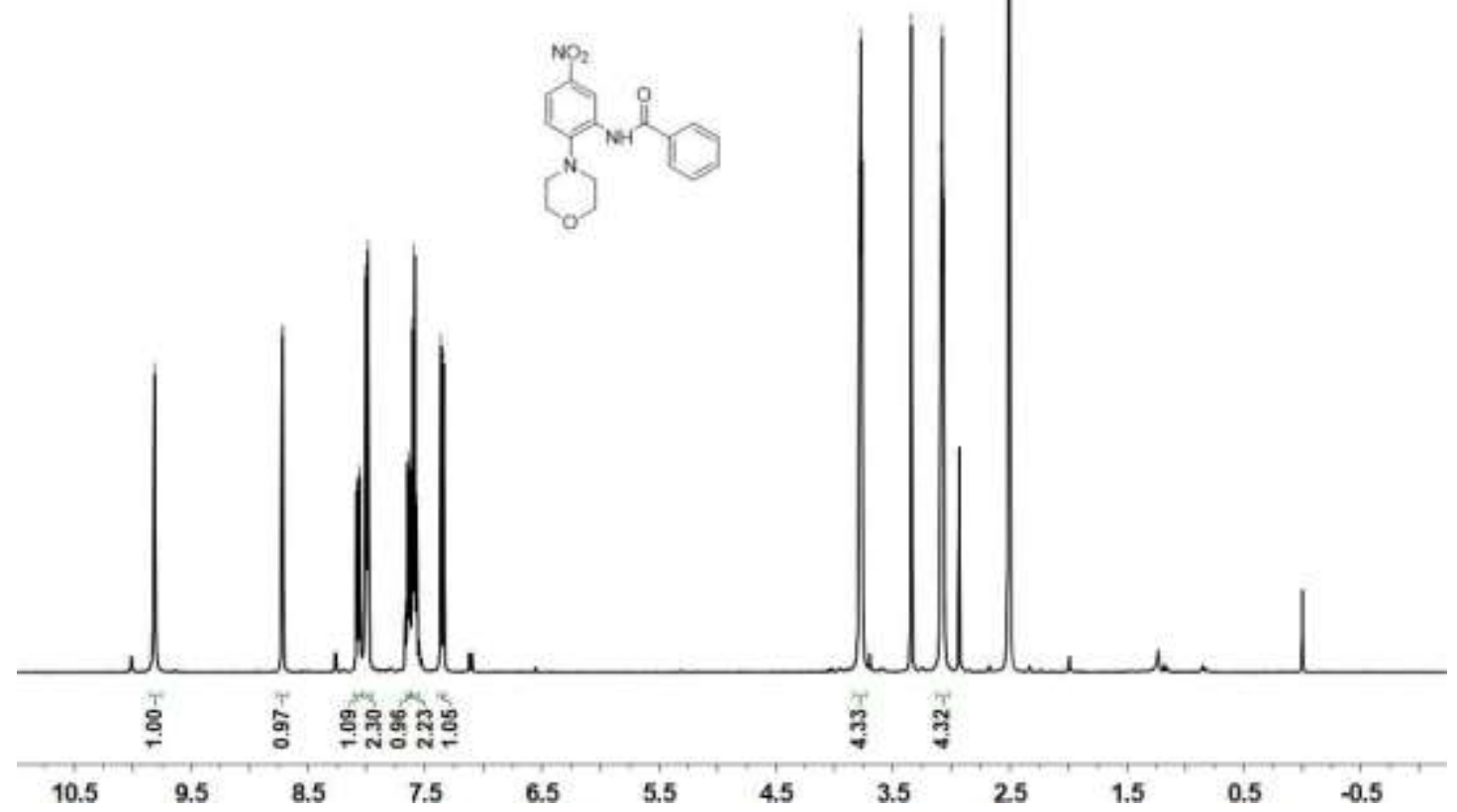

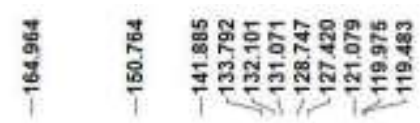
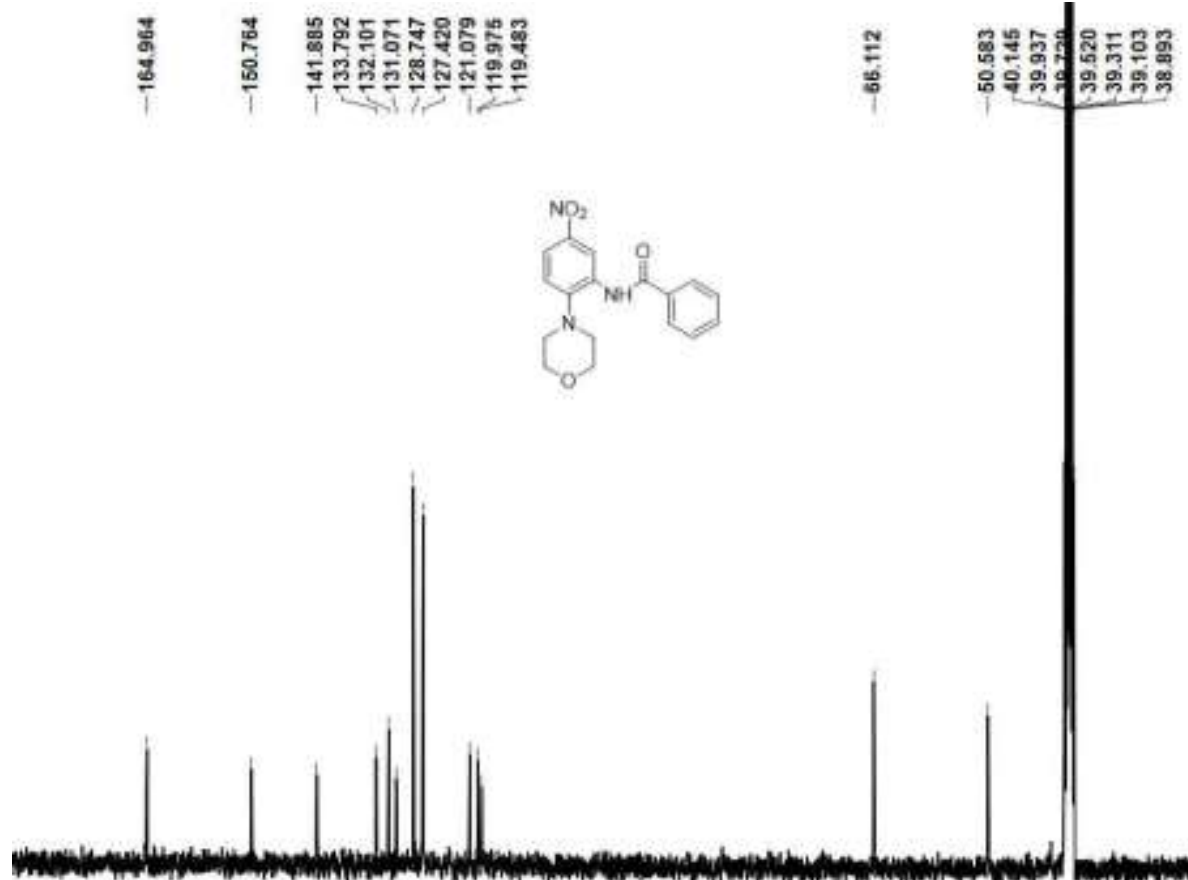

$\begin{array}{llllllllllllllllllll}180 & 170 & 160 & 150 & 140 & 130 & 120 & 110 & 100 & 90 & 80 & 70 & 60 & 50 & 40 & 30 & 20 & 10 & 0 & -10\end{array}$ 
N-(5-amino-2-(4-hydroxypiperidin-1-yl)phenyl)-4-methoxy-3-methylbenzamide (8g)

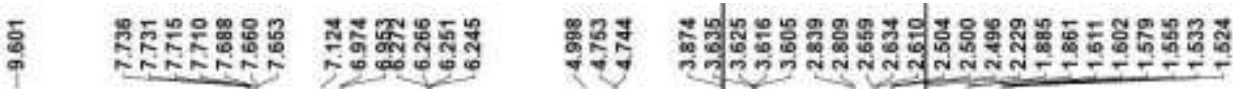
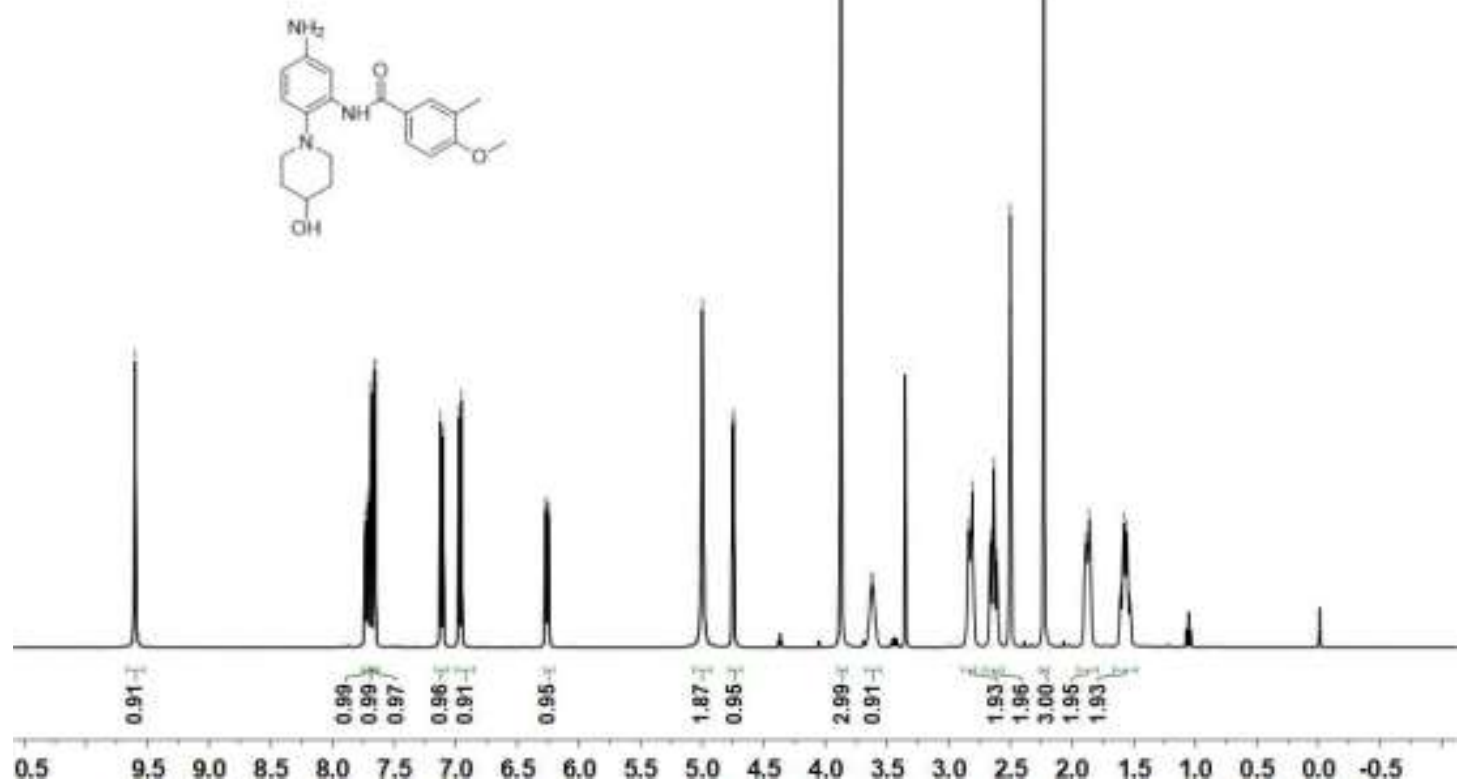

$\begin{array}{lllllllllllllllllllllll}0.5 & 9.5 & 9.0 & 8.5 & 8.0 & 7.5 & 7.0 & 6.5 & 6.0 & 5.5 & 5.0 & 4.5 & 4.0 & 3.5 & 3.0 & 2.5 & 2.0 & 1.5 & 1.0 & 0.5 & 0.0 & -0.5\end{array}$

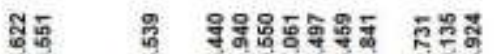

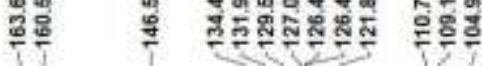
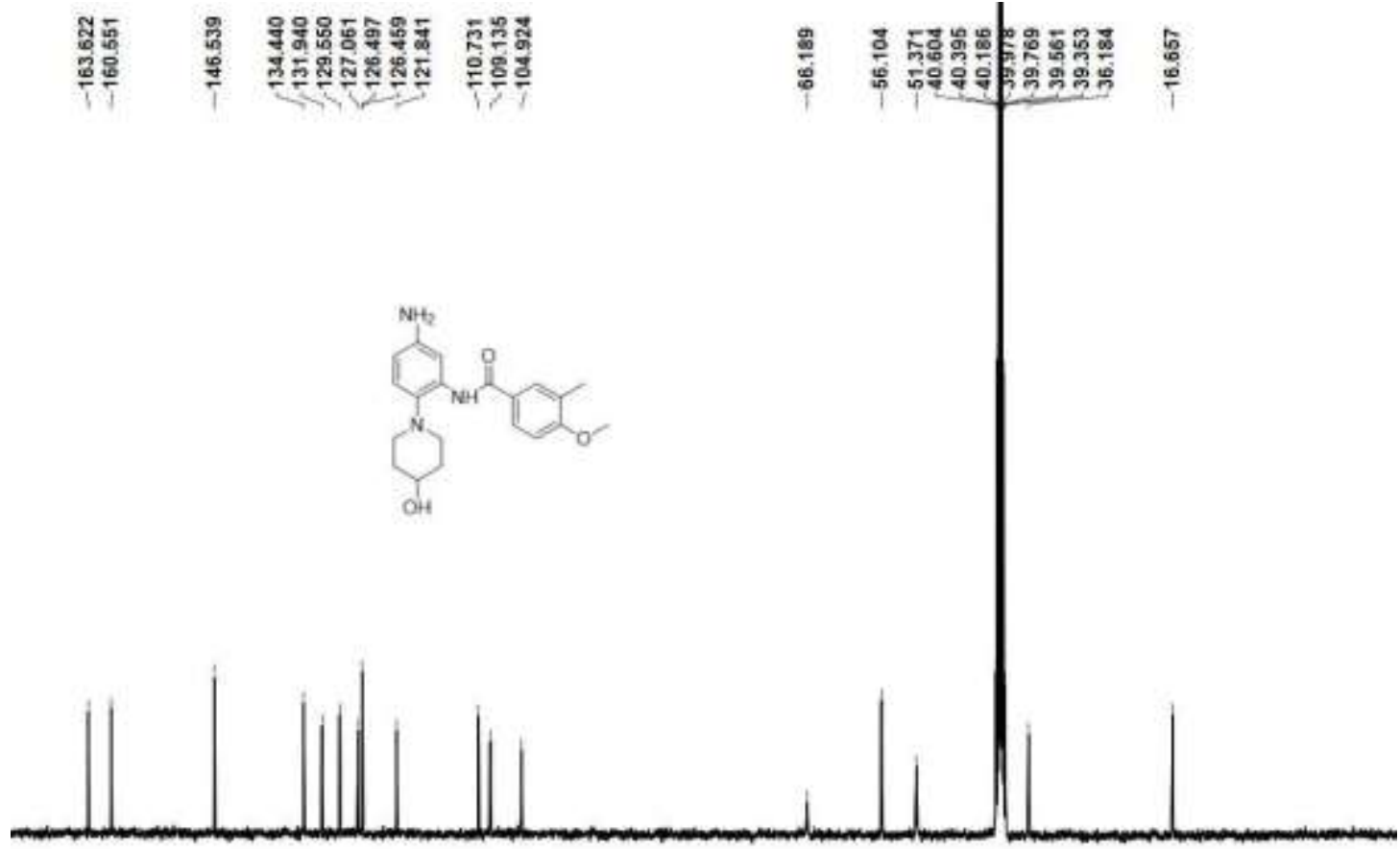

$\begin{array}{lllllllllllllllllll}170 & 160 & 150 & 140 & 130 & 120 & 110 & 100 & 90 & 80 & 70 & 60 & 50 & 40 & 30 & 20 & 10 & 0 & -10\end{array}$ 
N-(5-amino-2-(4-methylpiperazin-1-yl)phenyl)-4-methoxy-3-methylbenzamide (8h)
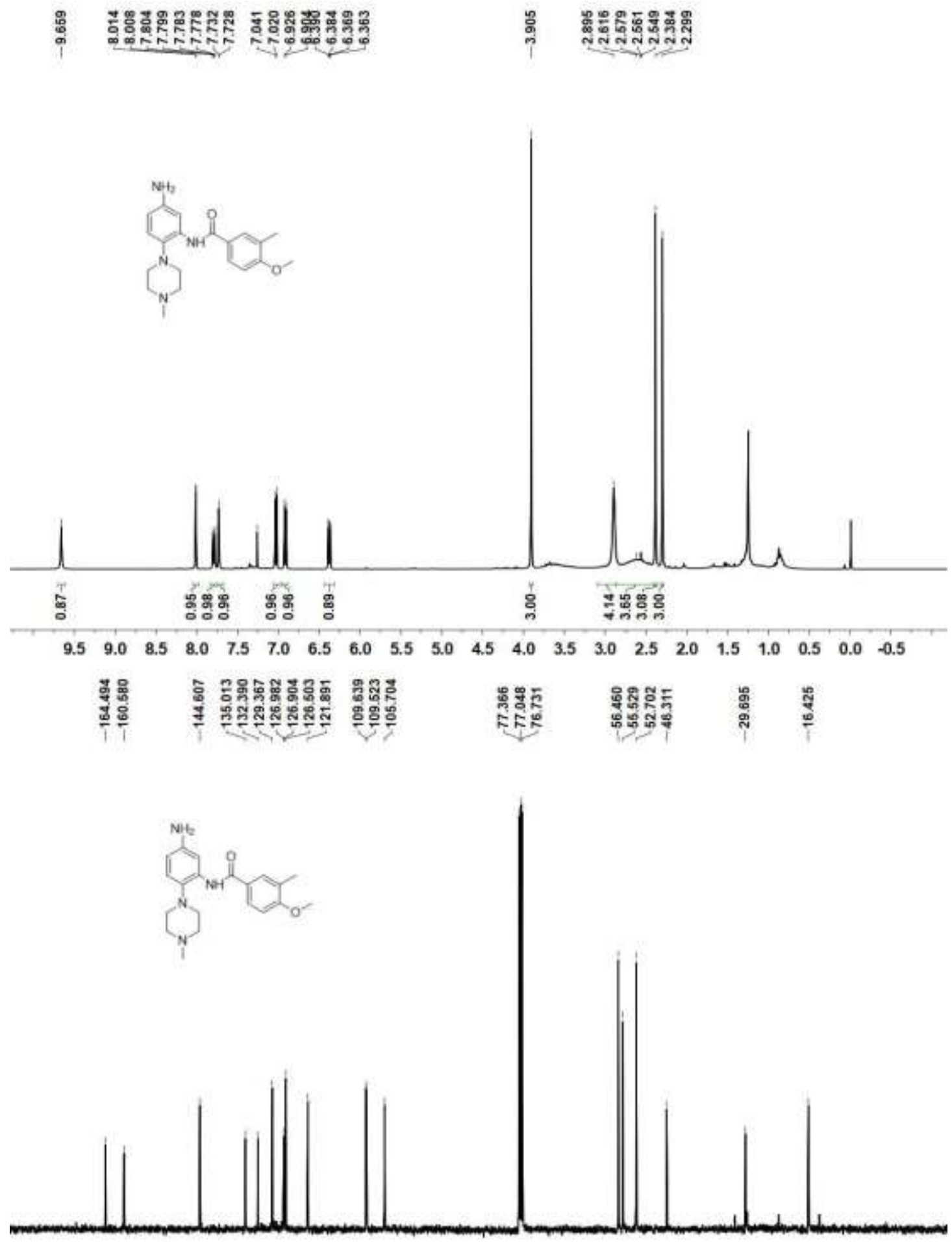

$\begin{array}{llllllllllllllllllll}180 & 170 & 160 & 150 & 140 & 130 & 120 & 110 & 100 & 90 & 80 & 70 & 60 & 50 & 40 & 30 & 20 & 10 & 0 & -10\end{array}$ 
N-(5-amino-2-morpholinophenyl)-4-methoxy-3-methylbenzamide (8i)

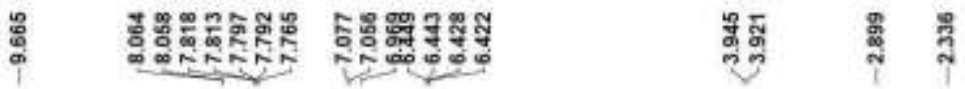
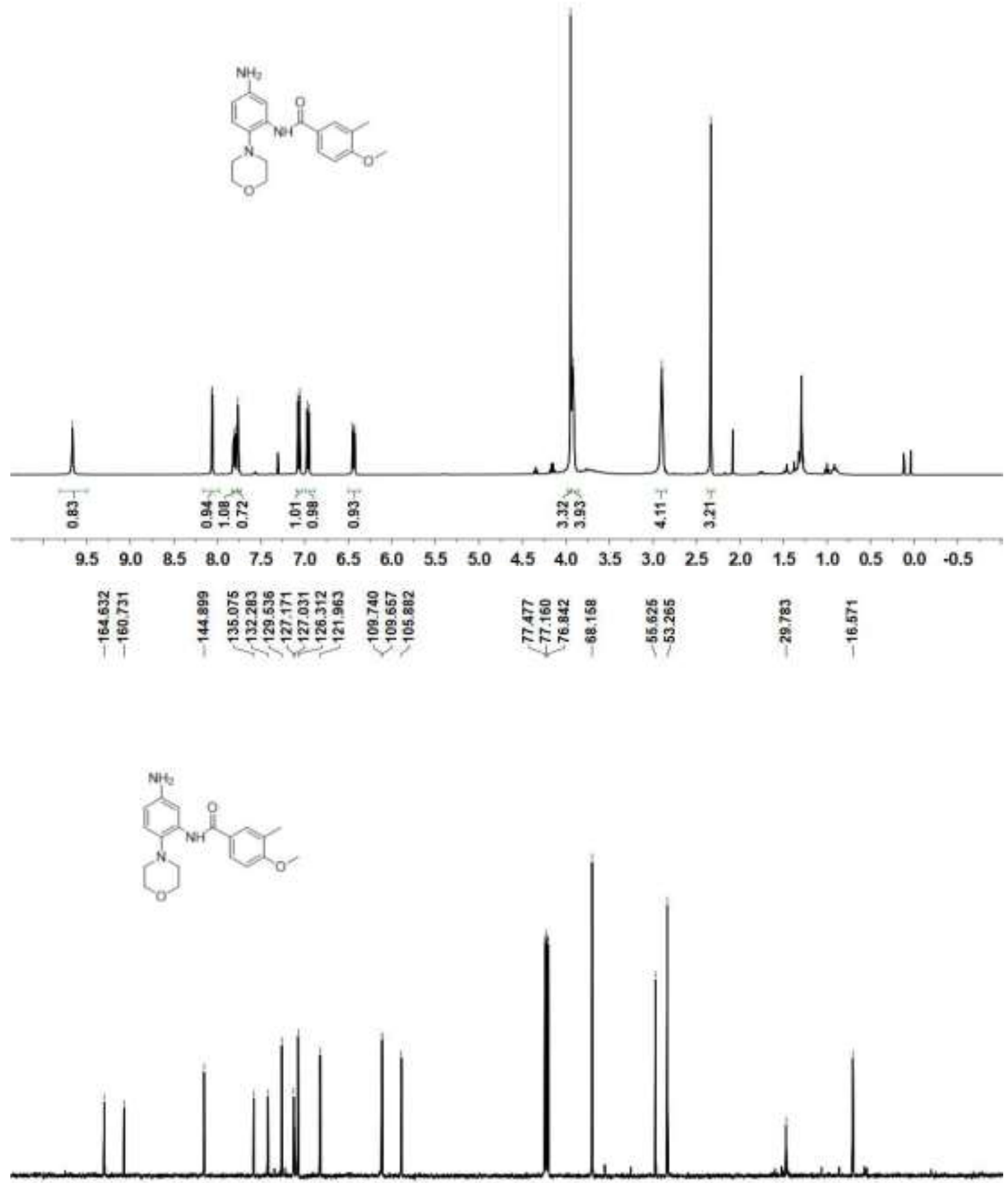

$\begin{array}{llllllllllllllllllll}180 & 170 & 160 & 150 & 140 & 130 & 120 & 110 & 100 & 90 & 80 & 70 & 60 & 50 & 40 & 30 & 20 & 10 & 0 & -10\end{array}$ 


\section{HPLC Spectra}

$\begin{array}{lcll}\text { Sample name: } & \text { 5a } & \text { Operator: } & \text { Keke Huang } \\ \text { Instrument: } & \text { LC01 } & \text { Location: } & \text { P1A11 } \\ \text { Inj. volume: } & 3.0 & \text { Injection Data File Name 20190221 150848.dx } \\ \text { Injection Data File Directory } & \text { NNew Drug Study/Results/JZG/20190221/JZG_20190221 150838.rslt }\end{array}$

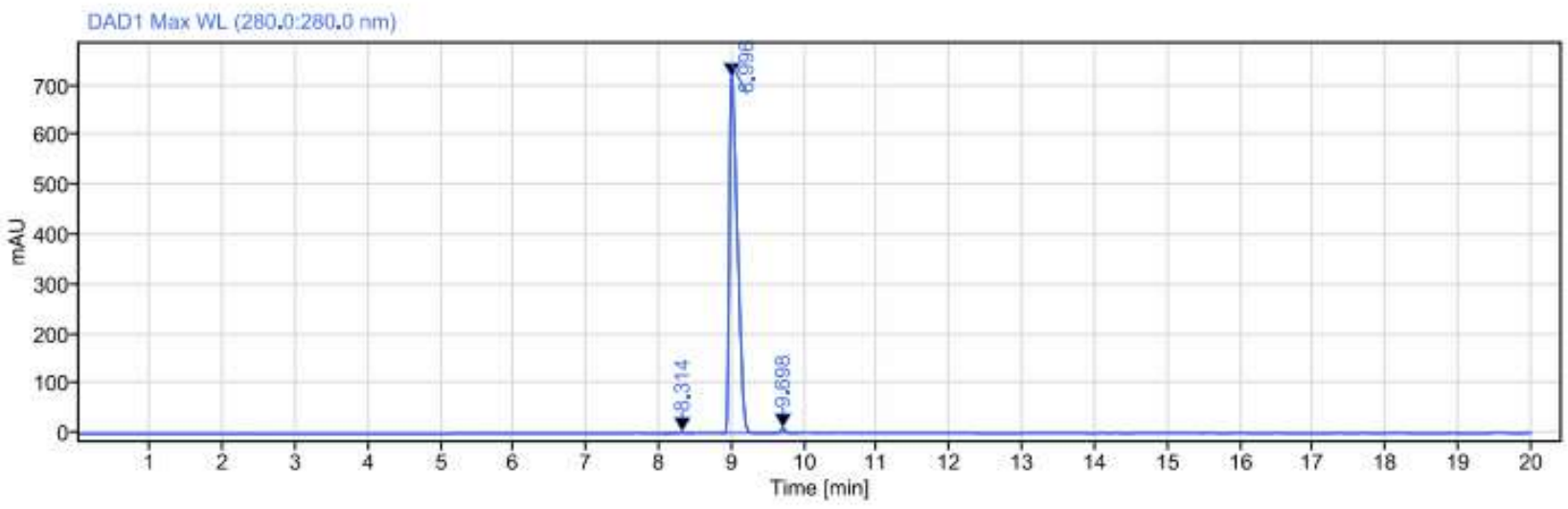

Signal: $\quad$ DAD1 Max WL $(280.0: 280.0 \mathrm{~nm})$

$\begin{array}{cccccc}\text { RT [min] } & \text { Width [min] } & \text { Area } & \text { Height } & \text { Area\% } & \text { Symmetry } \\ 8.314 & 0.44 & 7.68 & 1.87 & 0.14 & 0.93727 \\ 8.996 & 0.64 & 5553.95 & 714.51 & 99.09 & 0.41029 \\ 9.698 & 0.41 & 43.38 & 9.33 & 0.77 & 0.92724\end{array}$

Sum $\quad 5605.00$ 


$\begin{array}{llll}\text { Sample name: } & \text { 5b } & \text { Operator: } & \text { Keke Huang } \\ \text { Instrument: } & \text { LC01 } & \text { Location: } & \text { P1-A-2 } \\ \text { Inj. volume: } & 3.0 & \text { Injection Data File Name 20190222 103340.dx } \\ \text { Injection Data File Directory } & \text { NNew Drug Study/Results/JZG/20190222/JZG_20190222 100234.rslt }\end{array}$

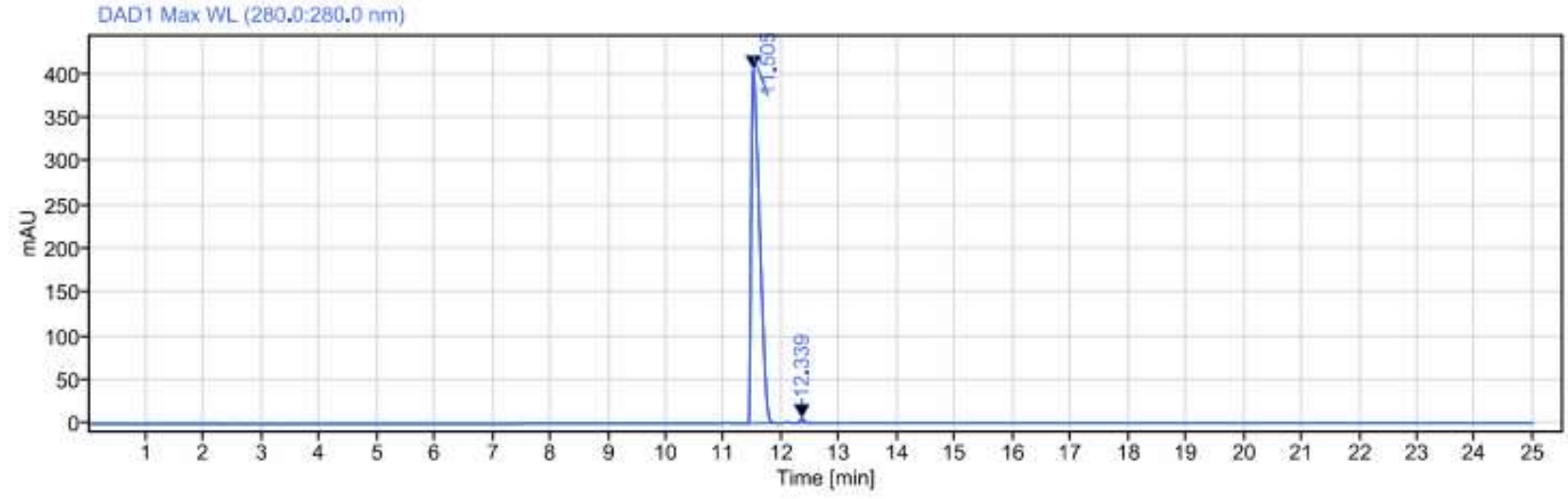

Signal: $\quad$ DAD1 Max WL $(280.0: 280.0 \mathrm{~nm})$

$\begin{array}{cccccc}\text { RT [min] } & \text { Width [min] } & \text { Area } & \text { Height } & \text { Area\% } & \text { Symmetry } \\ 11.505 & 0.60 & 4045.67 & 404.40 & 99.34 & 0.34946 \\ 12.339 & 0.39 & 26.74 & 5.02 & 0.66 & 0.74960 \\ & \text { Sum } & 4072.42 & & & \end{array}$




$\begin{array}{llll}\text { Sample name: } & \mathbf{5 c} & \text { Operator: } & \text { Keke Huang } \\ \text { Instrument: } & \text { LC01 } & \text { Location: } & \text { P1-A-3 } \\ \text { Inj. volume: } & 3.0 & \text { Injection Data File Name 20190222 110435.dx } \\ \text { Injection Data File Directory } & \text { /New Drug Study/Results/JZG/20190222/JZG_20190222 100234.rsit }\end{array}$

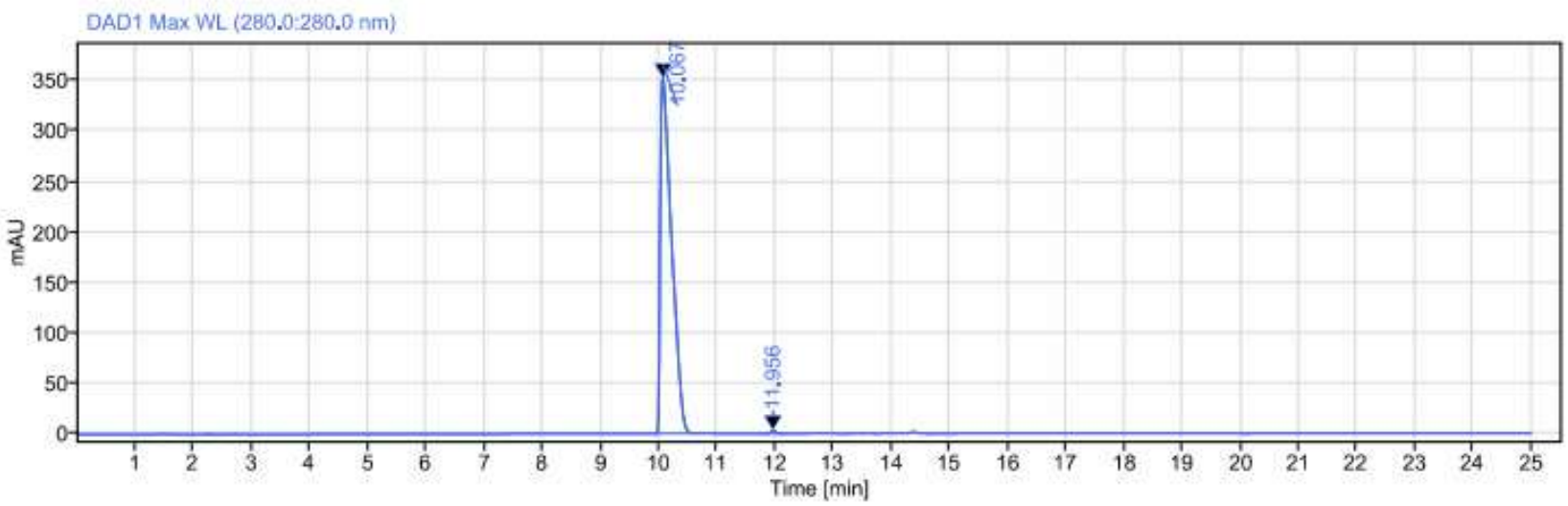

Signal: $\quad$ DAD1 Max WL $(280.0: 280.0 \mathrm{~nm})$

$\begin{array}{cccccc}\text { RT [min] } & \text { Width [min] } & \text { Area } & \text { Height } & \text { Area\% } & \text { Symmetry } \\ 10.067 & 0.85 & 4729.80 & 352.02 & 99.70 & 0.28037 \\ 11.956 & 0.34 & 14.40 & 2.84 & 0.30 & 0.80807 \\ & \text { Sum } & 4744.20 & & & \end{array}$




$\begin{array}{llll}\text { Sample name: } & \text { 5d } & \text { Operator: } & \text { Keke Huang } \\ \text { Instrument: } & \text { LC01 } & \text { Location: } & \text { P1-A-4 } \\ \text { Inj. volume: } & 3.0 & \text { Injection Data File Name 20190222 113530.dx } \\ \text { Injection Data File Directory } & \text { New Drug Study/Results/JZG/20190222/JZG_20190222 100234.rsit }\end{array}$

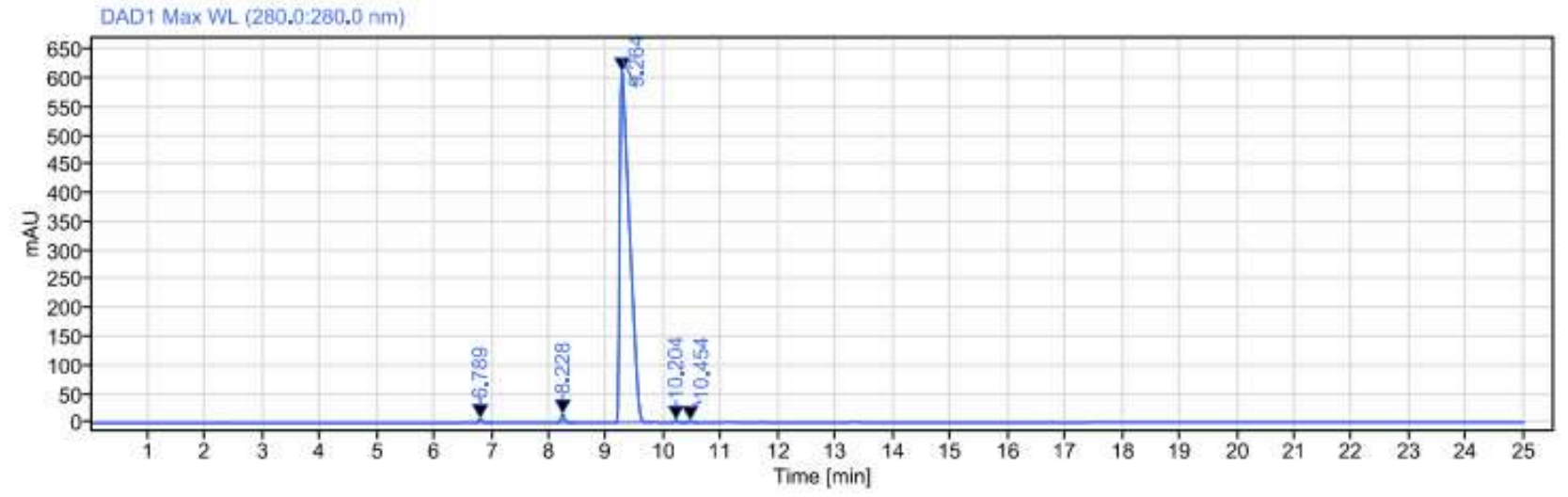

Signal: $\quad$ DAD1 Max WL $(280.0: 280.0 \mathrm{~nm})$

$\begin{array}{cccccc}\text { RT [min] } & \text { Width [min] } & \text { Area } & \text { Height } & \text { Area\% } & \text { Symmetry } \\ 6.789 & 0.31 & 29.04 & 6.54 & 0.39 & 0.76207 \\ 8.228 & 0.35 & 59.52 & 14.33 & 0.81 & 0.78208 \\ 9.264 & 0.63 & 7246.71 & 611.28 & 98.40 & 0.29190 \\ 10.204 & 0.25 & 16.78 & 3.83 & 0.23 & 0.81061 \\ 10.454 & 0.23 & 12.23 & 2.68 & 0.17 & 0.81988 \\ & \text { Sum } & 7364.28 & & & \end{array}$




$\begin{array}{llll}\text { Sample name: } & \text { 5e } & \text { Operator: } & \text { Keke Huang } \\ \text { Instrument: } & \text { LC01 } & \text { Location: } & \text { P1-A-5 } \\ \text { Inj. volume: } & 3.0 & \text { Injection Data File Name 20190222 120624.dx } \\ \text { Injection Data File Directory } & \text { /New Drug Study/Results/JZG/20190222/JZG_20190222 100234.rslt }\end{array}$

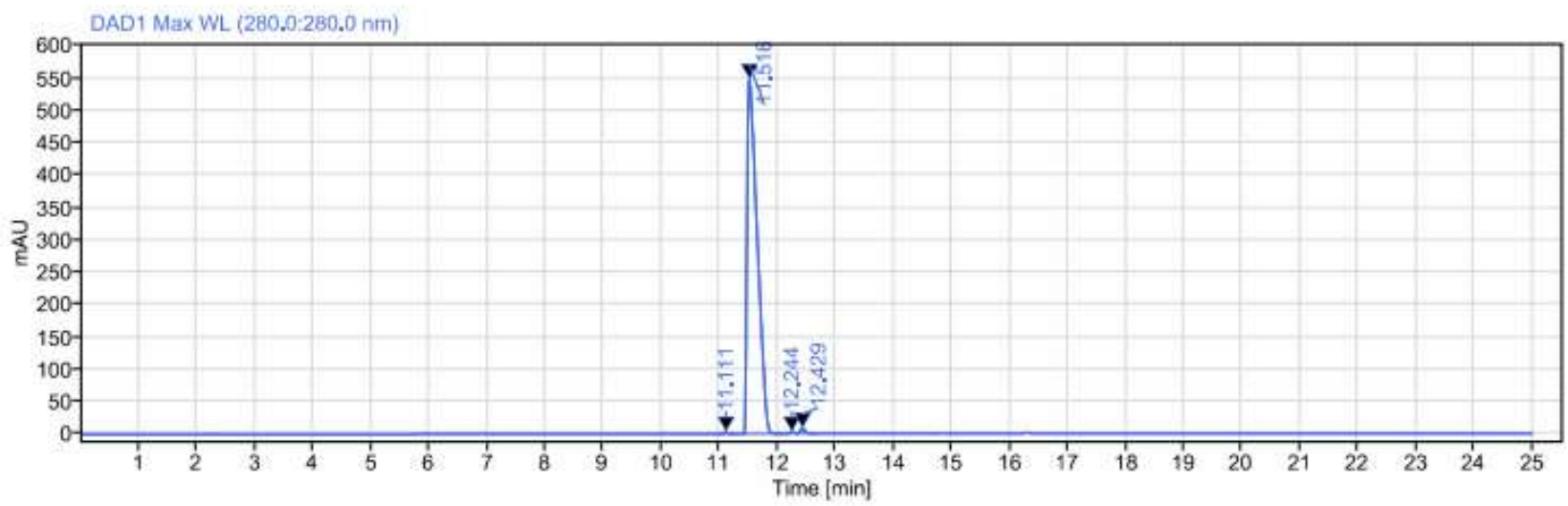

Signal: $\quad$ DAD1 Max WL $(280.0: 280.0 \mathrm{~nm})$

$\begin{array}{cccccc}\text { RT [min] } & \text { Width [min] } & \text { Area } & \text { Height } & \text { Area\% } & \text { Symmetry } \\ 11.111 & 0.29 & 16.00 & 3.23 & 0.24 & 0.95856 \\ 11.516 & 0.69 & 6604.84 & 548.07 & 98.86 & 0.29866 \\ 12.244 & 0.24 & 14.28 & 3.02 & 0.21 & 0.85612 \\ 12.429 & 0.33 & 45.74 & 8.79 & 0.68 & 0.76412 \\ & \text { Sum } & 6680.86 & & & \end{array}$


Sample name: $\quad 5 f$

Instrument:

Inj. volume:

Injection Data File Directory
LC01

5.0
Operator:

Location:

Injection Data File Name 20190222 123719.dx
Keke Huang

P1-A-6

/New Drug Study/Results/JZG/20190222/JZG_20190222 100234.rsIt

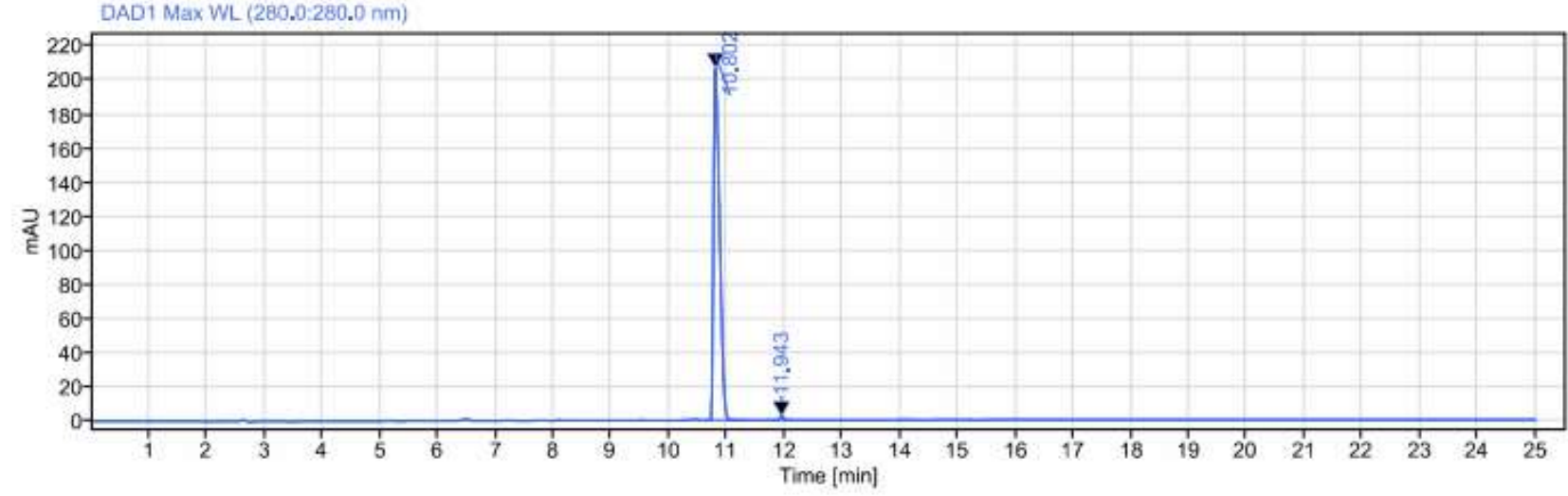

Signal: $\quad$ DAD1 Max WL $(280.0: 280.0 \mathrm{~nm})$

$\begin{array}{cccccc}\text { RT [min] } & \text { Width [min] } & \text { Area } & \text { Height } & \text { Area\% } & \text { Symmetry } \\ 10.802 & 0.69 & 1505.66 & 206.70 & 99.32 & 0.46198 \\ 11.943 & 0.36 & 10.29 & 2.21 & 0.68 & 0.79621 \\ & \text { Sum } & 1515.96 & & & \end{array}$


Sample name:

Instrument:

Inj. volume:

Injection Data File Directory
$6 a$

LC01

3.0
Operator:

Keke Huang

Location:

P1-A-7

Injection Data File Name 20190222 174633.dx

/New Drug Study/Results/JZG/20190222/JZG_20190222 100234.rslt

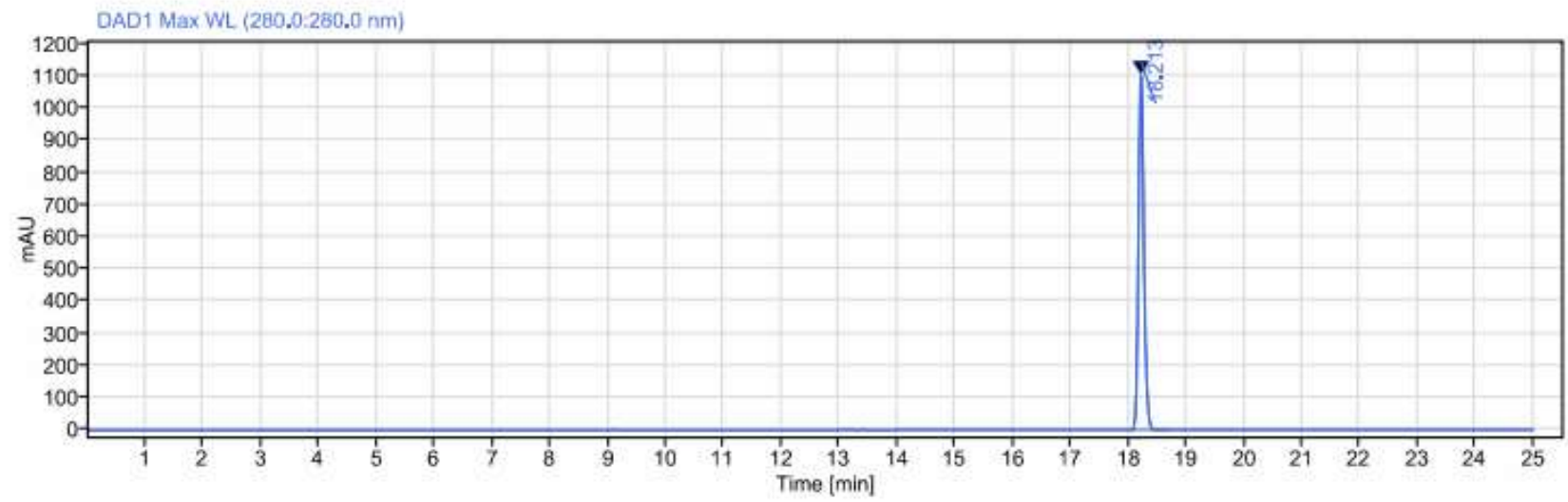

Signal: $\quad$ DAD1 Max WL $(280.0: 280.0 \mathrm{~nm})$

$\begin{array}{cccccc}\text { RT [min] } & \text { Width [min] } & \text { Area } & \text { Height } & \text { Area\% } & \text { Symmetry } \\ 18.213 & 0.62 & 7254.54 & 1100.11 & 100.00 & 0.82469 \\ & \text { Sum } & 7254.54 & & & \end{array}$


Sample name:

Instrument:

Inj. volume:
$6 b$

LC01

3.0
Operator:

Location:

Injection Data File Name 20190222 204827.dx

Injection Data File Directory ～/New Drug Study/Results/JZG/20190222/JZG_20190222 181742.rsIt

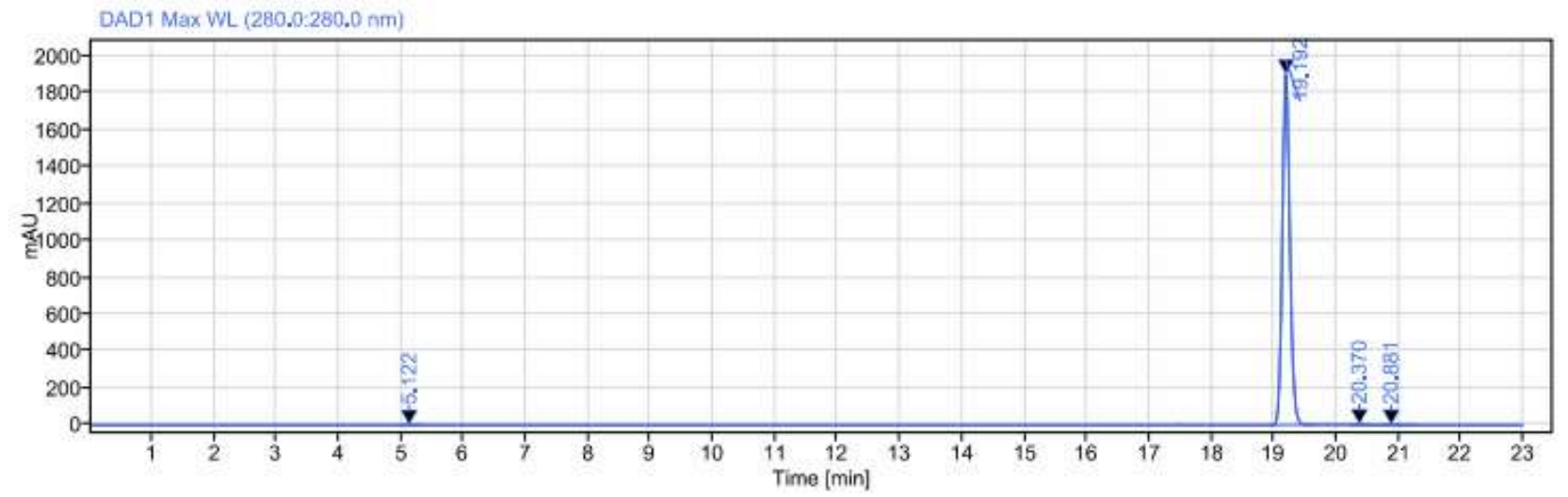

Signal: $\quad$ DAD1 Max WL $(280.0: 280.0 \mathrm{~nm})$

$\begin{array}{cccccc}\text { RT [min] } & \text { Width [min] } & \text { Area } & \text { Height } & \text { Area\% } & \text { Symmetry } \\ 5.122 & 0.33 & 9.88 & 1.81 & 0.06 & 0.82580 \\ 19.192 & 0.72 & 16018.23 & 1900.77 & 99.57 & 0.86837 \\ 20.370 & 0.41 & 34.30 & 4.02 & 0.21 & 0.85834 \\ 20.881 & 0.63 & 24.61 & 2.61 & 0.15 & 0.79314 \\ & \text { Sum } & 16087.02 & & & \end{array}$




$\begin{array}{llll}\text { Sample name: } & 6 c & \text { Operator: } & \text { Keke Huang } \\ \text { Instrument: } & \text { LC01 } & \text { Location: } & \text { P1-A-9 } \\ \text { Inj. volume: } & 3.0 & \text { Injection Data File Name 20190222 211722.dx } \\ \text { Injection Data File Directory } & \text { NNew Drug Study/Results/JZG/20190222/JZG_20190222 } & \text { 181742.rsit }\end{array}$

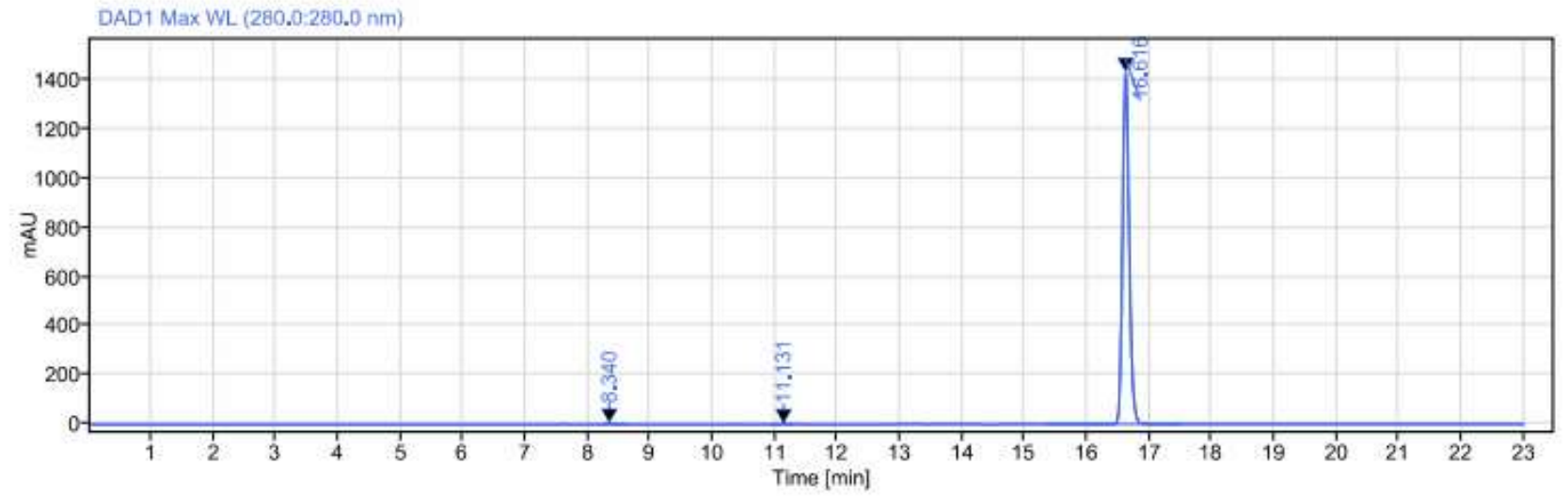

Signal: $\quad$ DAD1 Max WL $(280.0: 280.0 \mathrm{~nm})$

$\begin{array}{cccccc}\text { RT [min] } & \text { Width [min] } & \text { Area } & \text { Height } & \text { Area\% } & \text { Symmetry } \\ 8.340 & 0.39 & 20.90 & 4.02 & 0.20 & 0.72118 \\ 11.131 & 0.38 & 13.05 & 2.04 & 0.12 & 0.82334 \\ 16.616 & 2.14 & 10630.52 & 1427.01 & 99.68 & 0.84085 \\ & \text { Sum } & 10664.48 & & & \end{array}$




$\begin{array}{lcll}\text { Sample name: } & \text { 6d } & \text { Operator: } & \text { Keke Huang } \\ \text { Instrument: } & \text { LC01 } & \text { Location: } & \text { P1B11 } \\ \text { Inj. volume: } & 3.0 & \text { Injection Data File Name 20190221 174145.dx } \\ \text { Injection Data File Directory } & \text { NNew Drug Study/Results/JZG/20190221/JZG_20190221 174137.rslt }\end{array}$

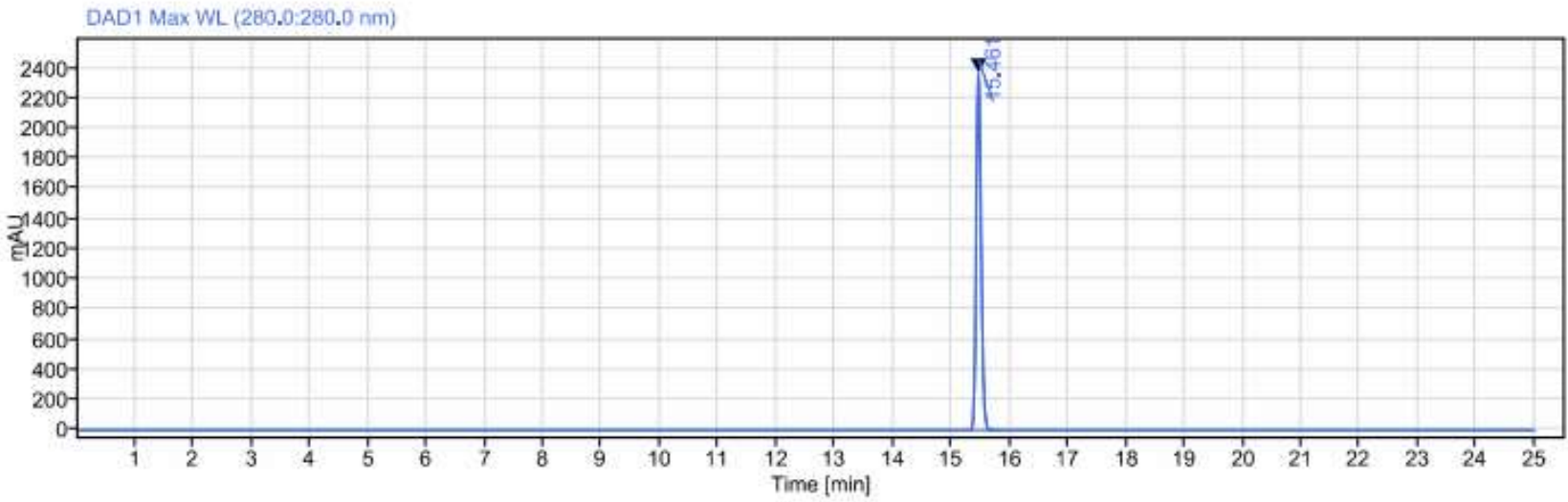

Signal: $\quad$ DAD1 Max WL (280.0:280.0 nm)

$\begin{array}{cccccc}\text { RT [min] } & \text { Width [min] } & \text { Area } & \text { Height } & \text { Area\% } & \text { Symmetry } \\ 15.461 & 0.50 & 14088.22 & 2366.93 & 100.00 & 0.82613 \\ & \text { Sum } & 14088.22 & & & \\ & & & & & \end{array}$


Sample name:

Instrument:

Inj. volume:
$6 e$

LC01

3.0
Operator: Keke Huang

Location: P1B1

Injection Data File Name $\quad 20190222$ 221515.dx

Injection Data File Directory ～/New Drug Study/Results/JZG/20190222/JZG_20190222 181742.rsIt

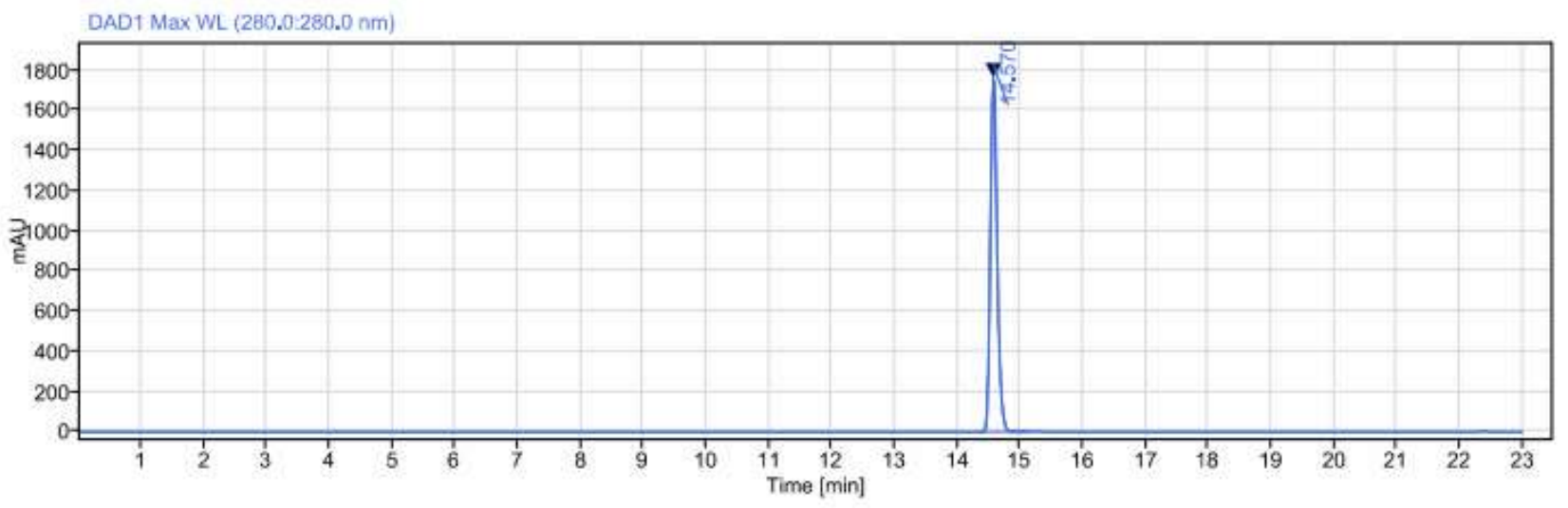

Signal: DAD1 Max WL $(280.0: 280.0 \mathrm{~nm})$

$\begin{array}{cccccc}\text { RT [min] } & \text { Width [min] } & \text { Area } & \text { Height } & \text { Area\% } & \text { Symmetry } \\ 14.570 & 0.75 & 13340.32 & 1760.93 & 100.00 & 0.80354 \\ & \text { Sum } & 13340.32 & & & \end{array}$




$\begin{array}{llll}\text { Sample name: } & 6 f & \text { Operator: } & \text { Keke Huang } \\ \text { Instrument: } & \text { LC01 } & \text { Location: } & \text { P1-B-2 } \\ \text { Inj. volume: } & 3.0 & \text { Injection Data File Name 20190222 224411.dx } \\ \text { Injection Data File Directory } & \text { /New Drug Study/Results/JZG/20190222/JZG_20190222 181742.rsIt }\end{array}$

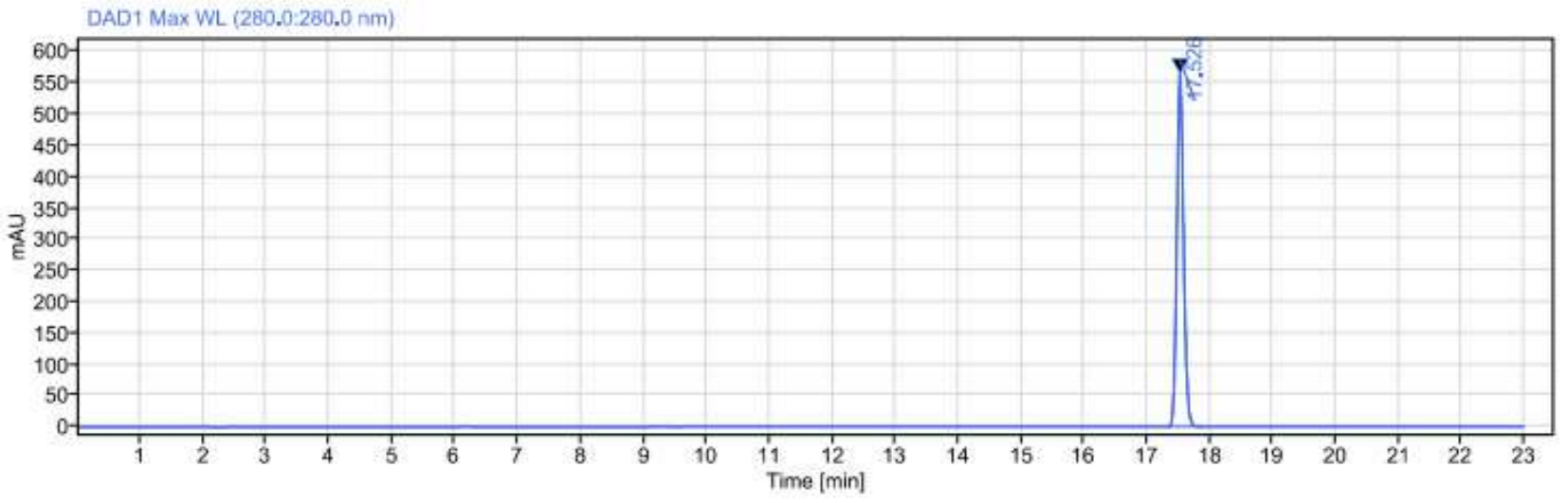

Signal: $\quad$ DAD1 Max WL (280.0:280.0 nm)

$\begin{array}{cccccc}\text { RT [min] } & \text { Width [min] } & \text { Area } & \text { Height } & \text { Area\% } & \text { Symmetry } \\ 17.526 & 0.56 & 4220.15 & 564.91 & 100.00 & 0.85610 \\ & \text { Sum } & 4220.15 & & & \end{array}$




$\begin{array}{llll}\text { Sample name: } & 6 \mathrm{~g} & \text { Operator: } & \text { Keke Huang } \\ \text { Instrument: } & \mathrm{LC} 01 & \text { Location: } & \text { P1-B-4 } \\ \text { Inj. volume: } & 3.0 & \text { Injection Data File Name 20190222 141002.dx } \\ \text { Injection Data File Directory } & \text { NNew Drug Study/Results/JZG/20190222/JZG_20190222 100234.rsIt }\end{array}$

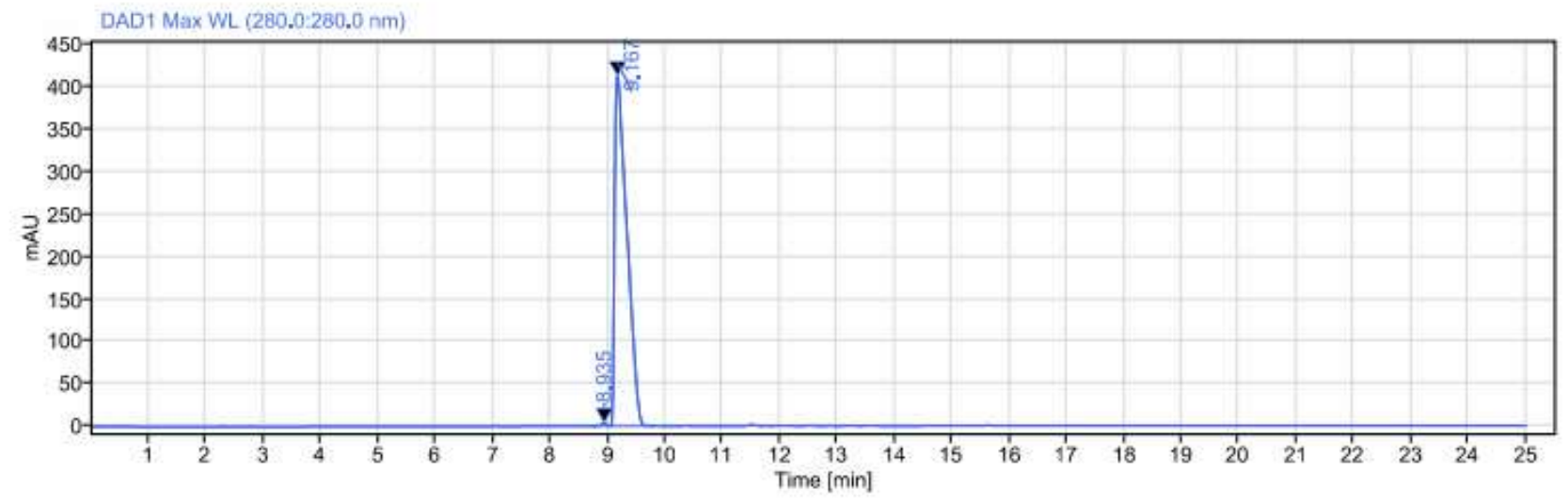

Signal: $\quad$ DAD1 Max WL $(280.0: 280.0 \mathrm{~nm})$

$\begin{array}{cccccc}\text { RT [min] } & \text { Width [min] } & \text { Area } & \text { Height } & \text { Area\% } & \text { Symmetry } \\ 8.935 & 0.32 & 22.15 & 3.53 & 0.36 & 1.17015 \\ 9.167 & 0.74 & 6092.77 & 412.92 & 99.64 & 0.27088 \\ & \text { Sum } & 6114.92 & & & \end{array}$


Sample name: $\quad 6 \mathrm{~h}$

Instrument:

LC01

Inj. volume:

Injection Data File Directory

3.0
Injection Data File Name 20190222 133909.dx
Operator:

Location:

Keke Huang

P1-B-3

20190222/JZG_20190222 100234.rsIt

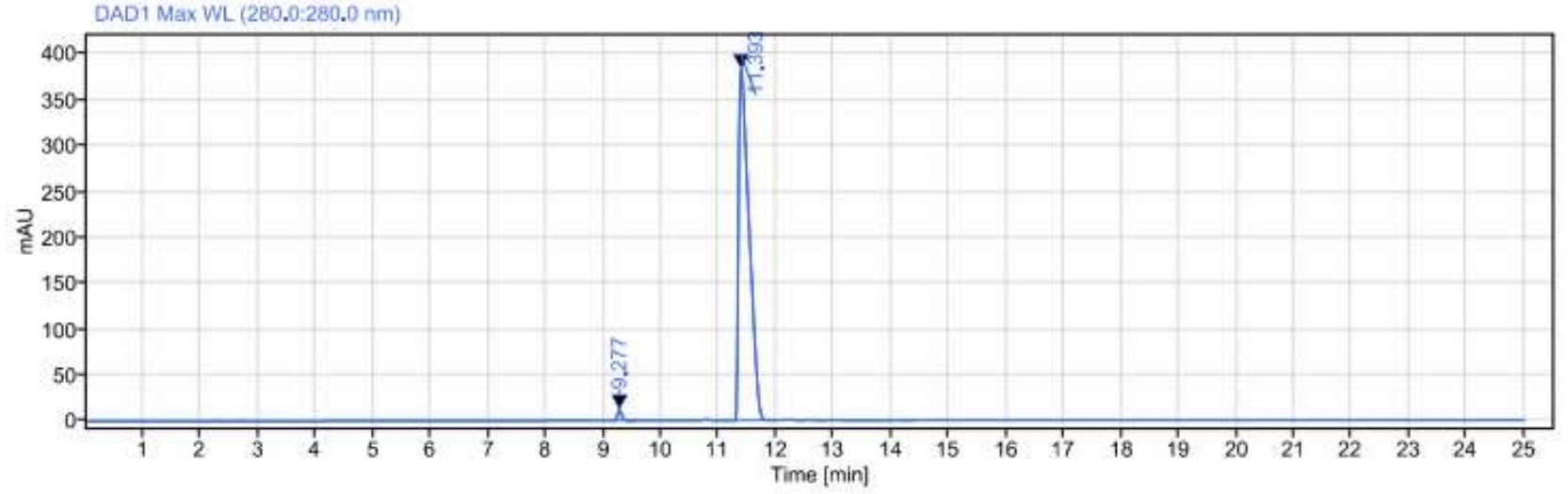

Signal: $\quad$ DAD1 Max WL $(280.0: 280.0 \mathrm{~nm})$

$\begin{array}{cccccc}\text { RT [min] } & \text { Width [min] } & \text { Area } & \text { Height } & \text { Area\% } & \text { Symmetry } \\ 9.277 & 0.39 & 58.00 & 12.05 & 1.19 & 0.76466 \\ 11.393 & 0.72 & 4811.12 & 383.11 & 98.81 & 0.30331 \\ & \text { Sum } & 4869.12 & & & \end{array}$




$\begin{array}{llll}\text { Sample name: } & 6 \mathrm{i} & \text { Operator: } & \text { Keke Huang } \\ \text { Instrument: } & \text { LC01 } & \text { Location: } & \text { P1B6 }\end{array}$

Inj. volume: $\quad 3.0 \quad$ Injection Data File Name $\quad 20190222181749 . \mathrm{dx}$ Injection Data File Directory ／New Drug Study/Results/JZG/20190222/JZG_20190222 181742.rslt

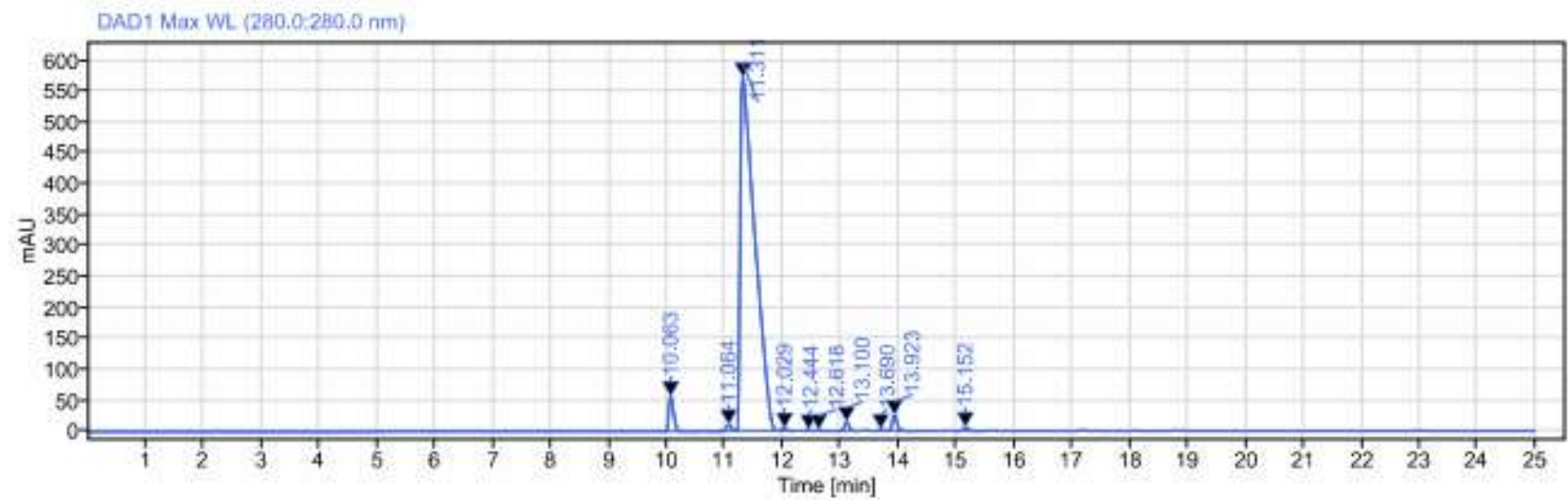

$\begin{array}{cccccc}\text { Signal: } & \text { DAD1 Max WL }(280.0: 280.0 \mathrm{~nm}) & & & \\ \text { RT [min] } & \text { Width [min] } & \text { Area } & \text { Height } & \text { Area\% } & \text { Symmetry } \\ 10.063 & 0.33 & 313.41 & 56.42 & 2.91 & 0.62929 \\ 11.064 & 0.36 & 64.07 & 10.68 & 0.59 & 0.92939 \\ 11.311 & 0.73 & 10077.83 & 571.68 & 93.44 & 0.22262 \\ 12.029 & 0.25 & 28.10 & 4.61 & 0.26 & 1.08937 \\ 12.444 & 0.18 & 9.73 & 1.98 & 0.09 & 0.78206 \\ 12.618 & 0.24 & 8.25 & 1.93 & 0.08 & 0.82520 \\ 13.100 & 0.32 & 77.35 & 14.57 & 0.72 & 0.83023 \\ 13.690 & 0.25 & 18.42 & 2.82 & 0.17 & 0.59350 \\ 13.923 & 0.56 & 148.22 & 25.57 & 1.37 & 0.68224 \\ 15.152 & 0.41 & 40.15 & 5.81 & 0.37 & 0.77742 \\ & \text { Sum } & 10785.52 & & & \end{array}$


Sample name:

Instrument:

Inj. volume: 6j

LC01

3.0
Operator:

Location:

Injection Data File Name $20190222144059 . d x$

Injection Data File Directory ～/New Drug Study/Results/JZG/20190222/JZG_20190222 100234.rslt

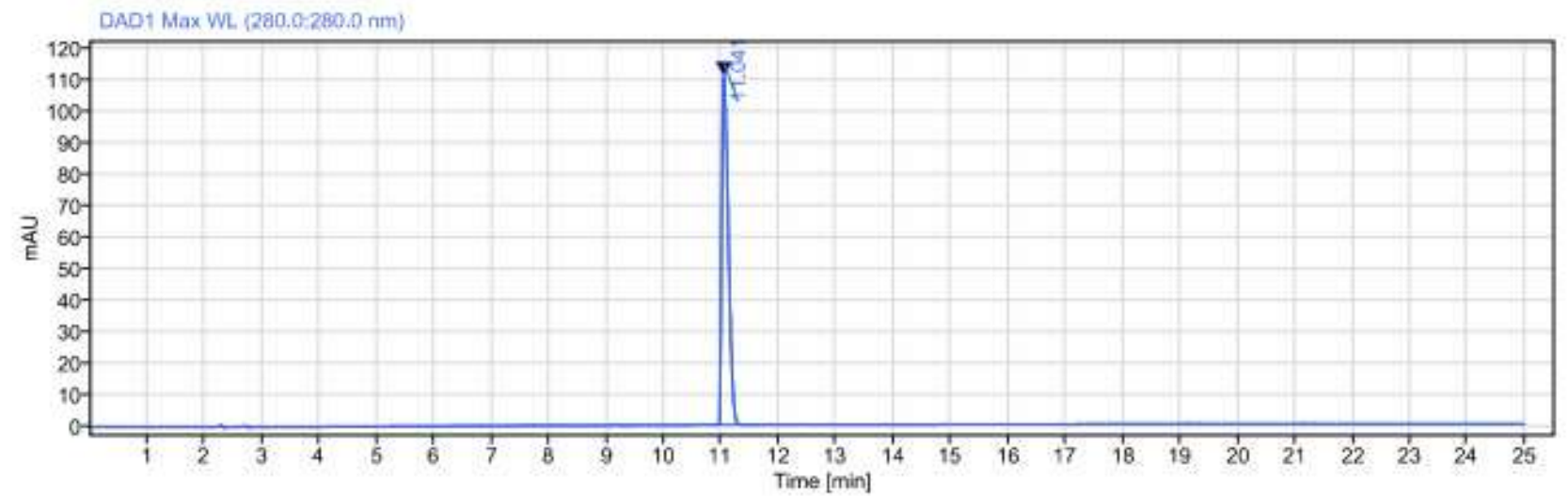

Signal: $\quad$ DAD1 Max WL $(280.0: 280.0 \mathrm{~nm})$

$\begin{array}{cccccc}\text { RT [min] } & \text { Width [min] } & \text { Area } & \text { Height } & \text { Area\% } & \text { Symmetry } \\ 11.041 & 0.73 & 875.23 & 110.77 & 100.00 & 0.44877 \\ & \text { Sum } & 875.23 & & & \end{array}$


Sample name: $\quad 6 k$

Instrument:

Inj. volume:

Injection Data File Directory
LC01

3.0
Operator:

Location:

Injection Data File Name 20190222 191939.dx
Keke Huang

P1-B-8

/New Drug Study/Results/JZG/20190222/JZG_20190222 181742.rsit

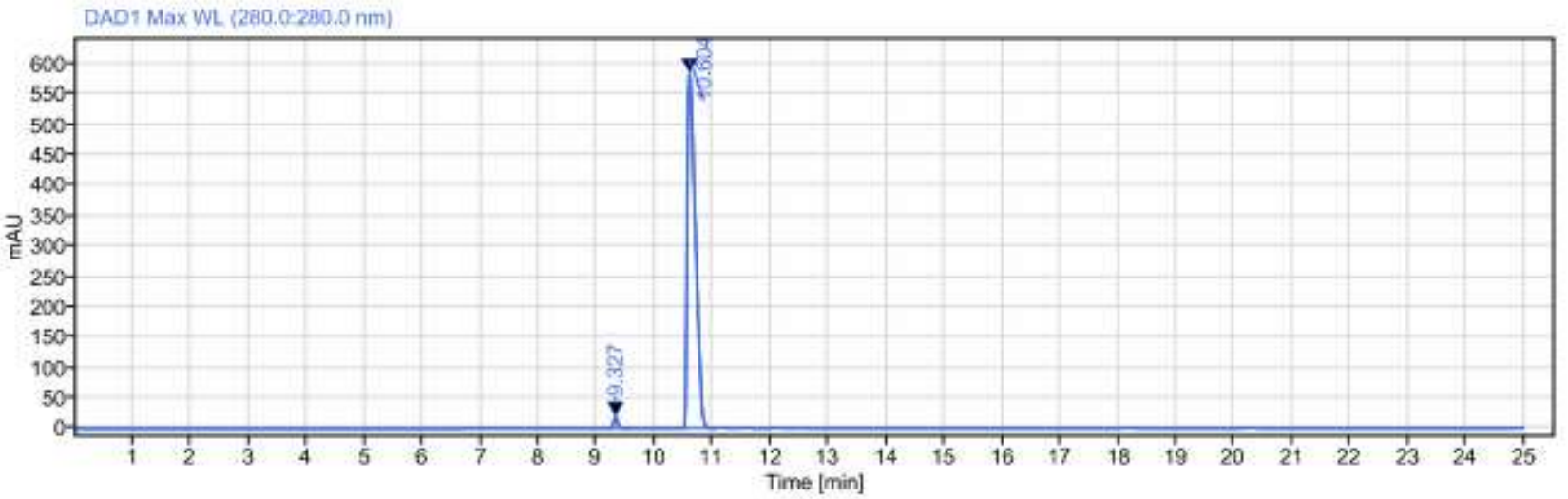

Signal: $\quad$ DAD1 Max WL $(280.0: 280.0 \mathrm{~nm})$

$\begin{array}{cccccc}\text { RT [min] } & \text { Width [min] } & \text { Area } & \text { Height } & \text { Area\% } & \text { Symmetry } \\ 9.327 & 0.37 & 86.07 & 18.83 & 1.51 & 0.76677 \\ 10.604 & 0.57 & 5625.61 & 584.94 & 98.49 & 0.37065 \\ & \text { Sum } & 5711.68 & & & \end{array}$


Sample name: $\quad 61$

Instrument:

Inj. volume:

Injection Data File Directory
LC01

3.0
Injection Data File Name 20190222 184843.dx
Operator:

Location:

Keke Huang

P1-B-7

20190222/JZG_20190222 181742.rsit

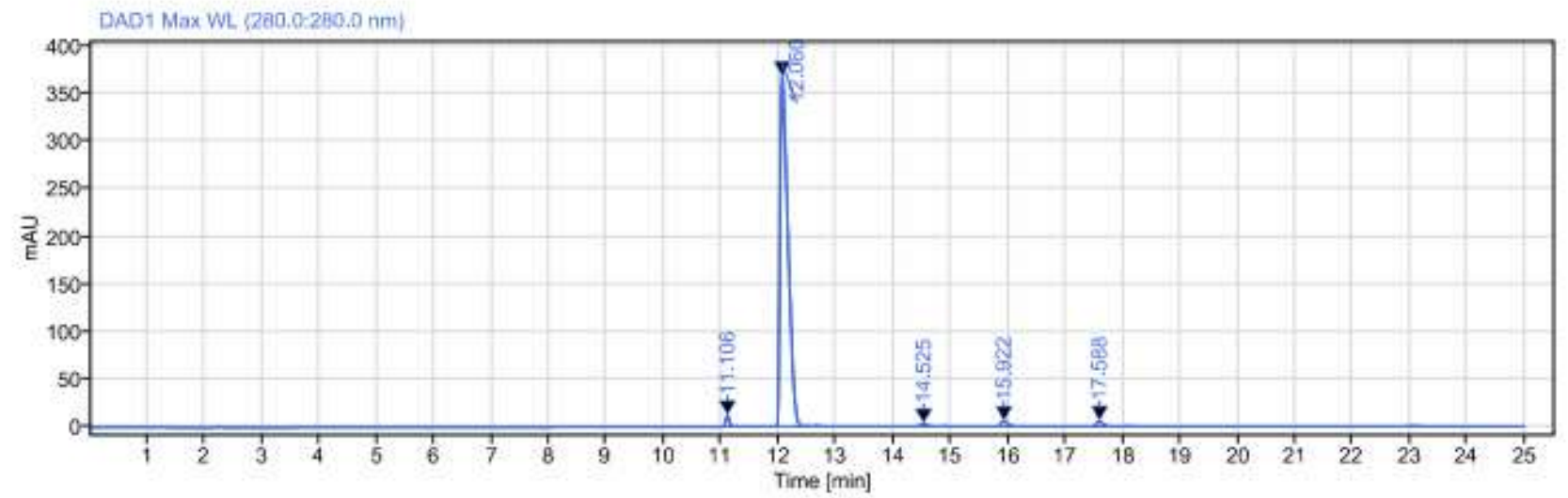

Signal: $\quad$ DAD1 Max WL (280.0:280.0 nm)

$\begin{array}{cccccc}\text { RT [min] } & \text { Width [min] } & \text { Area } & \text { Height } & \text { Area\% } & \text { Symmetry } \\ 11.106 & 0.29 & 50.81 & 11.91 & 1.37 & 0.78793 \\ 12.060 & 0.47 & 3539.11 & 367.94 & 95.63 & 0.36012 \\ 14.525 & 0.40 & 24.09 & 3.26 & 0.65 & 0.71905 \\ 15.922 & 0.49 & 44.31 & 5.79 & 1.20 & 0.67330 \\ 17.588 & 0.56 & 42.35 & 5.85 & 1.14 & 0.68692 \\ & \text { Sum } & 3700.68 & & & \end{array}$




$\begin{array}{llll}\text { Sample name: } & 7 \mathrm{a} & \text { Operator: } & \text { Keke Huang } \\ \text { Instrument: } & \mathrm{LC} 01 & \text { Location: } & \text { P1-B-9 } \\ \text { Inj. volume: } & 3.0 & \text { Injection Data File Name 20190222 151155.dx } \\ \text { Injection Data File Directory } & \text { /New Drug Study/Results/JZG/20190222/JZG_20190222 100234.rslt }\end{array}$

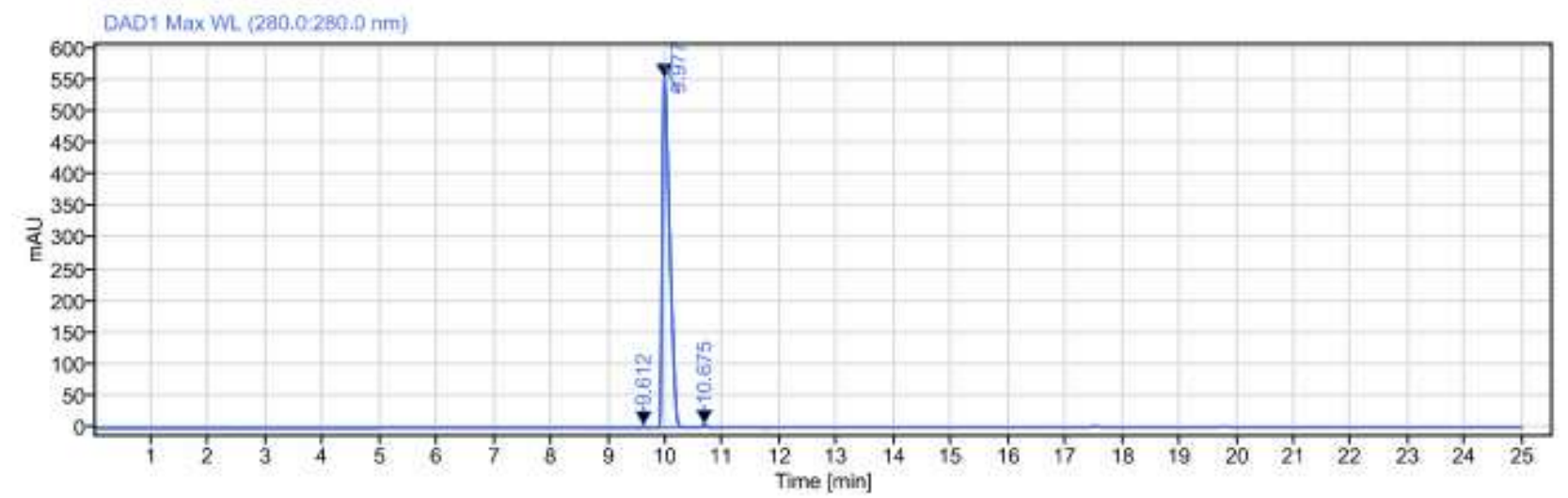

Signal: $\quad$ DAD1 Max WL (280.0:280.0 nm)

$\begin{array}{cccccc}\text { RT [min] } & \text { Width }[\mathrm{min}] & \text { Area } & \text { Height } & \text { Area\% } & \text { Symmetry } \\ 9.612 & 0.22 & 11.87 & 2.71 & 0.24 & 0.88228 \\ 9.977 & 0.61 & 4899.06 & 551.38 & 99.28 & 0.38203 \\ 10.675 & 0.49 & 23.87 & 4.30 & 0.48 & 0.80234 \\ & \text { Sum } & 4934.80 & & & \end{array}$


Sample name: $\quad 7 b$

Instrument: $\quad$ LCO1

Inj. volume: $\quad 3.0$

Injection Data File Directory
Operator:

Location:

Injection Data File Name 20190221 160039.dx

/New Drug Study/Results/JZG/20190221/JZG_20190221 150838.rsit

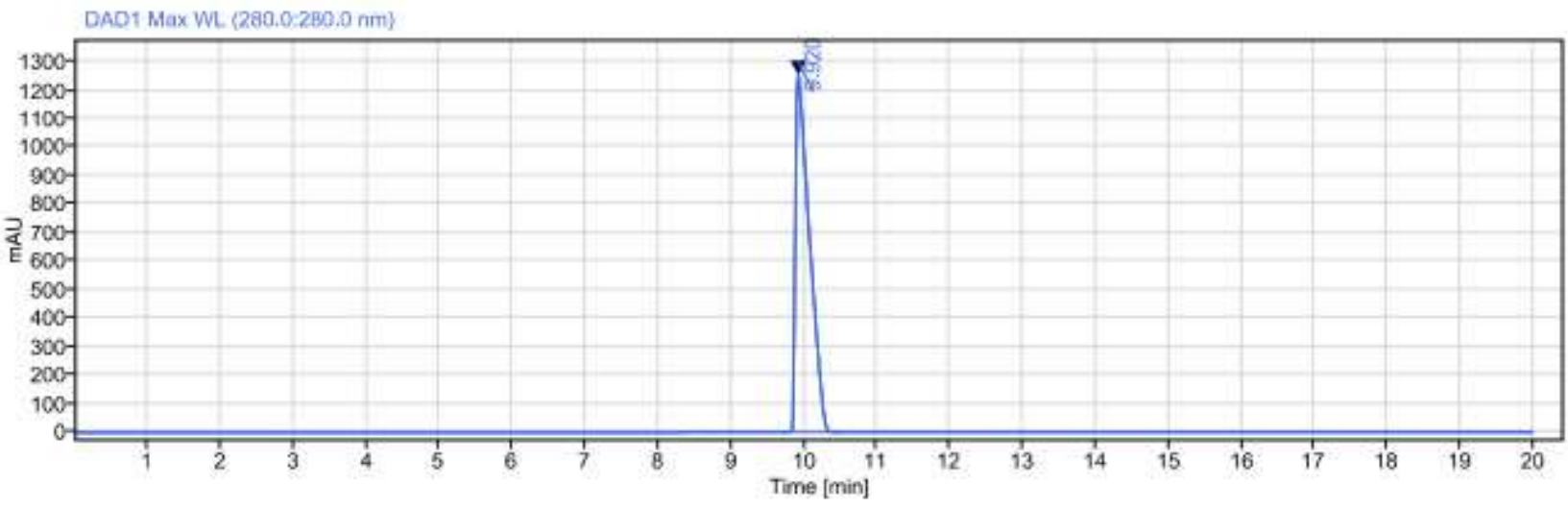

Signal: $\quad$ DAD1 Max WL $(280.0: 280.0 \mathrm{~nm})$

$\begin{array}{cccccc}\text { RT [min] } & \text { Width [min] } & \text { Area } & \text { Height } & \text { Area\% } & \text { Symmetry } \\ 9.920 & 0.78 & 16779.23 & 1251.12 & 100.00 & 0.25298 \\ & \text { Sum } & 16779.23 & & & \end{array}$




$\begin{array}{llll}\text { Sample name: } & 7 \mathrm{C} & \text { Operator: } & \text { Keke Huang } \\ \text { Instrument: } & \mathrm{LC} 01 & \text { Location: } & \text { P1-C1 } \\ \text { Inj. volume: } & 3.0 & \text { Injection Data File Name 20190222 154249.dx } \\ \text { Injection Data File Directory } & \text { /New Drug Study/Results/JZG/20190222/JZG_20190222 100234.rslt }\end{array}$

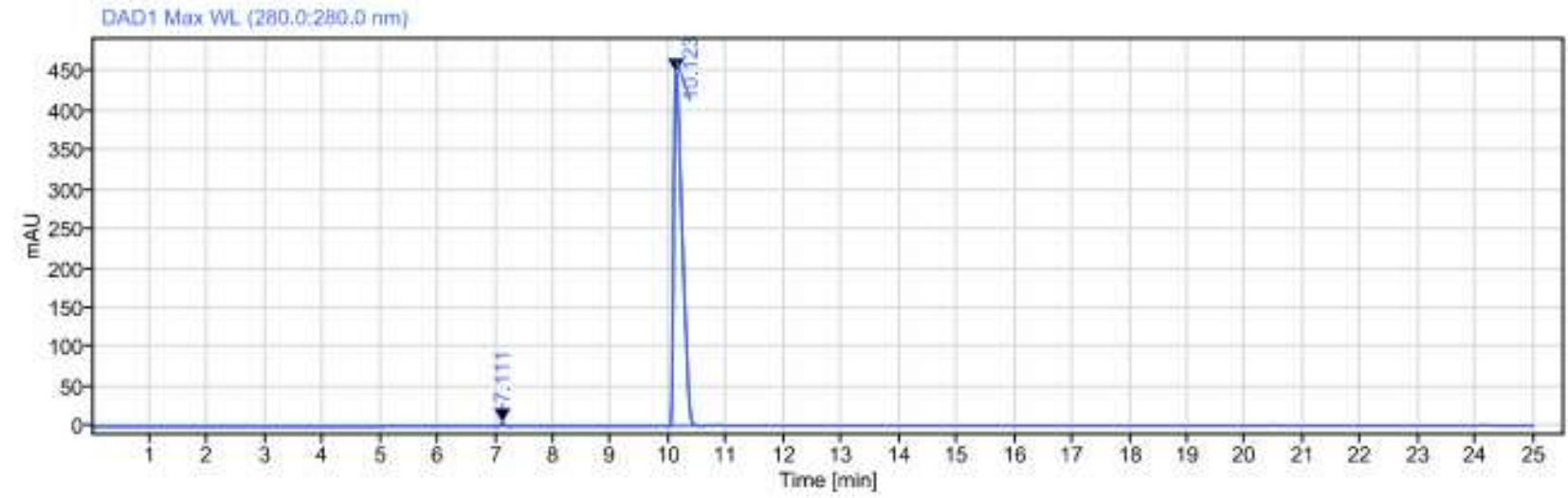

Signal: $\quad$ DAD1 Max WL $(280.0: 280.0 \mathrm{~nm})$

$\begin{array}{cccccc}\text { RT [min] } & \text { Width [min] } & \text { Area } & \text { Height } & \text { Area\% } & \text { Symmetry } \\ 7.111 & 0.31 & 15.72 & 3.75 & 0.35 & 0.82327 \\ 10.123 & 0.63 & 4529.31 & 448.13 & 99.65 & 0.35226 \\ & \text { Sum } & 4545.04 & & & \end{array}$




$\begin{array}{llll}\text { Sample name: } & \text { 7d } & \text { Operator: } & \text { Keke Huang } \\ \text { Instrument: } & \text { LCO1 } & \text { Location: } & \text { P1-C-2 } \\ \text { Inj. volume: } & 3.0 & \text { Injection Data File Name 20190222 161346.dx } \\ \text { Injection Data File Directory } & \text { /New Drug Study/Results/JZG/20190222/JZG_20190222 100234.rsit }\end{array}$

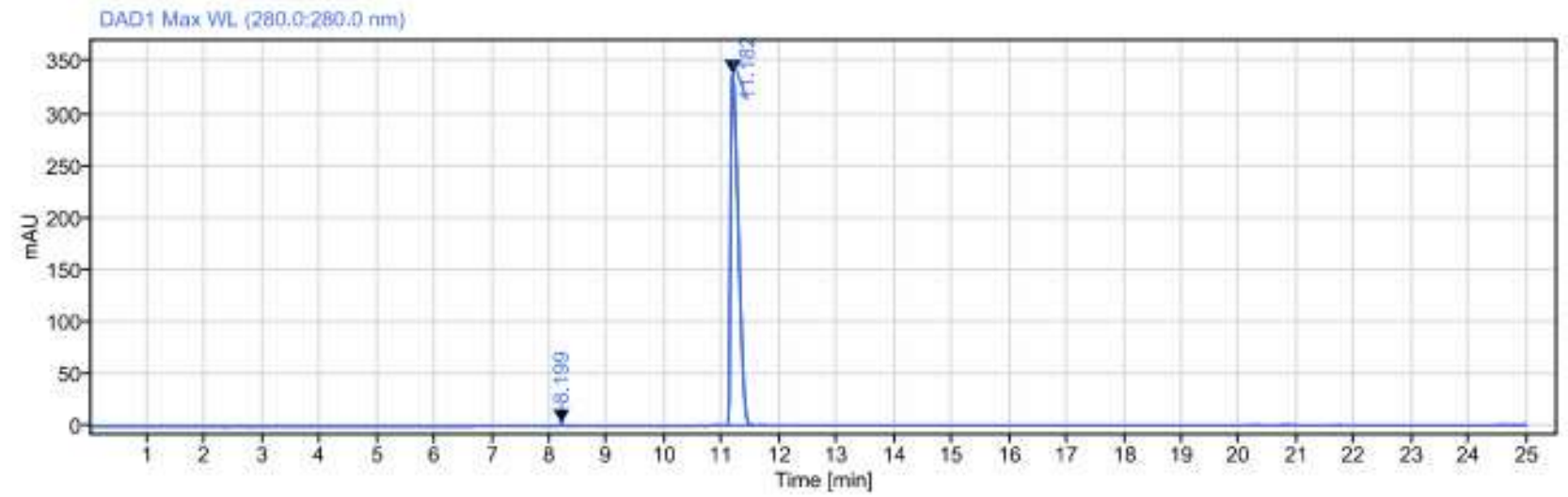

Signal: $\quad$ DAD1 Max WL $(280.0: 280.0 \mathrm{~nm})$

$\begin{array}{cccccc}\text { RT [min] } & \text { Width [min] } & \text { Area } & \text { Height } & \text { Area\% } & \text { Symmetry } \\ 8.199 & 0.52 & 8.25 & 1.88 & 0.26 & 0.83844 \\ 11.182 & 0.53 & 3117.44 & 337.36 & 99.74 & 0.37817 \\ & \text { Sum } & 3125.68 & & & \end{array}$


Sample name: $\quad 7 e$

Instrument:

Inj. volume:

Injection Data File Directory
$1 \mathrm{co1}$

3.0
Operator:

Location:

Keke Huang

Injection Data File Name 20190222 164440.dx

/New Drug Study/Results/JZG/20190222/JZG_20190222 100234.rsit

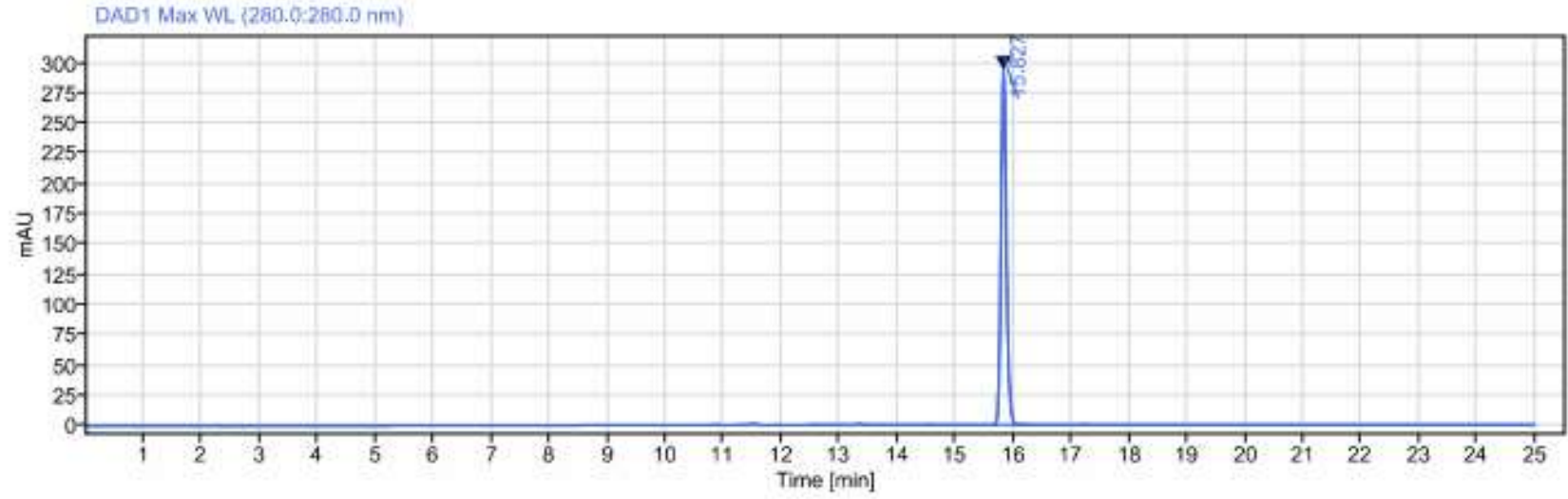

Signal: $\quad$ DAD1 Max WL (280.0:280.0 nm)

$\begin{array}{cccccc}\text { RT [min] } & \text { Width [min] } & \text { Area } & \text { Height } & \text { Area\% } & \text { Symmetry } \\ 15.827 & 0.64 & 1908.23 & 292.85 & 100.00 & 0.85198 \\ & \text { Sum } & 1908.23 & & & \end{array}$




$\begin{array}{llll}\text { Sample name: } & 7 f & \text { Operator: } & \text { Keke Huang } \\ \text { Instrument: } & \text { LC01 } & \text { Location: } & \text { P1-C-4 } \\ \text { Inj. volume: } & 3.0 & \text { Injection Data File Name 20190222 171536.dx } \\ \text { Injection Data File Directory } & \text { /New Drug Study/Results/JZG/20190222/JZG_20190222 100234.rsit }\end{array}$

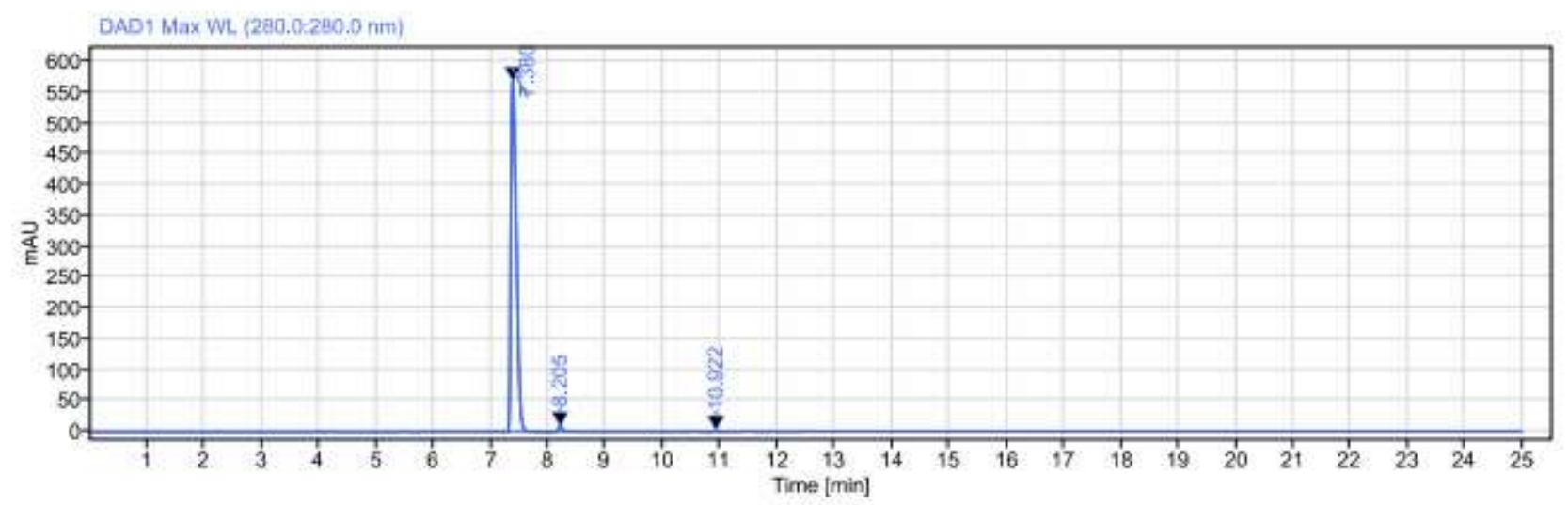

Signal: DAD1 Max WL (280.0:280.0 nm)

$\begin{array}{cccccc}\text { RT [min] } & \text { Width [min] } & \text { Area } & \text { Height } & \text { Area } \% & \text { Symmetry } \\ 7.380 & 0.82 & 3747.78 & 566.89 & 98.60 & 0.48600 \\ 8.205 & 0.34 & 43.11 & 8.01 & 1.13 & 0.68930 \\ 10.922 & 0.35 & 9.95 & 1.86 & 0.26 & 0.71716 \\ & \text { Sum } & 3800.85 & & & \end{array}$

